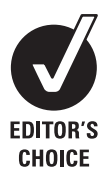

edicine Program University Health Network/ University of Toronto, Toronto, Ontario, Canada

Correspondence to: Maha Guindi, Laboratory Medicine Program, University Health Network/University of Toronto, 200 Elizabeth Street, Eaton 11-444, Toronto, Ontario Canada M5G 2C4; maha. guindi@uhn.on.ca

Accepted 1 October 2009 Published Online First 9 November 2009

\title{
Liver allograft pathology: approach to interpretation of needle biopsies with clinicopathological correlation
}

\author{
0 Adeyi, S E Fischer, M Guindi
}

\begin{abstract}
The spectrum of diseases encountered in post-transplant liver pathology biopsies is broad. In this review, these have been divided as belonging to one of three categories: (1) new-onset/de novo post-transplant abnormalities (early and late), (2) rejection, and (3) recurrence of original disease. The clinical and pathological features of the entities making up each category, with the relevant differential diagnosis and overlaps between and within these groups, are discussed and illustrated. Recurrent or de novo neoplasms make up a fourth category not included in this review. Early newonset conditions are mostly related to surgical complications, donor factors and ischaemia to the graft. These include reperfusion/preservation injury, lipopeliosis, smallfor-size-syndrome, biliary sludge syndrome and hepatic artery thrombosis. The various forms of rejection (cellular, chronic, antibody-mediated, and late atypical rejection) are detailed. Most chronic liver diseases can and do recur in the graft. They may display features that overlap with de novo conditions (eg, primary sclerosing cholangitis versus chronic rejection). As with most cases of allograft biopsy interpretation, accurate diagnosis rests with careful correlation of histological features with clinical, imaging and laboratory findings, and often comparison with previous sequential and follow-up biopsies. Lateonset new diseases include biliary strictures, idiopathic chronic hepatitis and de novo autoimmune hepatitis, among others. This review provides a practical approach to the interpretation of these challenging biopsies. Selected difficult scenarios or conundrums are identified and discussed in the relevant sections.
\end{abstract}

The spectrum of pathological findings and processes seen in the liver allograft is vast and transcends non-transplant-related and post-transplant-related pathology. Such pathology may be encountered in post-transplant liver biopsies and in the excised failed liver allografts. Traditionally post-transplant pathology has been divided anatomically or as to early or late occurrence in the posttransplant period. These approaches, while very useful, tend to generate long lists that may be difficult to remember. We have attempted to distil the questions posed to the pathologist interpreting such biopsies into thee broad categories: (1) is there rejection (2) is there recurrence of the underlying liver disease for which transplantation was needed, and (3) is there a new process occurring post transplant apart from rejection?

Needless to say, these are complicated patients and two or more clinicopathological processes may coexist. The pathologist plays an important role in defining these processes, especially since the patterns of liver enzyme abnormalities and other clinical parameters leading to a liver biopsy are not always clear-cut in differentiating between diverse conditions potentially affecting the allograft, and which not infrequently require diametrically opposite interventions.

Most diagnostically important pathological studies can be completed on routinely processed formalin-fixed, paraffin-embedded tissue sections. Routinely two H\&E-stained slides are prepared from each biopsy, each of which contains three or four sections. Trichrome, iron, periodic acid-Schiff with diastase (PASD), and any other histochemical or immunohistochemical stains are ordered after reviewing the H\&E findings. Immunofluorescence staining, to exclude antibody-mediated rejection, optimally requires fresh frozen tissue, but $\mathrm{C} 4 \mathrm{~d}$ staining on formalin-fixed, paraffin-embedded tissues can add important ancillary information in cases of suspected antibody-mediated rejection. ${ }^{1}$ In the post-transplant setting, immunohistochemistry is often performed in liver sections for localisation of viral antigens, identification of bile duct epithelium and post-transplant lymphoproliferative disease (PTLD) immunophenotyping.

\section{INDICATIONS FOR LIVER ALLOGRAFT BIOPSY}

Follow-up of transplanted solid organs involves monitoring for evidence of graft injury. Liver enzymes changes are quite sensitive to hepatocellular (transaminases) or biliary (alkaline phosphatase) injuries. In some cases, abnormalities of liver function (bilirubin, albumin and coagulation parameters) are present, either from failure to normalise post-transplant or as a result of severe or advanced-stage post-transplant injuries. In most cases, liver allograft biopsies are performed in response to changes in liver enzyme levels, abnormality in one or more liver function parameters, imaging abnormalities or functional abnormalities, to follow-up an earlier biopsy, or as part of a protocol that requires time-specific biopsies. The pathologist's first role is to understand the clinical question(s) the biopsy is meant to answer.

Specific indications for liver allograft biopsy in an individual patient typically depend on the age of the graft (ie, time from transplant grafting) and they can be divided into early and late periods. Early graft dysfunction refers to changes occurring within the first 3 months of transplantation, while late changes refer to those occurring after 6 months. ${ }^{23}$ The period of 3-6 months represents 
an intermediate time, when early and late changes overlap. Summaries of the indications for allograft biopsy in early and late graft periods are given in boxes 1 and 2 . The entities to consider in relation to each of these indications are listed, to be followed later by the histopathological characteristics of some of these the entities.

\section{EARLY NEW ONSET DISEASES/INJURIES IN THE IN LIVER ALLOGRAFT}

\section{Preservation and reperfusion injury}

At the time of organ harvesting, preservation injury may occur. This refers to tissue damage causing graft dysfunction immediately after transplantation. Factors that contribute to preservation injury include donor and recipient hypotension and other causes of warm ischaemia, cold ischaemia during organ preservation, and reperfusion injury.

Warm ischaemia occurs when the organ is maintained at body temperature but is inadequately perfused with blood. It

\section{Box 1: Early indications for liver allograft biopsy and} considerations

- Worsening or failure of liver function or enzymes to normalise post-transplant (primary or secondary non-function):

- Technical problems (anastomotic: duct or vascular; nonanastomotic vascular factors: eg, hepatic artery thrombosis)

- Immunological (cellular rejection, ABO incompatibility/ antibody-mediated rejection)

- Donor factors ("marginal" grafts including fatty liver, long warm and/or cold ischaemic period; small-for-size syndrome in live donor grafts)

- Extreme preservation/reperfusion injury

- Rise in liver enzymes after initial fall (or unsatisfactory nadir):

- Immunological factors (rejection)

- Infection (new or reactivated)

- Delayed manifestation of anastomotic problems

- Adverse drug reaction

- Recurrence of primary disease

- Donor factors

- Post-transplant lymphoproliferative disease

- Less than expected normalisation of liver enzymes following a treated event:

- Wrong initial clinical and/or pathological diagnosis

- Correct initial diagnosis, but no response to treatment

- Correct initial diagnosis, but missed or unmasked other pathology

- Adverse reaction to medication

- Patient non-compliance

- Follow-up to a prior biopsy:

- Compare response to prior intervention, progression and QA prior biopsy

- Other factors dependent on indication for follow-up biopsy

- Abnormalities of post-transplant imaging:

- Poor flow (ischaemic parenchymal injury, vascular thrombi, bile duct necrosis/ischaemic cholangitis, outflow obstruction, sinusoidal obstruction)

- Collections (haematoma, abscess, infarct, neoplasm)

Protocol biopsy (time defined):

- Compare with prior biopsies if available

- Document any pathology or absence of any

- Fibrosis staging preferentially damages hepatocytes. However, if restricted to less than 120 min in duration, it is not usually problematic. ${ }^{4}$ Warm ischaemia occurs in livers harvested from cardiac death donors as well.

Cold ischaemia occurs during storage of the liver in preservation fluid and ice bath immersion. It preferentially damages sinusoidal endothelial cells. ${ }^{67}$ Cold ischaemia causes loss of mitochondrial respiration and, consequently, adenosine triphosphate depletion. ${ }^{6-10}$ Eventually there is lifting of the sinusoidal endothelial cells away from the underlying matrix with loss of sinusoidal microvascular integrity and function.

The pathophysiology of preservation/reperfusion injury has been reviewed elsewhere. ${ }^{1}$

Much of the injury that occurs with liver preservation is attributable to the reperfusion phase. ${ }^{6-10}$ A cascade of processes is triggered that leads to an imbalance of vasoconstrictors over vasodilators - an additional important factor that contributes to microcirculatory failure. ${ }^{6-10}$ Reperfusion injury thus manifests in the biliary tree and in the hepatocytic parenchyma. Bile duct cells are directly susceptible to preservation and reperfusion injury. The biliary sludge syndrome is a caused by the pathophysiological mechanisms relevant to preservation/reperfusion injury and wound healing in the biliary tree. ${ }^{11}{ }^{12}$ Biopsy appearances of this will be discussed later in the section on biliary complications.

With regard to the hepatic parenchyma, biopsy samples obtained within hours of complete revascularisation are also referred to as "post-perfusion biopsies". In severe preservation/ reperfusion injury, there is zonal or confluent coagulative necrosis, sometimes with periportal or bridging necrosis, and severe neutrophilic exudation may be seen. The subcapsular parenchyma is especially susceptible to damage and drying. Histologically, this area may show a more severe pathological process than the deeper parenchyma and might not be representative.

Biopsies taken a few days after transplantation may show mild hepatocellular injury, such as microvesicular steatosis, rounding-up of hepatocyte cytoplasm with detachment from adjacent hepatocytes, and hepatocellular swelling. ${ }^{73}$ Repair responses in such cases are in the form of increased hepatocellular mitosis, thickening of the cell plates and nuclear enlargement. Mild zone 3 hepatocellular swelling and canalicular cholestasis may be present. Portal inflammation and ductular reaction at the portal/periportal interface are usually absent in mild injury.

In more severe injury, if hepatocellular necrosis was mainly in zone 3 , centrilobular hepatocyte dropout is seen. The adjacent viable zone 2 hepatocytes proliferate to restore the liver parenchyma, and mitoses are seen. If periportal necrosis and bridging necrosis are present, the parenchymal collapse triggers ductular reaction ${ }^{71}$ that can link adjacent portal tracts and distort the architecture. More severe injury is also usually accompanied by centrilobular hepatocellular swelling, and canalicular and cholangiolar cholestasis. ${ }^{73}$

The pathological differential diagnosis includes sepsis, biliary obstruction, antibody-mediated rejection and cholestatic hepatitis. Correlation is needed in such cases with the clinical history (eg, donor age, donation after cardiac death liver, details of cold and warm ischaemic times, operative note and microbiological studies).

Distinguishing between preservation injury and obstruction/ cholangitis (table 1 ) requires careful examination of the bile ducts located within the portal tract connective tissue and comparing them with the ductules located at the interface zone. 
Box 2: Late indications for liver allograft biopsy and considerations

- New-onset abnormality in liver function/rise in liver enzymes from baseline:

- Recurrent disease

- Infection (new or reactivated)

- Immunological (cellular rejection, ductopenic rejection)

- De novo post-transplant neoplasm (post-transplant lymphoproliferative disease, other)

- Recurrent neoplasm (usually hepatocellular carcinoma)

- Adverse drug reaction

- Newly acquired liver disease (eg. de novo hepatitis or any other form of liver disease seen in native livers)

- Late anastomotical complications (eg, biliary stricture)

- Vasculopathies (chronic rejection related, sinusoidal obstruction syndrome, cirrhosis)

- Metastatic neoplasm

- Liver involvement by another systemic disease

- Less than expected liver enzymes normalisation following a treated event:

- Wrong initial clinical and/or pathological diagnosis

- Correct initial diagnosis, but no response to treatment

- Correct initial diagnosis, but missed or unmasked other pathology

- Adverse reaction to medication

- Patient non-compliance

- Follow-up to a prior biopsy

- Imaging abnormalities:

- Neoplasm (primary, recurrent, metastatic)

- Non-neoplastic mass lesions

- Protocol (time defined):

- Compare with prior biopsies if available

- Document any pathology or important negatives

- Fibrosis staging

In obstruction or cholangitis, there is concentric periductal lamellar oedema, accompanied by neutrophils within the lumen or infiltrating between biliary epithelial cells. These bile duct changes are not seen in preservation injury. There is acute pericholangiolitis in preservation injury. Both disorders can show marked zone 3 hepatocanalicular and/or cholangiolar cholestasis and intralobular neutrophil clusters. ${ }^{1}$

\section{Lipopeliosis}

Lipopeliosis is a lesion that occurs in the early post-transplant period. It occurs when the engrafted donor liver is fatty, and is seen in approximately $5 \%$ of transplants. ${ }^{14}{ }^{15}$ The liver sinusoids have the appearance of being engorged with fat. The mechanism by which the lesion develops is that hepatocyte necrosis occurs in a steatotic graft after transplantation due to ischaemia or preservation injury. The fat globules are then released from the injured hepatocytes and are sequestered in the sinusoids and/or the space of Disse. ${ }^{16}$ The clinical outcome of lipopeliosis can vary greatly and probably depends on the severity of the underlying hepatocellular necrosis that caused the release of fat droplets from hepatocytes in the first place. ${ }^{15}$ Lipopeliosis may be associated with prolonged post-transplant cholestasis, ${ }^{15}$ which, as discussed earlier, is an important indication for liver biopsy in the early post-transplant period. The clinical and pathological course of the reported cases suggests that
Table 1 Differential diagnosis of biliary stricture

\begin{tabular}{|c|c|c|c|}
\hline $\begin{array}{l}\text { Histological } \\
\text { feature }\end{array}$ & Biliary stricture & $\begin{array}{l}\text { Preservation } \\
\text { injury }\end{array}$ & Acute rejection \\
\hline $\begin{array}{l}\text { Portal } \\
\text { inflammation }\end{array}$ & $\begin{array}{l}\text { Predominantly } \\
\text { neutrophilic }\end{array}$ & $\begin{array}{l}\text { Mild non-specific } \\
\text { inflammation }\end{array}$ & $\begin{array}{l}\text { Lymphocytes, plasma cells, } \\
\text { and eosinophils (which may } \\
\text { predominate when patients } \\
\text { are treated with } \\
\text { corticosteroid-sparing } \\
\text { immunosuppressive } \\
\text { regimens) }\end{array}$ \\
\hline $\begin{array}{l}\text { Bile duct } \\
\text { epithelium }\end{array}$ & $\begin{array}{l}\text { Relatively normal } \\
\text { nucleus-to- } \\
\text { cytoplasm ratio }\end{array}$ & \pm & $\begin{array}{l}\text { Reactive changes; increased } \\
\text { nucleus-to-cytoplasm ratio }\end{array}$ \\
\hline $\begin{array}{l}\text { Perivenular } \\
\text { mononuclear } \\
\text { inflammation }\end{array}$ & Absent & Absent & Present \\
\hline $\begin{array}{l}\text { Ductular } \\
\text { reaction }\end{array}$ & Usually present & $\begin{array}{l}\text { May be } \\
\text { prominent if } \\
\text { biliary sludge } \\
\text { syndrome } \\
\text { present }\end{array}$ & Usually absent \\
\hline $\begin{array}{l}\text { Periductal } \\
\text { oedema }\end{array}$ & Usually present & & Absent \\
\hline $\begin{array}{l}\text { Neutrophils and } \\
\text { bile ducts }\end{array}$ & $\begin{array}{l}\text { Intraepithelial and } \\
\text { intraluminal } \\
\text { neutrophils may } \\
\text { be present in } \\
\text { interlobular ducts }\end{array}$ & $\begin{array}{l}\text { Neutrophilic } \\
\text { pericholangitis (if } \\
\text { severe) }\end{array}$ & $\begin{array}{l}\text { No; duct injury by } \\
\text { lymphocytes seen infiltrating } \\
\text { biliary epithelium }\end{array}$ \\
\hline $\begin{array}{l}\text { Periportal } \\
\text { architectural } \\
\text { collapse }\end{array}$ & Absent & $\begin{array}{l}\text { May be present } \\
\text { in severe injury }\end{array}$ & Usually absent \\
\hline Parenchyma & $\begin{array}{l}\text { Centrilobular } \\
\text { cholestasis in } \\
\text { hepatocytes and } \\
\text { canaliculi; small } \\
\text { clusters of } \\
\text { neutrophils in } \\
\text { lobules may be } \\
\text { seen }\end{array}$ & $\begin{array}{l}\text { Zonal confluent } \\
\text { necrosis early. } \\
\text { Hepatocellular, } \\
\text { swelling, } \\
\text { rounding up, } \\
\text { centrilobular } \\
\text { cholestasis in } \\
\text { hepatocytes and } \\
\text { canaliculi }\end{array}$ & \\
\hline
\end{tabular}

lipopeliosis by itself is reversible and not toxic to the liver but is indicative of a more severe form of preservation injury. ${ }^{14} 15$

In our experience, the lesion is easily detectable when florid, but can be very subtle when mild, or when the biopsy is done later on in the course of the lesion, which by then may have started to resolve. Thus the pathologist needs to remember to think of the lesion and search for it. Trichrome stains help to make the extruded fat droplets stand out in contrast against the darker-staining surrounding hepatocytes (fig 1). Factor-VIIIrelated antigen and type IV collagen immunoperoxidase stains help to delineate the contours of dilated sinusoids, or may show that fat droplets are present just outside the sinusoid, in the space of Disse, and are compressing the sinusoid. CD68 immunoperoxidase stain demonstrates the cytoplasm of macrophages surrounding the "empty spaces" that represent the extruded fat droplets ${ }^{15}{ }^{16}$ indicating that the fat is no longer within the hepatocytic cytoplasm.

\section{Small-for-size graft syndrome}

The portal hyperperfusion (PHP) or small-for-size graft syndrome (SFSS) is a complication that occurs primarily in living donor or reduced-size liver allografts. This complication occurs when the transplanted donor segment is less than 30\% of the standard or expected liver volume of the recipient, or less than $0.8 \%$ recipient body weight, ${ }^{17-20}$ that is when a transplanted liver is not large enough to accommodate the markedly increased portal vein blood flow. Patients with cirrhosis coming to liver transplantation have markedly increased portal blood flow. ${ }^{21}$ 
The arterial buffer response regulates a balanced portal vein and hepatic artery inflow. ${ }^{21-23}$ There is reciprocal regulation between portal vein and hepatic arterial inflow. Increased portal venous flow diminishes hepatic artery flow, whereas decreased portal flow increases hepatic artery flow. A constant release of adenosine, a vasodilator substance, among the hepatic arterioles and portal venules maintains balanced inflows. Increased portal flow decreases local adenosine concentrations resulting in hepatic artery branch constriction and a reduction in arterial flow. This is observed in PHP/SFSS liver allografts. Conversely, decreased portal flow results in decreased adenosine and hepatic artery vasodilatation. ${ }^{21} 22$ However PHP/SFSS also occurs following transplantation of whole cadaveric livers and partial allografts that are greater than $0.8 \%$ body weight, thus factors other than graft size may be at play. The findings of Demetris et al suggest that portal hyperperfusion, venous pathology and the arterial buffer response contribute to early and late clinical and histopathological manifestations of the SFSS. ${ }^{24}$

The features of SFSS may be divided into early and late. Early findings include: portal hyperperfusion resulting in portal vein and periportal sinusoidal endothelial denudation and focal haemorrhage into the portal tract connective tissue. This dissects into the periportal hepatic parenchyma when severe; and poor hepatic arterial flow and vasospasm. In severe cases, this can result in functional dearterialisation, ischaemic cholangitis and parenchymal infarcts. Late sequelae seen in excised grafts that survive the earlier insults are small portal vein branch thrombosis with occasional luminal obliteration or recanalisation, nodular regenerative hyperplasia and biliary strictures. ${ }^{24}$ Thus, SFSS results in changes that are present in the peripheral and central liver. Since core biopsies sample the peripheral liver parenchyma, it follows that not all features of SFSS will be captured in a core biopsy. In peripheral core needle biopsies, affected grafts most commonly show the following triad: centrilobular hepatocanalicular cholestasis, centrilobular hepatocyte microvesicular steatosis, and a ductular reaction at the interface zone. ${ }^{24}$
However venous findings are uncommon in peripheral core needle biopsies. ${ }^{24}$ Detection in the liver core biopsy of the above mentioned in the proper setting such as early post transplant merits a recommendation to the clinician to investigate this possibility. It should be noted that the zone 3 changes and ductular reaction are not specific for SFSS. The differential diagnosis would also include suboptimal arterial flow because of hepatic artery thrombosis or bile duct stricturing not related to the SFSS, and systemic causes such as sepsis with or without systemic hypotension.

\section{Hepatic artery thrombosis}

The liver allograft, contrary to the native liver, is devoid of a collateral arterial circulation, especially early post transplantation, thus susceptibility to ischaemic injury is increased. Although with improving surgical techniques the incidence of hepatic artery thrombosis post-transplant has dramatically improved, it remains the most frequent cause of vascular complications after liver transplantation. ${ }^{25-27}$

Due to their predominant or exclusive dependence on arterial supply, the structures most commonly affected include are the hilum and large bile ducts, which are not routinely sampled in the liver biopsy. Peripheral core needle biopsies thus may show variable changes, but are not always reliable for establishing a diagnosis of hepatic artery thrombosis. ${ }^{13}$ Findings can range from completely normal to marked centrilobular hepatocyte swelling (later centrilobular hepatocellular atrophy and sinusoidal widening), ductular reaction, with or without bile plugs, and acute cholangiolitis or frank coagulative necrosis. In some cases, spotty acidophilic necrosis of hepatocytes, so-called ischaemic hepatitis, can mimic acute viral hepatitis, while duct ischaemia often leads to biliary tract injury and stricturing (discussed in Biliary complications). ${ }^{1}$

\section{REJECTION}

As in other solid organ transplants, liver allografts are prone to immunologically mediated rejection, but the roles played by the
Figure 1 (a) Low-power view showing empty spaces representing extruded fat droplets that appear to be engorging sinusoids (Masson trichrome stain $\times 100$ ). (b) Higher magnification of liver parenchyma showing findings similar to those in (a). Note that the appearances of nuclei abutting the extruded fat droplets are not those of hepatocyte nuclei but rather of macrophage nuclei (H\&E $\times 200$ ). (c) CD68 immunostain showing immunoreactivity (brown colour) in the cytoplasm abutting and surrounding the extruded fat droplets, confirming their location within macrophages $(\times 400)$. (d) Type IV collagen immunostain showing linear staining of sinusoidal wall (arrow), with adjacent fat droplet $\left({ }^{*}\right)$ located outside the sinusoid in the space of Disse $(\times 400)$.

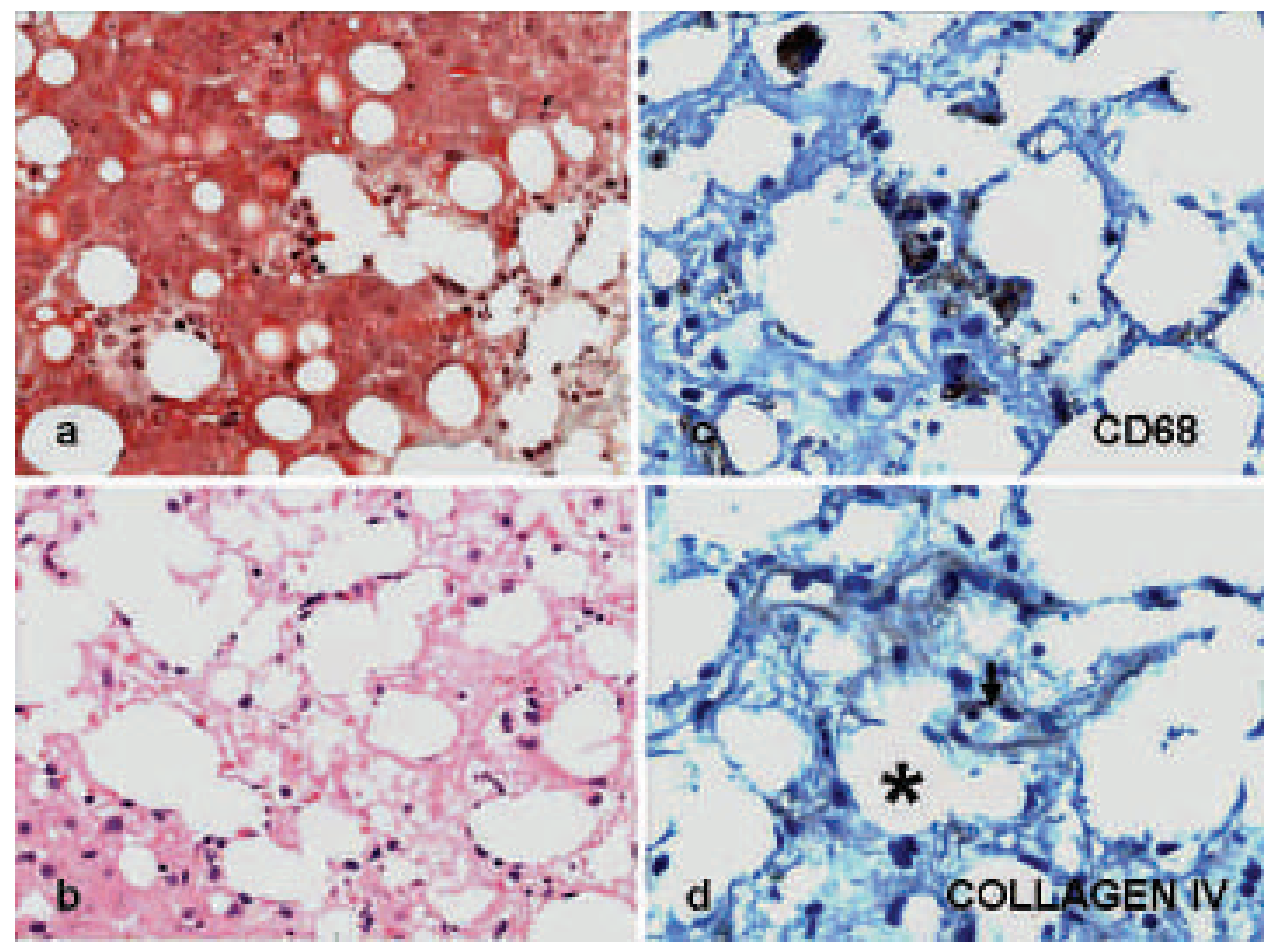


major histocompatibility complex (MHC) antigens are not as well defined, ${ }^{28}$ and many programmes do not perform donorrecipient human leucocyte antigen comparison or cross-matches prior to transplant. Types of rejection in liver allografts include acute cellular (cell-mediated) rejection, "atypical" features associated with late cellular rejection, chronic rejection, and antibody-mediated rejection. Antibody-mediated rejection can be hyperacute (very rare outside of $\mathrm{ABO}$ mismatch) or it may occur days to weeks post-transplant. The parameters for recognising this entity, as discussed later, are largely dependent on the demonstration of relevant circulating donor-specific antibodies.

\section{Acute cellular rejection}

Acute cell-mediated rejection (ACR) remains the commonest cause of early graft dysfunction, with incidence ranging from $24-80 \%$, with a mean of $49.8 \%$. The reported incidence often includes ACR diagnosed clinically, with or without confirmatory biopsies. The Banff 1997 document defining criteria for scoring ACR on a scale of 0-9 is widely used and the total score of all the rejection features present in a given biopsy is known as the Rejection Activity Index (RAI) (table 2). At the University Health Network Laboratory Medicine Program, Toronto, Ontario, Canada, only $8.11 \%$ of 887 liver allograft biopsies performed between July 2007 and June 2009 showed histopathological features of rejection, $94.4 \%$ of which were either mild (RAI 3-4) or moderate (RAI 5-6) rejection. Severe rejection $($ RAI $\geqslant 7$ ) was less commonly seen, representing only $5.6 \%$ of biopsies showing rejection (unpublished data). Factors determining the incidence of ACR include site of transplant, type of immunosuppression, perioperative factors (ischaemia, infections), type of post-transplant surveillance, donor characteristics (including age, cadaveric versus living, etc), and other factors. ${ }^{29-34}$

The definition of ACR is not based on time of occurrence from transplant, but rather on characteristic morphological changes. Although most ACR occur in the early post-transplant period, late-occurring ACR, up to several years post-transplant, is not uncommon. As discussed earlier, late ACRs are those occurring 6 months post-transplant or later, and have been estimated to occur in $6-10 \%$ of adult patients, and are more likely to show "atypical" histopathological features, be resistant to treatment, require rescue therapy, or progress to ductopenic rejection. $^{3}{ }^{31}$ 35-37 The atypical features in ACR are discussed below.

\section{Histopathological features of ACR}

The 1997 Banff scoring system for liver allografts is the most widely employed scoring system for liver allograft injuries, including $\mathrm{ACR},{ }^{38}$ and will be employed throughout this discussion. ACR is an immunologically mediated injury directed at specific targets, (ie, bile duct epithelium and vascular endothelial cells). ${ }^{39-41}$ This understanding underscores the resulting morphology. Therefore inflammatory infiltrates of cellular rejection are to be sought and found around these targets, namely portal tracts and in perivenular areas of zone 3 . Notably the lobular regions between the portal tract and zone 3 venules show no significant involvement by the immune effector cells; this is a potentially helpful factor in differentiating typical ACR from hepatitis, where lobular inflammation with evidence of hepatocellular injury and death/apoptosis would be expected with absent or not-so-prominent endothelial and bile duct injury (table 2). In ACR, since the portal vein
Table 2 Summary of the Banff 1997 criteria for scoring acute cellular rejection in liver allografts

\begin{tabular}{|c|c|c|}
\hline Parameter scored & Criteria* & $\begin{array}{l}\text { RAI } \\
\text { score }\end{array}$ \\
\hline \multirow[t]{3}{*}{ Portal inflammation } & $\begin{array}{l}\text { Inflammation in minority of portal tracts, not } \\
\text { expanding and mostly lymphocytic }\end{array}$ & 1 \\
\hline & $\begin{array}{l}\text { Inflammation in and expanding majority or all portal } \\
\text { tracts, mixed lymphocytic including occasional } \\
\text { blast/activated lymphocytes and neutrophils, } \\
\text { eosinophils }\end{array}$ & 2 \\
\hline & $\begin{array}{l}\text { Inflammation in and expanding majority or all portal } \\
\text { tracts, mixed lymphocytic including numerous blast/ } \\
\text { activated forms and neutrophils, eosinophils, with } \\
\text { spillover to interface/periportal hepatocytes }\end{array}$ & 3 \\
\hline \multirow[t]{3}{*}{$\begin{array}{l}\text { Bile duct injury/ } \\
\text { inflammation }\end{array}$} & $\begin{array}{l}\text { Inflammation affecting duct epithelium in minority of } \\
\text { portal tracts with mild evidence of epithelial injury } \\
\text { such as increased nucleocytoplasmic ratio, or } \\
\text { irregular spacing in epithelium }\end{array}$ & 1 \\
\hline & $\begin{array}{l}\text { Inflammation affecting duct epithelium in most portal } \\
\text { tracts with marked evidence of epithelia injury in } \\
\text { few ducts, such as increased nucleocytoplasmic } \\
\text { ratio, cytoplasmic vacuolisation, disordered polarity } \\
\text { and/or irregular spacing in epithelium }\end{array}$ & 2 \\
\hline & $\begin{array}{l}\text { Inflammation affecting duct epithelium in most portal } \\
\text { tracts with marked evidence of epithelial injury in } \\
\text { most ducts, such as increased nucleocytoplasmic } \\
\text { ratio, cytoplasmic vacuolisation, disordered polarity } \\
\text { and/or irregular spacing in epithelium; outright duct } \\
\text { necrosis can be seen in some ducts }\end{array}$ & 3 \\
\hline \multirow[t]{2}{*}{ Venous phlebitis } & $\begin{array}{l}\text { Subendothelial lymphocytes in some but not the } \\
\text { majority of portal and/or hepatic venules }\end{array}$ & 1 \\
\hline & $\begin{array}{l}\text { Subendothelial lymphocytes in most portal and/or } \\
\text { hepatic venules }\end{array}$ & 2 \\
\hline
\end{tabular}

The table is modified from the Banff schema for grading liver allograft rejection: an international consensus document. ${ }^{38}$

* Key features differentiating one score in each parameter from the next higher score are underlined.

RAl, Rejection Activity Index.

endothelium and bile ducts are targets, the infiltrates, except in the more severe forms, tend to cluster around these targets with little to no spillover to the lobule through the interface hepatocytes. When the terminal hepatic venules are involved, the infiltrates are seen under the endothelial cells (endotheliitis, phlebitis), but in the more severe forms of rejection these infiltrates involve the perivenular parenchyma, with or without hepatocellular necrosis.

The three histological parameters underlying ACR are each scored on a scale of $0-3$ to give a total RAI on a scale of $0-9$, using the Banff 1997 criteria. $^{38}$ These parameters are portal inflammation, bile duct injury, and portal and/or terminal hepatic venule endothelial injury; the scoring parameters are charted in table 2, as defined by the Banff 1997 criteria. $^{38}$

\section{Portal inflammation}

Portal infiltrates in ACR are usually but not always mixed, and may include activated lymphocytes (including blast forms), eosinophils and neutrophils. These infiltrates range from mild to severe depending on the density, and can involve few to all sampled portal tracts. As seen in table 2, the density and extent of portal tract involvement both factor into apportioning a score for this aspect of ACR, examples of which are illustrated in fig 2 .

\section{Bile duct injury}

Bile duct injury in cellular rejection is characterised by the presence of inflammatory cells within duct epithelial cells, but associated with evidence of epithelial injury, such as high $\mathrm{N}: \mathrm{C}$ 
ratio, variation in nuclear size, cytoplasmic vacuolisation and disruption of lumen. Outright necrosis of ducts can be present in the most severe injuries (fig 2).

\section{Endothelial injury}

Injury to the portal and/or terminal hepatic vein endothelium comprises inflammatory infiltrates beneath the endothelium, variably referred to as endotheliitis or phlebitis. The authors prefer the term phlebitis as this seems to more aptly describe the process, and is used in the remaining portion of this article. Phlebitis can be seen in non-rejection processes including recurrent chronic hepatitis $\mathrm{C}$ virus (HCV); however, the rejection-related phlebitis is usually associated with morphological evidence of endothelial injury; this ranges from mere lifting of the endothelium that consequently assumes a more plump shape, to "embolisation" into the vascular lumen and/or nuclear atypia. In the more severe forms, phlebitis is accompanied by perivenular extension (usually around terminal hepatic venules) of inflammation into the lobule producing necrosis of surrounding hepatocytes (fig 2B-D)

\section{Other helpful findings}

Histological features of ACR can also be seen at the hepatic hilum, although this portion of the liver is rarely included in diagnostic liver allograft biopsies. However, when present, inflammation of hilar nerve twigs and/or large hepatic arterial intimal inflammation with endothelial injury are helpful findings, although not typically scored in the Banff schema (fig 3).

Evaluation of liver allografts for cellular rejection involves the recognition of diagnostic histopathological features as well as exclusion of non-rejection differentials and co-existing independent pathological processes. Since ACR is an inflammatory process, the most difficult and important differential diagnoses are other inflammatory processes, especially those due to viral infections, de novo non-viral and non-infective hepatitis, and

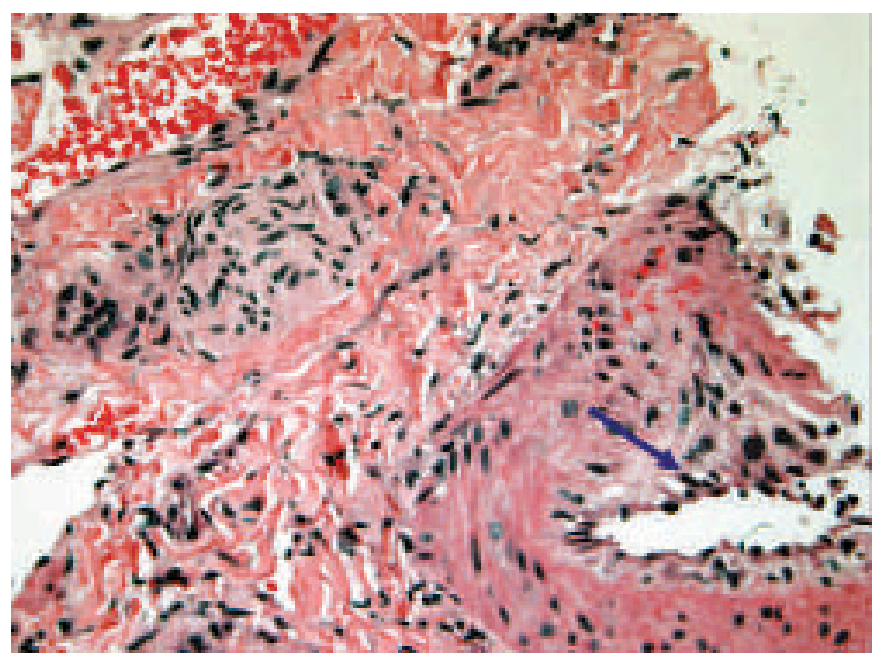

Figure 3 When the hepatic hilum is included, inflammation of nerves (top left) and/or hepatic artery intima with endothelia injury (blue arrow) can be seen in acute cell-mediated rejection (H\&E $\times 100)$.

lymphoproliferative diseases. The infective agents that pose the most problems are recurrent (or less commonly de novo) viral hepatitis B or C. However other viral infections (Epstein-Barr virus (EBV), cytomegalovirus (CMV) and others) should always be considered in this context of immunosuppression. Druginduced hepatitis and de novo autoimmune hepatitis are diagnoses of exclusion when the inflammatory process shows a prominent hepatitic profile, and should be carefully correlated with clinical and serological markers. The history of temporal association of liver injury markers with exposure to potentially hepatotoxic drugs, pattern, rate and peak of enzyme changes, and presence or absence of relevant autoantibodies, should be employed in making this correlation. Table 3 highlights helpful histopathological (and clinical) features to consider in making
Figure 2 (A) Typical low-power view of acute cellular rejection (ACR) showing portal but no lobular inflammation (H\&E $\times 50$ ). (B) Higher magnification of the portal tract within the box in $(A)$ showing bile duct injury (blue arrows), portal phlebitis and mixed infiltration that includes eosinophils and activated lymphocytes. Subendothelial inflammation with lifting of portal vein endothelial cells (green arrow) exemplifies endothelial injury (H\&E $\times 200$ ). (C) Hepatic vein phlebitis is another feature of acute cellular rejection, as shown in this illustration; perivenular inflammation is also present (trichrome stain $\times 200$ ). (D) Inflammatory infiltrates from two portal tracts in a case with severe acute cellular rejection illustrate the typical mixed nature of cells that include activated/blastoid lymphocytes as well as eosinophils and neutrophils, but largely limited to portal tracts with some interface activity but otherwise quiescent hepatic lobule; note in addition prominent portal phlebitis in the right panel (top left panel and right panel, H\&E $\times 100$; bottom left panel, trichrome stain $\times 100$ ).
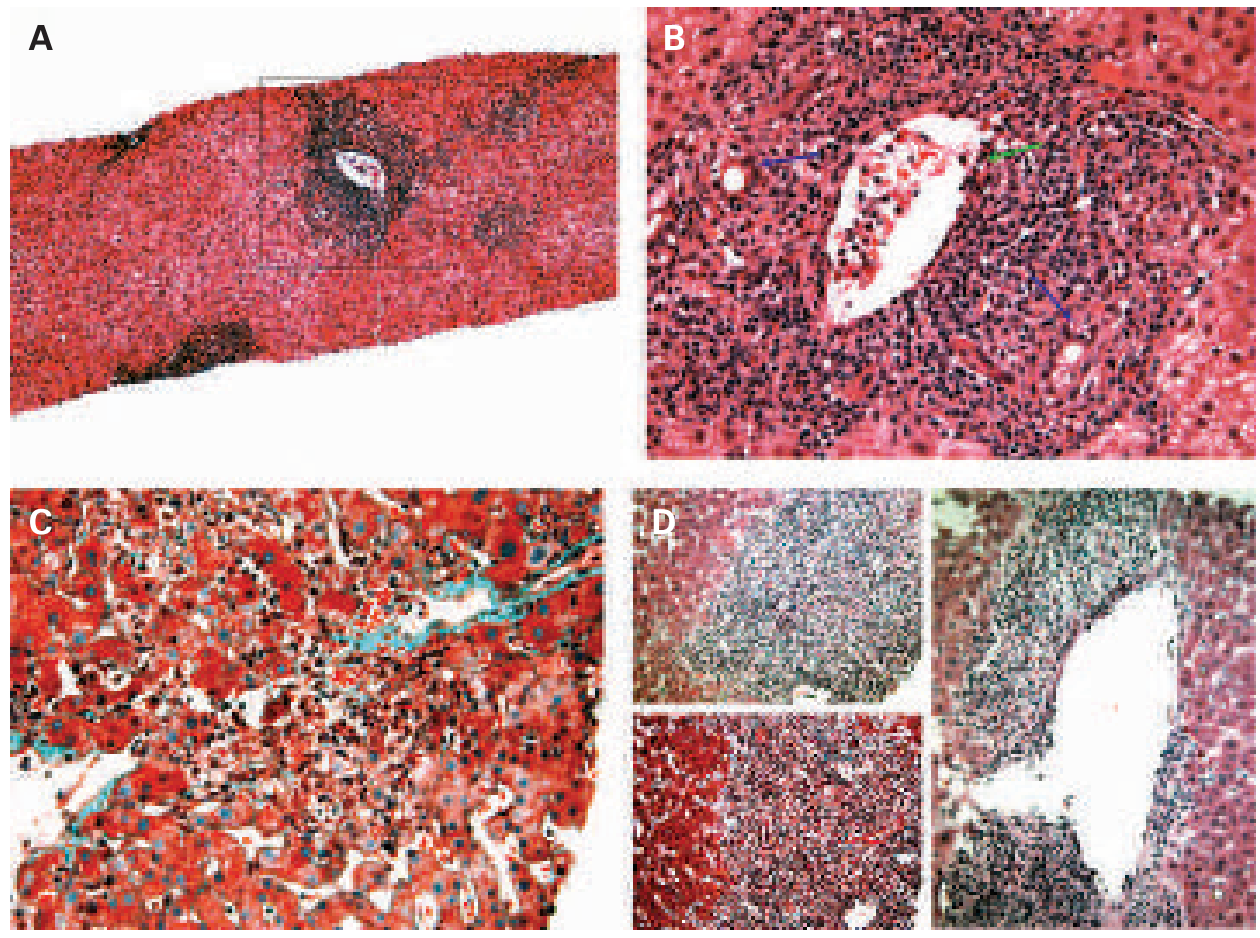
the distinction between ACR and HCV; this represents the most commonly encountered diagnostic dilemma.

\section{Atypical features in late cellular rejection}

ACR occurs late in transplant, but not as often as in early graft period. When late ACR occurs, the pattern and nature of inflammatory infiltrates sometimes differ from early ACR, in having more hepatitic features (interface activity, central perivenulitis and lobular inflammation), tendency towards monotypic/less mixed portal infiltrates, and less prominent duct injury. ${ }^{42}{ }^{43}$ Late ACRs are those occurring after 6 months, but these atypical features are more likely to be observed in the much older grafts. Poor compliance to medication, biliary complications, and forced reduction in immunosuppressive regimen due to infections (such as tuberculosis, CMV, recurrent $\mathrm{HCV}$ ) or PTLD, are some of the documented reasons for late ACR, although in many patients, no identifiable reasons are apparent. $^{2} 3744$

Of the features associated with late ACR, central perivenulitis (CPV) (fig 4) warrants more discussion. CPV can be mild, moderate or severe, and occurs with or without perivenular hepatocellular necrosis. ${ }^{42}$ Allograft CPV can be isolated or associated with hepatitic lobular inflammation, and/or portalbased features of ACR, including duct injury. ${ }^{45-47}$ When it occurs in association with portal features of ACR, the diagnosis is usually easy to make, and the treatment approach often follows established anti-rejection protocols. Isolated CPV is a more difficult feature to characterise as it can present with normal or only minimally elevated liver enzymes. ${ }^{46}$ When CPV is present in the biopsy with parenchymal or portal changes other than those of ACR, the aetiology of CPV in such a setting becomes the subject of debate. For example, when there are biopsy

Table 3 Histopathological and clinical differences between acute cellular rejection recurrent viral hepatitis C

\begin{tabular}{|c|c|c|}
\hline & $\begin{array}{l}\text { Acute cellular } \\
\text { rejection }\end{array}$ & Viral hepatitis \\
\hline Portal inflammation & + & $+/-$ \\
\hline Nature of portal inflammation & $\begin{array}{l}\text { Mixed includes } \\
\text { activated lymphocytes, } \\
\text { eosinophils }+/- \\
\text { neutrophils }+/-\end{array}$ & $\begin{array}{l}\text { Tends to be more } \\
\text { monotypic; } \\
\text { lymphocytes } \\
\text { predominate }\end{array}$ \\
\hline Interface activity & $-^{*}$ & $+^{*}$ \\
\hline Lobular inflammation & $-{ }^{*}$ & + \\
\hline Lobular apoptoses & - & $+/-$ \\
\hline $\begin{array}{l}\text { Zone } 3 \text { accentuation of inflammation } \\
\text { without phlebitis }\end{array}$ & $-^{*}$ & $-/+$ \\
\hline $\begin{array}{l}\text { Zone } 3 \text { phlebitis with or without } \\
\text { perivenular dropout }\end{array}$ & + & $-/+$ \\
\hline Portal vein phlebitis & + & $-/+$ \\
\hline Bile duct injury & + & $-/+$ \\
\hline HCV, HBV or other viral serology & Not helpful & + \\
\hline $\begin{array}{l}\text { Rate and timing of liver enzyme } \\
\text { changes }\end{array}$ & $\begin{array}{l}\text { Recent change from } \\
\text { baseline and may be } \\
\text { associated with } \\
\text { suboptimum } \\
\text { immunosuppression }\end{array}$ & $\begin{array}{l}\text { Usually smouldering, } \\
\text { rarely steep except in } \\
\text { FCH }\end{array}$ \\
\hline Predominant enzyme pattern & $\begin{array}{l}\text { ALT/AST, ALP or } \\
\text { mixed }\end{array}$ & ALT/AST \\
\hline
\end{tabular}

\footnotetext{
*Lobular inflammation, interface activity or zone 3 accentuation without phlebitis can be seen in late acute cell-mediated rejection (also known as atypical acute cellmediated rejection).

- , Absent; $+/-$, usually present but can be absent; $-/+$, usually absent but can be present occasionally; + , should be present.

$A L P$, alkaline phosphatase; ALT, transaminase; EBV, Epstein-Barr virus; $F C H$, fibrosing cholestatic hepatitis; HBV, hepatitis B virus; HCV, hepatitis C virus; PTLD, posttransplant lymphoproliferative disease.
}

changes to suggest recurrent $\mathrm{HCV}$, or when the infiltrate is plasma-cell rich, such as may be seen in recurrent or de novo autoimmune hepatitis (AIH), the issue becomes whether coexistent CPV in the biopsy is part of each of these processes (ie, one diagnosis in the biopsy), or whether CPV continues to represent ACR that is coexistent with other disease. This issue is further discussed below.

\section{Chronic rejection}

The 2000 Banff document describes the criteria for grading, recognising and scoring chronic rejection (CR) in liver allografts. ${ }^{48} \mathrm{CR}$ occurs in less than $3 \%$ of liver transplant patients at 5 years, and the incidence does not appear to increase with increasing years post-transplant; this supports the view that factors determining its occurrence are determined early in transplant. ${ }^{49} 50$ These factors include repeated ACR, CMV infection, high donor age, long cold ischaemic period, and inadequate/suboptimum immunosuppression. ${ }^{49}{ }^{51} 52 \mathrm{CR}$ is an immunological injury directed at the vascular endothelium of the hepatic artery and peribiliary plexus, as well as the bile duct epithelium. The resulting duct injury is characterised by epithelial senescence and ultimately loss of small bile ducts (ductopenia), with changes in the intima of hepatic artery that include thickening and accumulation of foamy macrophages. Most CR is diagnosed several months post-transplant, with a mean of 25.1 months in one large series. ${ }^{53}$ However, accelerated chronic rejection can also occur within few weeks posttransplant, although such events are fortunately rare, and usually seen in highly sensitised or suboptimally immunosuppressed patients.

Clinical history could include prior (multiple) or ongoing cellular rejection episodes, problems attaining satisfactory serum levels of immunosuppression, and rising alkaline phosphatase; bilirubin elevation is usually late. Needle biopsy should first be evaluated for adequacy in all cases of allograft biopsies, but more importantly in evaluating suspected CR, where diagnosis hangs on review of an adequate number of portal tracts (a minimum of seven fully sampled portal tracts is required). Histological features of $\mathrm{CR}$ are listed in table 4, and include senescence affecting the majority of interlobular bile ducts with less than $50 \%$ ductopenia in early CR, or duct loss in more than $50 \%$ in late ACR. Senescence or atrophy of bile ducts is characterised by epithelial disruption with irregular spacing, cytoplasmic eosinophilia, high nucleocytoplasmic ratio, nuclear hyperchromasia and luminal narrowing. There is none to minimally expanded portal tracts, and ductular proliferation or copper retention is not seen; inflammation is minimal (typically lymphoplasmacytic when present) (fig 5). Other helpful findings include zone 3 perivenular fibrosis, cholestasis that is typically hepatocellular with or without accentuation in zone 3, sinusoidal foam cells, and foam cell arteriopathy (if hilar structures are included). ${ }^{49}$ Although ductular reaction is typically absent in CR, this can be seen, as in the response recovery phase following increase in or switch of immunosuppressive agent. ${ }^{49}$

Early duct senescence and/or loss can be subtle on routine stains and thus should always be searched for in patients with unexplained elevation of cholestatic liver enzymes. The use of cytokeratin 7 immunostain (or other biliary epithelial markers) for additional evaluation should be employed (fig 5C). CR is an evolving process and several biopsies may be needed before a definite histological diagnosis is feasible.

Recurrent primary sclerosing cholangitis (PSC) is difficult to distinguish from CR. This subject is discussed below in the 
Figure 4 Late-occurring cellular rejection tends to be more hepatitic than typical acute cell-mediated rejection in the early post-transplant period; the inflammation involves portal, central perivenular (CV) and mid-lobular areas (upper panel, H\&E $\times 200$ ). As shown in the lower panels, the infiltrates in portal (left lower panel, H\&E $\times 400$ ) and zone 3 areas (right lower panel, H\&E $\times 400$ ) include mild duct injury (blue arrow) and rich perivenular plasma cell population (H\&E prominent).
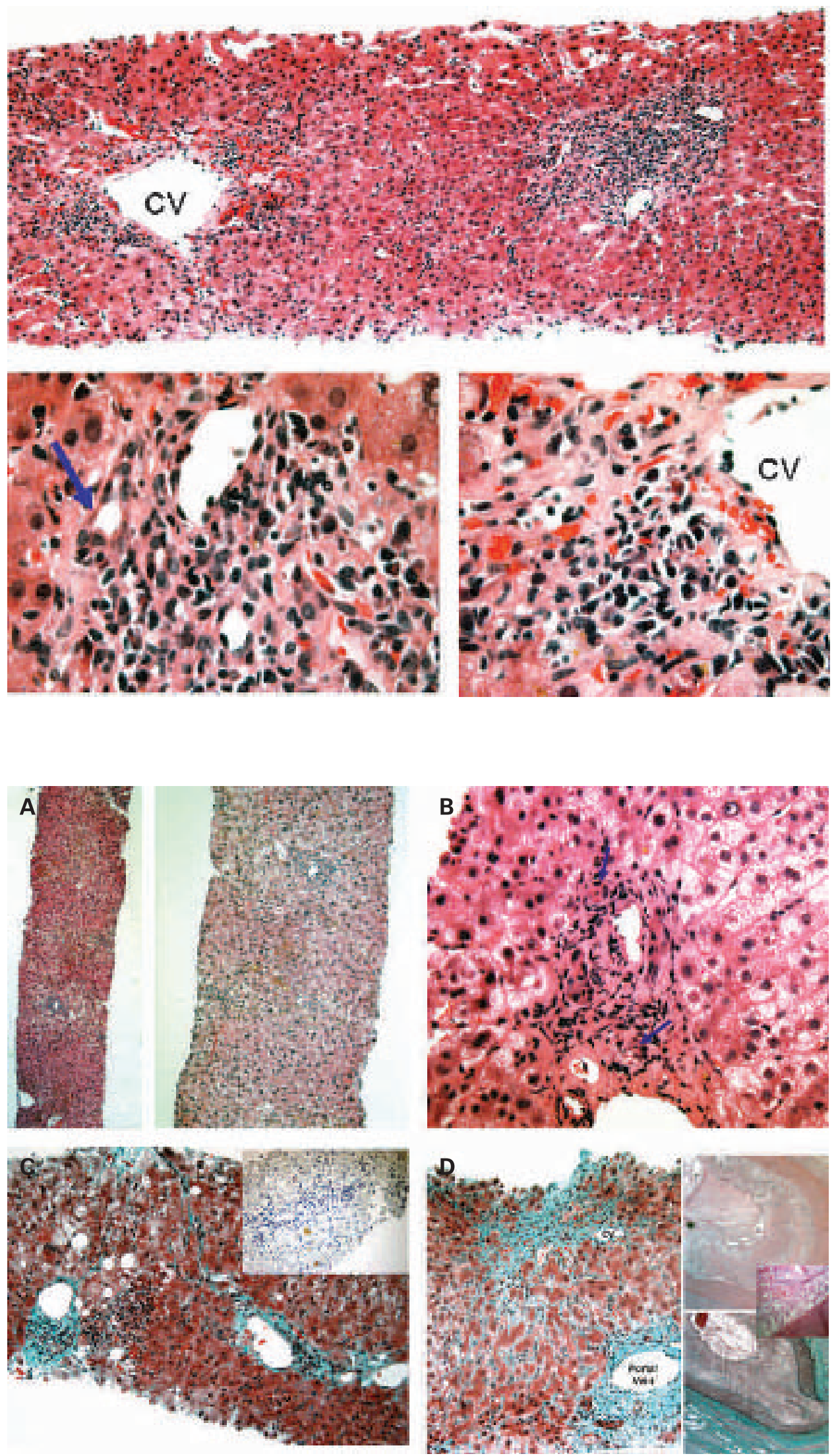

histiocytes (inset), and luminal narrowing, called chronic graft arteriopathy (upper panel, H\&E $\times 25$; lower panel, elastic trichrome stain $\times 25$; inset, H\&E $\times 100$ ). 
Table 4 Histopathological features of early and late phases of chronic rejection

\begin{tabular}{lll}
\hline Structure & Early chronic rejection & Late chronic rejection \\
\hline Interlobular bile ducts, $<60 \mu \mathrm{m}$ & $\begin{array}{l}\text { Senescence/atrophy affecting the majority of small } \\
\text { ducts, but }<50 \% \text { duct loss }\end{array}$ & $\begin{array}{l}\text { Duct loss in } \geqslant 50 \% \text { of portal tracts and senescence of remaining } \\
\text { ducts }\end{array}$ \\
Hepatic venules/perivenular zone 3 hepatocytes & $\begin{array}{l}\text { Mild perivenular fibrosis, } \pm \text { intimal or luminal } \\
\text { inflammation }\end{array}$ & $\begin{array}{l}\text { Marked perivenular fibrosis; hepatic vein remodelling, } \\
\pm \text { inflammation }\end{array}$ \\
Hepatic artery branches in interlobular portal tracts & $\begin{array}{l}\text { Missing interlobular artery in }<25 \% \text { of portal tracts } \\
\text { Missing interlobular artery in }>25 \% \text { of portal tracts }\end{array}$ \\
Hilar (large) hepatic artery & $\begin{array}{l}\text { Foam cell arteriopathy with no significant } \\
\text { narrowing }\end{array}$ & $\begin{array}{l}\text { Foam cell arteriopathy with luminal narrowing/fibrointimal } \\
\text { proliferation }\end{array}$ \\
Others & "Transition" hepatitis with spotty/lytic & Cholestasis, sinusoidal foam cell accumulation \\
& hepatocellular necrosis & \\
\hline
\end{tabular}

Table modified from that published by Demetris et al (2000). ${ }^{48}$

section on recurrent PSC, and helpful distinguishing features are listed in table 5. Ductopenia in the liver allograft calls to mind $\mathrm{CR}$, but other causes of the so called vanishing duct syndrome should always be considered, explored, and reasonably excluded, especially those emanating from drugs such as antibiotics like Septra ${ }^{\circledR 54}$ and ACE-inhibitors, to which many transplant patients are invariably exposed (see later sections).

\section{Antibody-mediated rejection}

There is no doubt that antibody-mediated rejection (AMR) occurs in liver allografts, either rapidly in the immediate perioperative period (hyperacute), usually but not only due to $\mathrm{ABO}$ incompatibility, or later but in the first few days following transplant. ${ }^{55-58}$ The incidence of these events is difficult to determine as they are both uncommon and under-recognised.

Compared with other solid organs, the liver is relatively protected from hyperacute AMR because the Kupffer cells of the liver are able to mop up deleterious antibodies, in addition to the helpful presence of dual circulation providing immense vascular reserve. Also many other immediate post-transplant complications, including sepsis and hepatic artery thrombosis, superimposed on prolonged preservation ischaemia, usually provide alternative explanations for primary non-function in liver allografts. However, most agree that the protection of the liver from antibody-mediated injury is not absolute, and that

Table 5 Comparison of the features of recurrent primary sclerosing cholangitis and chronic rejection

\begin{tabular}{|c|c|c|}
\hline & $\begin{array}{l}\text { Recurrent primary sclerosing } \\
\text { cholangitis }\end{array}$ & Chronic rejection \\
\hline Clinical features & $\begin{array}{l}\text { Original disease PSC, years after } \\
\text { transplantation, selective rise of ALP/ } \\
\text { GGT }\end{array}$ & $\begin{array}{l}\text { Typically within 1st year } \\
\text { post-transplant, inadequate } \\
\text { immunosuppression, } \\
\text { unresolved ACR, or after } \\
\text { multiple episodes of ACR }\end{array}$ \\
\hline Cholangiogram & $\begin{array}{l}\text { Mural irregularity, diverticulum-like } \\
\text { outpouchings, beading and "pruning" } \\
\text { of bile ducts }\end{array}$ & $\begin{array}{l}\text { "Pruning" of peripheral bile } \\
\text { ducts }\end{array}$ \\
\hline \multicolumn{3}{|l|}{ Liver biopsy: } \\
\hline Portal changes & $\begin{array}{l}\text { Uneven, portal expansion by mixed } \\
\text { infiltrate, periductal lamellar oedema, } \\
\text { and pericholangitis; focal biliary } \\
\text { epithelial degenerative changes }\end{array}$ & $\begin{array}{l}\text { No significant expansion, } \\
\text { biliary epithelial } \\
\text { degenerative changes in } \\
\text { most portal tracts, duct } \\
\text { loss }\end{array}$ \\
\hline $\begin{array}{l}\text { Interface } \\
\text { changes }\end{array}$ & $\begin{array}{l}\text { Oedema, cholate stasis, ductular } \\
\text { reaction, copper deposits in } \\
\text { periportal hepatocytes }\end{array}$ & Usually not significant \\
\hline CPV & Usually not significant & Often present \\
\hline Cholestasis & Variable & Usually present \\
\hline Fibrosis & Slow progression in time, biliary type & $\begin{array}{l}\text { Perivenular with or without } \\
\text { bridging septa, if present. }\end{array}$ \\
\hline
\end{tabular}

ACR, acute cell-mediated rejection; ALP, alkaline phosphatase; CPV, central

perivenulitis; GGT, $\gamma$ glutamyl transpeptidase; PSC, primary sclerosing cholangitis.
AMR does occur. When it does occur, it is usually within the first week post-transplant. ${ }^{57}$

The more aggressive (hyperacute) variant occurs immediately post-perfusion, usually but not only in the context of $\mathrm{ABO}$ isoagglutinins. The clinical features include hypotension, coagulopathy, progressive hyperbilirubinaemia, renal failure and refractory thrombocytopenia (ie, rapidly evolving and worsening hepatic failure). Imaging studies can reveal portal vein thrombosis and parenchymal necrosis. Serological demonstration of donor-recipient incompatibility at the $\mathrm{ABO}, \mathrm{MHC}$ or other levels is present, as well as relevant donor-specific antibodies. The pathogenesis stems from transplantation into a sensitised host with preformed antidonor antibodies. The titre, class and specificity of these preformed antibodies determine the degree of injury, and the higher titres are more likely to result in more severe injury. ${ }^{5960}$ Because of the associated coagulation problems, as well as the rapidity of progression, these cases hardly come to the pathologist as diagnostic needle biopsies, but are more likely to be seen as explanted failed graft or at autopsy. Pathologically the liver is enlarged up to twice the preengraftment weight, ${ }^{57}$ and congested/mottled on the capsular and cut surfaces. Patchy foci of haemorrhage and necrosis can be grossly recognised. Microscopically the liver shows haemorrhagic and coagulative areas of necrosis and, in the less affected areas, features mimicking preservation/reperfusion injuries (zone 3 hepatocellular "loosening" and cholestasis) can be identified. Ischaemic necrosis of bile ducts of all calibres is also present, as well as loss of small bile ducts, despite the short duration post-grafting. Findings in the vessels (small, intermediate and sometimes large) include thromboses and vasculitis, with evidence of neutrophilic exudation and fibrin deposits in and around vascular walls. Tissue demonstration of antibody activity by the presence of $\mathrm{C} 4 \mathrm{~d}, \mathrm{C} 1 \mathrm{q}$ or immunoglobulins (almost always $\operatorname{IgG}, \pm \mathrm{IgM}$ also) in vascular and sinusoidal walls can be seen, but is hardly necessary.

Less aggressive development of AMR as a cause of graft dysfunction can present in the setting of slow normalisation of liver enzymes post-transplant and/or increasing liver enzymes in the first week of transplant. The diagnosis of AMR in this context should include a combination of clinical, serological (demonstration of donor-recipient mismatch and presence of donor-specific antibody). The histopathological features of AMR are not as well defined as in ACR. AMR shows features that overlap with preservation/reperfusion injury, but are commoner and more pronounced in patients with preformed circulating donor antibodies. ${ }^{60}$ These features include zone-3accentuated cholestasis, portal expansion with oedema and ductular proliferation (exclude obstruction/stricturing), as well as C4d deposition in the walls of portal capillaries and veins and hepatic venule; sinusoidal C4d can be seen, but its specificity is yet to be determined. ${ }^{57}{ }^{60}$ If perihilar tissue is included in the 
biopsy, arterial injury and thrombi are present, as evidenced by endothelial hypertrophy and myocyte necrosis, vacuolisation and thickening, while necrosis of large bile ducts and congestion of peribiliary plexus complete the picture. ${ }^{6061}$

\section{DISEASE RECURRENCE}

Long-term survival after liver transplantation is now expected due to improvements in surgical techniques, patient selection and immunosuppression regimens. Approximately $85-90 \%$ of liver transplant patients are alive after 1 year and $75 \%$ after 5 years. ${ }^{1}$ Disease recurrence represents the major cause of graft dysfunction and loss after 6 months. ${ }^{29}$ The frequency of disease recurrence after liver transplantation is highly influenced by the aetiology of the primary liver disease ${ }^{29}{ }^{62-64}$; for example hepatitis $\mathrm{B}$ and $\mathrm{C}$ almost universally recur. Furthermore, a different set of human leucocyte antigen (HLA) molecules present in the allograft may alter the recognition and response of the body to viral particles. Other factors influencing the prevalence and/ or severity of disease recurrence include the immunosuppressive environment, which clearly facilitates viral replication and can underlie aggressive behaviour when the disease recurs. ${ }^{1}$ On a more positive note, the advent of effective prophylactic and therapeutic measures in the last 15-20 years has dramatically improved the post-transplantation outcome of patients transplanted for hepatitis B virus (HBV) infection. ${ }^{65-70}$

Primary biliary cirrhosis (PBC), PSC and AIH may all recur after liver transplantation and diagnostic criteria for recurrence may differ from the ones used for similar native liver disease. ${ }^{71-75}$ Recurrence of alcoholic liver disease, non-alcoholic fatty liver disease and non-alcoholic steatohepatitis have also been reported. ${ }^{130}$ 76-78 Liver transplantation for primary hepatic malignancies (hepatocellular carcinoma or cholangiocarcinoma) is based on stage of disease, and the likelihood of recurrence is dependent on several risk factors, such as microscopic vascular invasion, multiple tumours and tumour burden, for hepatocellular carcinoma. ${ }^{1070-84}$ Cholangiocarcinoma has a poor prognosis after liver transplantation and its recurrence influenced largely by disease stage. ${ }^{79}{ }^{81}$ Liver disease is cured by transplantation in cases of $\alpha_{1}$-antitrypsin disease, Wilson disease and cystic fibrosis, and most metabolic liver diseases, do not recur after transplantation. Post-transplant outcome for patients with haemochromatosis is yet uncertain, but there seems to be little impact up to 5 years after transplantation. ${ }^{185}$

\section{Recurrent HBV infection}

In the past, liver transplantation for HBV-related liver disease was often followed by aggressive recurrence and reduced

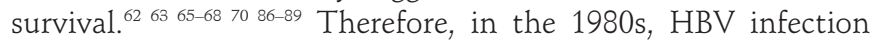
was considered an absolute or relative contraindication for orthotopic liver transplantation (OLT). Currently, combination therapy by oral antiviral agents (eg, lamivudine, adefovir) and hepatitis B immunoglobulin in the pretransplant and posttransplant setting achieves nearly $100 \%$ of protection against adverse outcomes from graft reinfection. 656770868790

The course of post-transplant HBV infection is well known. ${ }^{88}$ Similar to that which occurs in non-transplanted patients with $\mathrm{HBV}$ infection, reinfection also occurs in three phases, with an incubation period (approximately 3 months post-transplant), followed by acute infection (up to 6 months) and chronic infection (more than 6 months). ${ }^{91} \mathrm{HBV}$ infection sources include the patient's circulation and extrahepatic replicating sites. ${ }^{88}$ Disease activity and progression tend to be more severe compared with non-transplanted livers, but may be attenuated by coexistent HCV or hepatitis D virus (HDV) infection due to decreased viral replication. ${ }^{180}$ Nevertheless, fulminant recurrent $\mathrm{HBV}$ and HDV have been reported in patients with HDV infection and active HBV replication. ${ }^{92}$ The most common clinical feature of acute hepatitis $B$ in the allograft is mild elevation of liver enzymes. Nausea, vomiting, jaundice and hepatic failure signal severe recurrent disease. Within the first month after transplantation, an atypical pattern of recurrent HBV infection, known as fibrosing cholestatic hepatitis (FCH), may rapidly lead to graft failure. Patients with chronic HBV infection may be without symptoms or may complain of fatigue or other non-specific gastrointestinal symptoms. ${ }^{92}$

\section{Pathogenesis of recurrence}

As in non-immunosuppressed patients, liver damage in allograft recipients is also secondary to virally directed immunological injury. Recognition of viral antigens by memory $\mathrm{T}$ helper cells leads to expansion and activation of antigen-specific TH1-type CD4+ lymphocytes. ${ }^{193}$ This results in macrophage activation and pro-inflammatory cytokine production. Interferon (IFN) $\gamma$ and tumour necrosis factor (TNF) $\alpha$ cause damage by recruiting and activating non-specific inflammatory cells, upregulating TNF-receptor expression, exerting a direct cytotoxic effect on the hepatitis B surface antigen ( $\mathrm{HBs} A g$ )-expressing hepatocytes, and inducing local mediators of tissue injury such as nitric oxide. ${ }^{1}$ It has been suggested that despite immunosuppression, HLA-class-I-independent immune mechanisms have a significant pathogenic role in liver damage associated with HBV recurrence after liver transplantation. ${ }^{93}$ In the setting of fibrosing cholestatic hepatitis, which usually affects overimmunosuppressed patients and is associated with massive viral replication, liver injury may be attributable to a direct HBV-mediated cytopathic effect. ${ }^{1}$

\section{Histological findings}

The pathological features of HBV infection in liver allografts are similar to those seen in non-allograft livers. However, in liver transplant patients, antiviral therapy can decrease viral replication and therefore alter disease histology. ${ }^{181}$ Inadequate antiviral treatment or the development of resistant viral strains may result in progression from acute to chronic hepatitis and cirrhosis. Resolution of disease can sometimes occur after a bout of acute hepatitis.

Scattered nuclear and cytoplasmic staining for hepatitis B core antigen ( $\mathrm{HBcAg}$ ) can be demonstrated by immunohistochemistry 2-5 weeks after transplantation in biopsies reinfected by HBV. Subsequently, surface antigen is expressed, but ground glass cells are not easily found during the acute phase. ${ }^{92}$ This generally corresponds to the onset of necroinflammatory activity, Kupffer cell hypertrophy, lobular disarray and portal inflammation. ${ }^{62} 699294$ Clinically, these changes are associated with graft dysfunction. Individual hepatocytes undergoing eosinophilic or ballooning degeneration (spotty necrosis) can be found sporadically in the lobules. Patients with low immunosuppression may develop bridging or submassive necrosis, which is a reflection of more robust immune response against the virus.

Recurrent chronic HBV infection has a more aggressive course with more rapid progression of fibrosis and more severe activity, and it is most likely to be due to enhanced viral replication and attenuated host response. ${ }^{92}$ Liver biopsies show lymphoplasmacytic portal inflammation and fibrosis, interface hepatitis, ductular reaction, lobular disarray, Kupffer cell hypertrophy 
and variable lobular necroinflammatory activity. There may be ground glass cells or sanded-appearing nuclei corresponding to HBV surface antigen or core antigen expression, respectively. These can be demonstrated by immunostaining for HBsAg and $\mathrm{HBcAg}$. A complete absence of stainable $\mathrm{HBcAg}$ should raise the possibility of other causes of graft dysfunction, including coinfection with HCV or HDV.

$\mathrm{FCH}$ is an atypical pattern of liver injury associated with HBV infection, and it can also affect renal transplant recipients. ${ }^{92}$ Histologically, FCH is characterised by diffuse hepatocellular swelling, cholestasis, prominent ductular reaction and perisinusoidal fibrosis, but lack of significant inflammatory infiltrate (fig 6). The swollen hepatocytes often show cytoplasmic and nuclear immunoreactivity for $\mathrm{HBcAg}$ as indicative of viral replication..$^{92}$ Some other atypical forms of recurrent $\mathrm{HBV}$ infection associated with heavy viral load have been described as fibrosing cytolytic hepatitis, fibroviral hepatitis B and steatoviral hepatitis B. ${ }^{69} 92$

In HDV/HBV coinfection, hepatitis $\mathrm{D}$ antigen can be identified in the nuclei of infected hepatocytes by immunohistochemistry. ${ }^{92}$ Recurrent HDV infection can also be confirmed by HDV RNA detection by molecular studies or the presence of anti-HDV IgM. ${ }^{92} \mathrm{HDV}$ hepatitis associated with non-replicative HBV infection can result in hepatitic lesions similar to fibrosing cholestatic, fibrosing cytolytic or steatoviral hepatitis, but without $\mathrm{HBcAg}$ expression. In contrast, in the presence of active HBV replication, combined HBV/HDV hepatitis in allografts is histologically similar to that in non-allograft livers. ${ }^{181}$

The differential diagnosis of recurrent HBV infection includes HCV and non-hepatotropic viruses, drug-induced liver injury and immune-mediated hepatitis. There may be some overlapping features between recurrent HBV infection and acute or chronic rejection. Preferential lobular involvement and serological data are helpful in distinguishing HBV infection from rejection. ${ }^{94}$

\section{Recurrent HCV infection}

HCV infection is the most common indication for OLT, and disease recurrence in the allograft is among the leading causes of graft loss and the need for re-transplantation. ${ }^{62}{ }^{63}$ 88-91 95-116 Viral recurrence is universal and graft injury occurs routinely. Reinfection occurs during allograft reperfusion, and pretransplant viral titres are reached in about $72 \mathrm{~h} .{ }^{95}$ Histological recurrence with hepatitis due to HCV occurs in up to $90 \%$ of individuals by 5 years after transplant. ${ }^{95} 96116$ However, progression of HCV infection is variable: some patients will present an indolent course, whereas others rapidly progress to cirrhosis and graft failure. Overall, progression of HCV infection is accelerated after liver transplantation as compared with patients without transplants. ${ }^{95} 101102$

The clinical presentation of allograft recipients with recurrent HCV hepatitis is similar to that of non-allograft patients with primary infection. Liver enzymes increase in parallel with histological evidence of hepatitis, usually within 3-6 weeks after transplantation. Severe recurrent HCV can cause fibrosing cholestatic hepatitis. This is usually associated with overimmunosuppression and is clinically manifested by fatigue, jaundice and a marked increase of serum bilirubin, alkaline phosphatase (ALP) and $\gamma$ glutamyl transpeptidase (GGT). The presence of markedly elevated HCV RNA levels is helpful to establish a correct diagnosis. Cirrhosis will develop in $5-20 \%$ of patients because of recurrent HCV hepatitis. ${ }^{62} 9798$

\section{Pathogenesis of recurrence}

Several factors related to the virus (ie, genotype $1 b$, viral genomic heterogeneity), the host, the environment and the donor are implicated in the outcome. 101102104107 The immune status is likely to be the more important factor influencing disease severity: more intense immunosuppression leads to worse outcomes. ${ }^{95} 99$ Some other predictors of HCV infection after liver transplantation include donor age at time of transplant, donor steatosis, length of cold ischaemic time at
Figure 6 Fibrosing cholestatic hepatitis $B$ virus infection in the liver allograft. (A) Diffuse hepatocellular swelling, without accompanying inflammatory reaction (H\&E $\times 100)$. (B) Lobular disarray with several eosinophilic apoptotic bodies (H\&E $\times 200)$. (C) Perisinusoidal fibrosis (Masson trichrome stain $\times 200$ ). (D) Staining of hepatitis $B$ surface antigen (orcein $\times 200$ ).

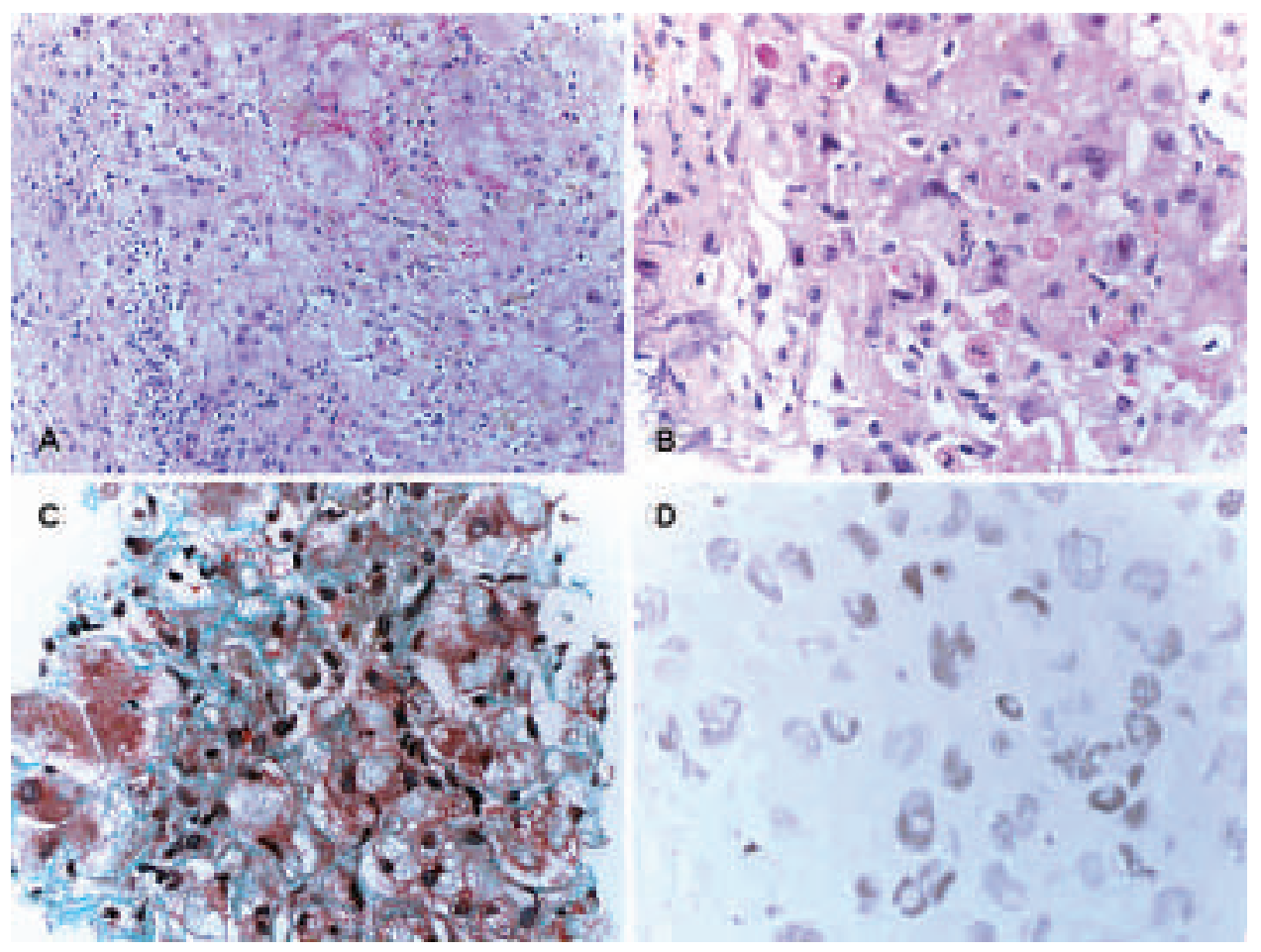


transplant, host immunogenetic background (ie, HLA matching), and timing of recurrence and early histological findings. ${ }^{95} 102$ Furthermore, rapid tapering doses of steroids and steroid-free immunosuppression, with or without induction antibodies, have been thought to reduce the likelihood of severe recurrent HCV infection. ${ }^{95} 102117118$ Pretransplant viral eradication by antiviral therapy prevents disease progression and improves survival, whereas post-transplant treatment before or after histological recurrence has shown variable outcomes. ${ }^{95} 102107$ The presence of coexistent CMV infection after transplant and a history of acute allograft rejection are also associated with increased severity of HCV recurrence. ${ }^{1}$ Obesity and alcohol influences are likely to be similar to those in nontransplanted patients. ${ }^{95}$

As mentioned earlier, the initial biochemical and histological hepatitis usually occurs between 1 and 3 months after transplant. The acute phase is marked by a peak of HCV replication and induction of hepatocyte apoptosis and proliferation, CD8/NKT cellular infiltrate in the graft, and specific antiHCV CD4 response. ${ }^{119}$ Persistent HCV infection in the allograft most often evolves to chronic hepatitis (6-12 months). At this point, the increased viral load seems to overcome the inhibitory effects of immunosuppressive therapy on the immune system with subsequent events characterised by: (1) enhanced inflammatory response and upregulation of IFN $\gamma$-inducible genes, (2) induction of antiviral IFN $\alpha$-inducible genes that are not associated with reduced viral replication, and (3) a HCV-driven enhanced proliferation, apoptosis and fibrosis response in the allograft. ${ }^{103}$ Infiltrating inflammatory cells often lack a specific HCV-directed antigen response.

Less than $10 \%$ of patients may develop severe liver injury (ie, fibrosing cholestatic hepatitis C). In this particular scenario, a reduced immune response with undetectable HCV-specific CD4 response and stable quasispecies takes place as a result of overimmunosuppression. ${ }^{103}$ These allografts typically show a non-specific TH2 cytokine response, with high levels of interleukin (IL) 10 and/or IL4. Together, these events are believed to allow rapid HCV replication resulting in extremely high viral burdens (HCV RNA levels in serum are typically more than 30 million $\mathrm{IU} / \mathrm{ml}$ ), and cytopathic allograft injury. ${ }^{192}$ Early hepatic stellate activation has been shown to occur in patients at greater risk to develop progressive fibrosis and more aggressive recurrent HCV infection in the allograft. ${ }^{90} 108114$

\section{Histological findings}

The pathological features of HCV in liver allografts are similar to those of primary infection in non-allograft livers (fig 7A, B). Histological recurrence may be evident within 3-6 weeks after transplant, or sometimes as early as 10-14 days. Liver biopsies performed during the acute phase of recurrent HCV infection may show lobular disarray, Kupffer cell hypertrophy, hepatocyte apoptosis, mild sinusoidal lymphocytosis and mild mononuclear portal inflammation. Periportal and mid-zonal large droplet steatosis is often seen. ${ }^{1}$ Mild bile duct injury may be present in the form of intraepithelial lymphocytes and scattered biliary epithelial reactive changes. Such mild duct injury needs to be interpreted with caution so as not to overcall ACR in this setting. As disease progresses into a chronic phase, usually beginning at 4-12 months after transplant, the portal inflammation increases, often with lymphoid aggregates, and interface hepatitis of variable severity, lobular disarray, and mild necroinflammatory activity. If present, inflammatory bile injury is, most commonly, mild and focal. Bile duct loss is not a feature of recurrent HCV infection. Perivenular (zone 3) inflammation can be present but it typically involves a minority of hepatic veins. ${ }^{42}$ Prominent interface activity can occur in aggressive conventional recurrent HCV infection.

\section{Fibrosing cholestatic HCV}

This is an aggressive variant of recurrent HCV that occurs in occasional patients with rapid deterioration. This is characterised histologically by extensive dense portal fibrosis with immature pericellular/sinusoidal fibrous bands, extensive hepatocyte swelling and degeneration, ductular reaction, marked canalicular and cellular bilirubinostasis, and moderate mononuclear inflammation (fig 7C, D).$^{96}$ It is very important to recognise $\mathrm{FCH}$ in order to ensure proper therapy.

It has been shown that a small subset of patients with recurrent $\mathrm{HCV}$ infection present clinical and morphological features that overlap with AIH (ie, post-liver transplant AIHlike hepatitis). ${ }^{97}$ In these particular cases, the allograft biopsies show a prominent portal, periportal and lobular plasma-cell-rich infiltrate, and perivenular (zone 3) necrosis. Some of these patients also have positive autoimmune serology with increased serum globulins, presence of anti-nuclear antibody and antismooth muscle antibody. Its recognition is clinically important because of increased fibrosis progression; however, this may be difficult to separate from de novo AIH and atypical acute rejection.

\section{Differential diagnosis}

Distinction between ACR and recurrent HCV infection is very important because treatment for ACR with corticosteroids and OKT3 is associated with increased risk of allograft cirrhosis and mortality. On the other hand, if left untreated, ACR may progress to chronic rejection, especially in IFN-treated patients. ${ }^{42}$ Not only do these two conditions often share similar clinical and histological features, but they may also coexist in the liver allograft. A careful review of the post-transplant clinical course, including liver enzymes results and HCV RNA levels when available, should be considered in parallel to interpretation of the biopsy findings. Mononuclear portal inflammation and lymphocytic cholangitis are common features of recurrent HCV infection and ACR. However, in ACR, inflammatory bile duct injury tends to involve a majority of bile ducts. Perivenular (zone 3) inflammation involving a majority of hepatic veins also favours rejection. ${ }^{36} 91116$ Lobular necroinflammatory activity and interface hepatitis with ductular reaction tend to be more prominent in recurrent $\mathrm{HCV}$ infection (table 3). If ACR and recurrent HCV coexist, the predominant process should be identified. In doubtful cases where low-grade ACR cannot be reliably excluded, patients should be monitored closely with re-biopsy recommended if liver enzymes continue to rise. ${ }^{36}{ }^{120}$ Chronic rejection with or without coexistent recurrent $\mathrm{HCV}$ infection is identified by biliary epithelial degenerative changes or small duct loss or perivenular (zone 3) inflammation and fibrosis involving a majority of bile ducts/ terminal hepatic veins. ${ }^{36}$

Distinguishing recurrent HCV from other viral hepatitides, de novo AIH, drug-induced hepatitis, PBC and PSC is based primarily on a combination of clinical, biochemical, serological and histopathological findings. AIH usually shows more prominent plasma cell inflammation and less steatosis compared with recurrent $\mathrm{HCV}$ infection.

FCH due to HCV needs to be distinguished from large duct obstruction and hepatic artery thrombosis (ischaemic cholangitis). Bile duct obstruction is identified by portal oedema and 
Figure 7 Recurrent hepatitis $C$ virus infection in the liver allograft. (A) Portal inflammation with interface activity and mild bile duct injury (H\&E $\times 200)$. (B) Foci of necroinflammation in the lobule (H\&E $\times 100$ ). (C) Fibrosing cholestatic hepatitis C infection: marked hepatocellular ballooning with minimal inflammation, and ductular reaction (H\&E $\times 100)$. (D) Portal expansion and perisinusoidal fibrosis (Masson trichrome stain $\times 50)$.

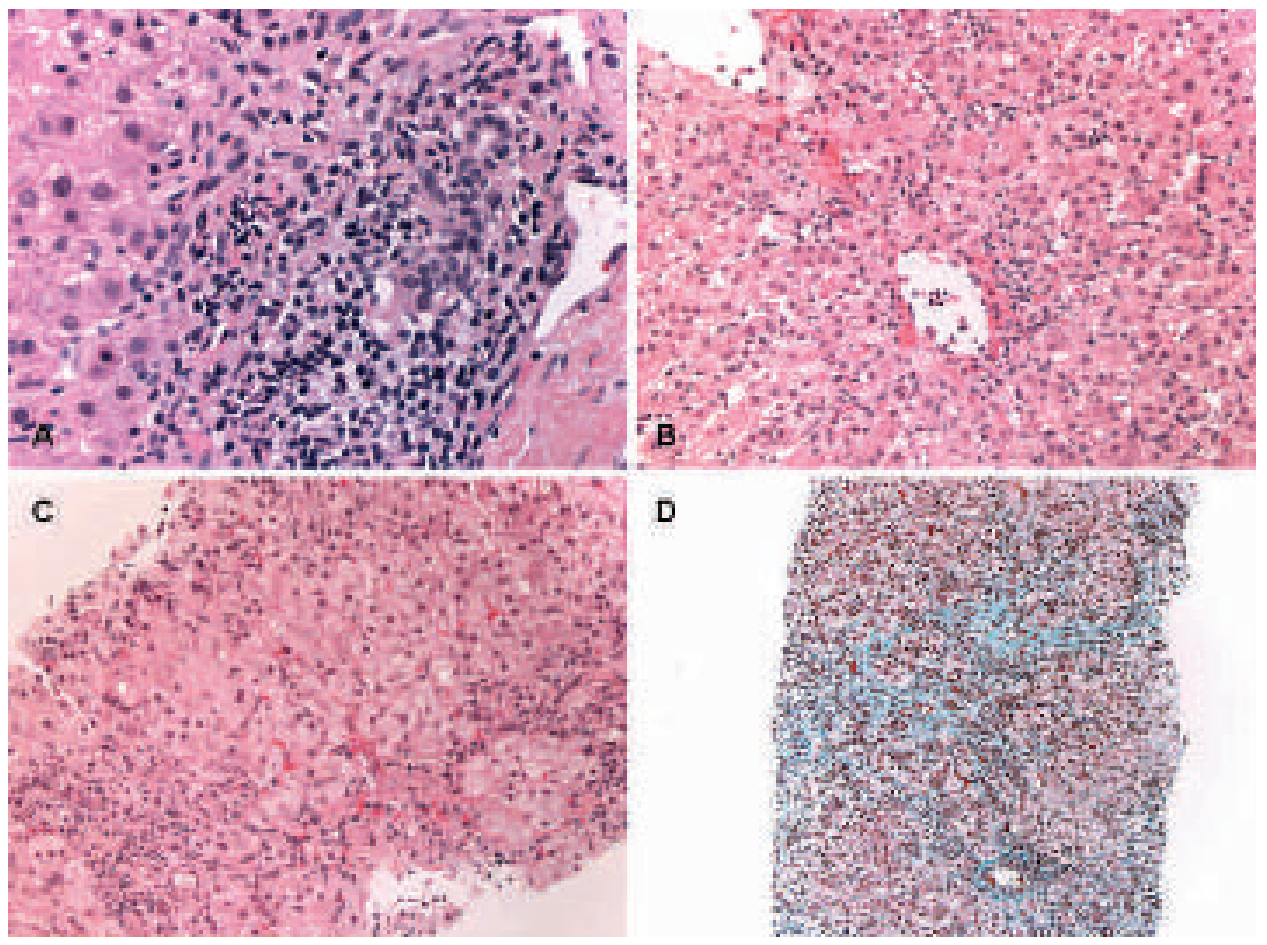

ductular reaction with or without acute cholangitis. ${ }^{121} \mathrm{~A}$ far more challenging scenario is when recurrent HCV (ie, non-FCH) coexists with a biliary problem or another cause of cholestasis (eg, adverse drug reaction or sepsis). In these situations, the histological features may be very similar to FCH. A careful review of the clinical course to rule out an infectious process, or history of new medications, and imaging of the biliary tree may be helpful to exclude or confirm a second problem. Still, in some instances, especially when the actual viral load cannot be determined by reliable quantitative methods, FCH cannot be excluded with certainty, and the decision whether or not to treat HCV infection will depend on weighing the risks and benefits. Anti-HCV therapy may be given as the only feasible intervention and, on occasion, response to anti-HCV therapy or lack thereof provides the answer in hindsight.

\section{Recurrent autoimmune hepatitis}

Autoimmune hepatitis is a relatively uncommon indication of liver transplant. Outcomes are good with 1-year and 5-year patient survival rates of about $87 \%$ and $80-90 \%$, respectively. Graft survival rates at 1 year and 5 years are $84 \%$ and $74-76 \%$, respectively. ${ }^{88}{ }^{122-126}$ The reported recurrence rate for $\mathrm{AIH}$ in most studies is in the range of $17-42 \%$ at 5 years. ${ }^{71} 727482$ In general, recurrent $\mathrm{AIH}$ appears at variable time periods after transplantation, and progression seems to be slow. ${ }^{122}$ Recurrent $\mathrm{AIH}$ responds well to increases in immunosuppression or addition of corticosteroids. ${ }^{72}$ The pathogenesis of AIH is unknown. Whether or not an autoimmune response will perpetuate seems to be influenced by a genetic susceptibility to present self or cross-reacting antigens, a sensibility to aetiological triggers (ie, viruses or toxins), and the composition cytokine environment. ${ }^{74}{ }^{123}$ Aberrant exposure of HLA-II antigens and enhanced presentation of normal constituents on hepatocytes with subsequent activation and proliferation of cytotoxic $\mathrm{T}$ lymphocytes may take place. Hepatocellular damage seems to be secondary to proinflammatory cytokines released by sensitised T cells. ${ }^{71}{ }^{127}$

There seems to be no consistent risk factors for recurrence, but recurrent $\mathrm{AIH}$ has been shown to be more common in transplant recipients who were HLA-DR3 positive or HLA-DR4 positive in one study. ${ }^{74}$ Furthermore, suboptimal immunosuppression, the presence of type I autoimmune disease, and severe inflammation in the native liver before transplantation, may also be associated with a greater incidence of recurrent disease. ${ }^{122} 124$

Diagnostic criteria for recurrent $\mathrm{AIH}$ are similar to those used in the non-transplanted liver and include biochemical, serological and histological abnormalities, and steroid dependency (see box 3). ${ }^{128}$ However, these criteria are more difficult to apply in the allograft liver for a number of reasons including biochemical and histological overlap with ACR, the immunosuppressive environment, and the possibility of alloimmune disease directed against allograft antigens. ${ }^{124}$ Because of the lack of reliable disease markers, a liver biopsy is often the main or sole diagnostic tool for identifying recurrent $\mathrm{AIH}$ in the allograft.

\section{Histological findings}

The histological changes attributed to recurrent $\mathrm{AIH}$ are not specific and need to be distinguished from other causes of chronic hepatitis, ACR, chronic rejection, adverse drug reactions and recurrent PBC and PSC. Early changes include lobular hepatitis with hepatocyte "rossetting". ${ }_{2} 74124$ The chronic phase is usually marked by portal infiltrate composed of lymphocytes and plasma cells with prominent interface activity. A plasma-cell-rich infiltrate directs attention to the possibility of $\mathrm{AIH}$, but it is not a requirement for diagnosis. Lobular necroinflammatory activity is variable, and confluent and bridging necrosis are not uncommon. Perivenular (zone 3) inflammation can be present in a majority of hepatic venules similar to rejection. If present, bile duct inflammatory damage involves a minority of ducts. ${ }^{42} 124$ 
Box 3: Criteria for the diagnosis of recurrent autoimmune hepatitis, primary sclerosing cholangitis and primary biliary cirrhosis

\section{Recurrent autoimmune hepatitis}

- Liver transplant for autoimmune hepatitis

- Autoantibodies in significant titre $(>1: 40)$

- Sustained rise in serum aminotransferase activity (more than two times normal)

- Elevated serum immunoglobulins

- Diagnostic or compatible liver histology

- Corticosteroid dependency

- Exclusion of other causes of graft dysfunction (eg, HCV infection, rejection)

\section{Recurrent primary sclerosing cholangitis}

- Liver transplant for primary sclerosing cholangitis

- Multiple nonanastomotic biliary strictures

- Exclusion of other causes (ie, rejection, infection, ischaemia)

- Diagnostic or compatible liver histology

\section{Recurrent primary biliary cirrhosis}

- Liver transplant for primary biliary cirrhosis

- Persistence of antimitochondrial antibodies

- Elevated immunoglobulins

- Diagnostic or compatible liver histology

- Exclusion of other causes of graft damage

\section{Recurrent PBC}

$\mathrm{PBC}$ is considered to be a disease of disordered immune regulation characterised by progressive loss of interlobular and septal bile ducts leading to cholestasis and cirrhosis. Antimitochondrial antibodies are present in $95 \%$ of patients. Liver transplantation is indicated for advanced PBC, with excellent overall patient and graft outcomes. The 5-year survival rate after deceased donor liver transplantation is approximately $80 \%$. Recurrent PBC after transplantation is controversial, but has now become accepted. Recurrent PBC is seen in $17 \%$ of patients at a mean of 36 months, and $30 \%$ at 10 years. The reported median time recurrence is between 3.7 and 5 years. ${ }^{7-75}$ 129-132 The role of ursodeoxycholic acid in the treatment and prevention of recurrent $\mathrm{PBC}$ is controversial. ${ }^{73}$ It is not clear whether donor and recipient age, cold and warm ischaemia time, and type of immunosuppression used, may influence disease recurrence. However, it seems to be more common after living-related liver transplantation and after corticosteroid withdrawal. ${ }^{130}$

The diagnostic criteria for recurrent $\mathrm{PBC}$ are summarised in box 3. A diagnosis of recurrent $\mathrm{PBC}$ is made in the setting of characteristic histology and absence of other causes of graft damage. Elevated serum immunoglobulins and persisting antimitochondrial antibodies are not sufficient for the diagnosis of disease recurrence. Histological changes may be present in the allograft, even in the absence of biochemical abnormalities. ${ }^{73}$

\section{Histological findings}

Changes of recurrent $\mathrm{PBC}$ are similar to those present in native livers. Liver biopsies with recurrent $\mathrm{PBC}$ may show one or more of the following features: variable portal inflammation with mononuclear (or mixed) infiltrate, lymphoid aggregates with germinal centres, lymphocytic cholangitis with biliary epithelial eosinophilia, and periductal epithelioid non-necrotising granulomatous reaction. ${ }^{121} 132$ The diagnostic lesions (ie, epithelioid granulomas and florid duct lesions) are often focal, and therefore may not be present in needle biopsies in the early stages (fig 8). As disease progresses, there is development of lymphoplasmacytic interface activity resembling $\mathrm{AIH}$, and biliary interface activity with cholate stasis. Additional features include ductular reaction, portal and periportal fibrosis, small bile duct loss and periportal oedema (halo sign). The parenchyma may show spotty necrosis or even scattered foci of lytic necrosis, and deposition of copper and copper-associated proteins at the portal/parenchymal interface provides supportive evidence of recurrent $\mathrm{PBC}$ if other causes of biliary tract disease have been excluded.

Bile duct injury or loss due to recurrent $\mathrm{PBC}$ needs to be distinguished from ACR, chronic rejection, adverse drug reaction, CMV and HCV infection, recurrent PSC, ischaemic cholangitis, recurrent or de novo $\mathrm{AIH}$, and graft versus host disease. Usually, the clinical scenario, serological investigations and imaging results are very important to make the diagnosis clear. A diagnosis of recurrent $\mathrm{PBC}$ can be definitive when granulomatous bile duct destruction and/or florid bile duct lesions are present in the proper clinical context. In the absence
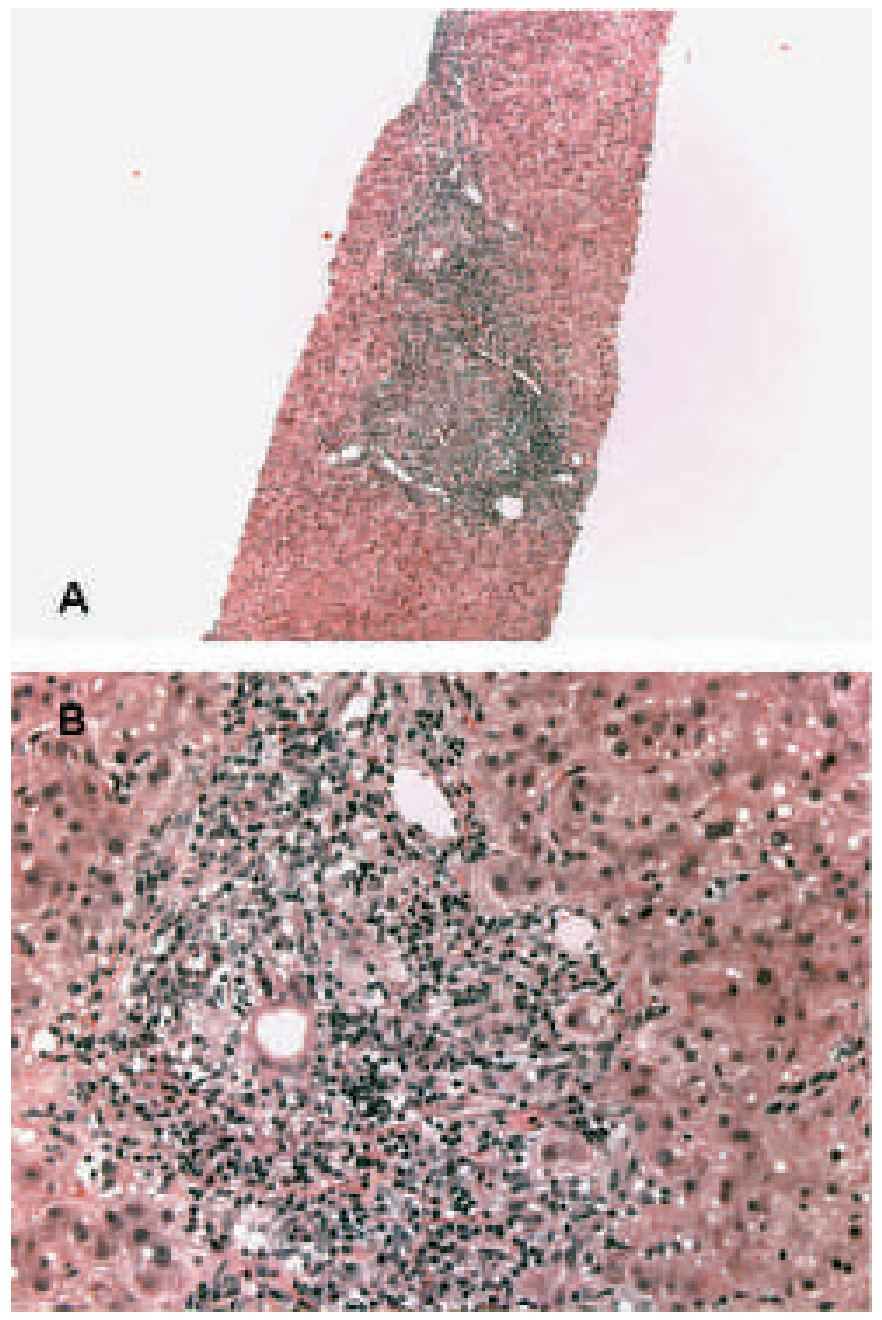

Figure 8 Recurrent primary biliary cirrhosis. (A) Predominantly portalbased changes with marked inflammatory infiltrate and interface activity $(\mathrm{H} \& \mathrm{E} \times 50)$. (B) Portal tract with a granulomatous bile duct lesion (H\&E $\times 100)$. 
of these features, the presence of a prominent but focal lymphocytic cholangitis, accompanied by portal-based lymphoid aggregates with germinal centres and bile ductular reaction, are highly suggestive, although not diagnostic, of recurrent $\mathrm{PBC} .{ }^{121}$ Sometimes the time frame of rise of ALP is a clue: a sudden rise in ALP is unlikely to be due to recurrent PBC.

\section{Recurrent PSC}

PSC is a progressive cholestatic disease of unknown aetiology that usually involves both the extrahepatic biliary tree and the intrahepatic biliary tree, and has a close association with inflammatory bowel disease. The hallmark clinical lesion of PSC is an abnormal cholangiogram. Endoscopic retrograde cholangiopancreatography and magnetic resonance cholangiopancreatography typically show irregular strictures, beading, diverticular outpouching, and pruning of bile ducts. Liver transplantation is indicated for patients with end-stage disease. The long-term outcome after transplantation is very good, with survival rates of $86 \%$ at 5 years, and $70 \%$ at 10 years. ${ }^{62}$ A higher incidence of acute and chronic and steroid-resistant rejection in PSC patients has been reported, especially in the presence of coexistent inflammatory bowel disease. ${ }^{49}{ }^{62}$ Recurrence of PSC after transplantation ranges from 9\% to 47\%. ${ }^{62} 63707174133-139$ Risk factors for disease recurrence include donor-recipient gender mismatch, male gender, and intact colon at the time of transplantation. ${ }^{49} 140$ The presence of hilar cholangiocarcinoma before transplantation significantly decreases survival after transplantation. ${ }^{135}$ As a matter of fact, the presence of cholangiocarcinoma is considered an absolute contraindication to transplantation at most centres due to the high risk of recurrence in the graft. ${ }^{136}$ There is yet no effective treatment to delay the presentation or progression of recurrent PSC in the allograft. ${ }^{136}$ Selective elevation of ALP and GGT due to PSC recurrence usually manifests 1 year after transplantation. It is very difficult to separate recurrent PSC from other causes of biliary strictures (eg, choledochojejunal anastomotic stricture, hepatic artery thrombosis, preservation injury, chronic ductopenic rejection, $\mathrm{ABO}$ blood group incompatibility, viral/bacterial biliary tract infection, SFSS in living donors, non-heartbeating donors). ${ }^{49} 136$ The diagnostic criteria for recurrent PSC are summarised in box 3. Non-anastomotic intrahepatic strictures that develop within 90 days after transplantation are not considered recurrent disease. The diagnosis of recurrent PSC requires cholangiographic and histological evaluation.

\section{Histological findings}

The histological features of recurrent PSC are identical to those seen in the native livers with PSC. Early changes in the peripheral liver include mild non-specific acute and chronic "pericholangitis" and mild ductular reaction. ${ }^{42} 72$ As disease progresses, there is periductal lamellar oedema with increased ductules and mixed portal inflammation with eosinophils and neutrophils, periportal oedema, ductular reaction and scattered small duct loss. ${ }^{121}$ Later stages are featured by biliary cirrhosis, cholestasis, marked copper deposition, and Mallory bodies in paraseptal hepatocytes. Periductal concentric fibrosis and duct loss involve small and medium-sized bile ducts (fig 9A-E). These so-called "fibro-obliterative duct lesions" can also be seen in patients with ischaemic cholangitis (hepatic artery thrombosis) and other post-transplant causes of secondary sclerosing cholangitis. The large intrahepatic and extrahepatic bile ducts may show ulceration, biliary sludge and marked periductal lymphoplasmacytic infiltrate. ${ }^{49}$
The distinction between recurrent PSC and chronic rejection may be challenging, as both cause a cholestatic pattern of liver enzyme elevation and duct loss (fig 9F). The clinical history, evaluation of serial biopsies and histopathological findings are useful to separate these two conditions (table 5). ${ }^{121}$

\section{Recurrent alcoholic liver disease, non-alcoholic fatty liver disease and non-alcoholic steatohepatitis}

Alcoholic liver disease represents a leading cause indication for liver transplantation with short-term survival rates comparable to those for patients who undergo liver transplantation for other conditions. ${ }^{76-78}$ The rate of alcohol relapse is considered low, and resumption of alcohol seems to begin within the first year after transplantation. ${ }^{141}{ }^{142}$ There is no significant evidence supporting a detrimental effect on graft or patient survival associated with recidivism. Fatty liver and steatohepatitis are the main histological features of alcohol relapse. ${ }^{142}$ More severe recidivism can lead to frank alcoholic hepatitis with Mallory's hyaline, foamy degeneration of hepatocytes and perivenular fibrosis. ${ }^{121}$

Accurate data on the percentage of liver transplants performed for non-alcoholic steatohepatitis (NASH)-related cirrhosis are not available, in part because many cases identified as cryptogenic cirrhosis may in fact represent "burnt out" NASH. ${ }^{143}$ Steatosis has been reported to occur within 612 months and cirrhosis within 2 years of transplantation in patients undergoing liver transplantation for NASH. ${ }^{143} 144$ Recurrent NASH seems to occur at later times than fatty liver alone, with increasing incidence over time during follow-up.

\section{Recurrent metabolic diseases}

In disorders such as type 1 tyrosinaemia, $\alpha_{1}$-antitrypsin deficiency, Wilson disease, neonatal haemochromatosis, and glycogen storage disease types 1, 3 and 4, the liver is replaced by a genetically normal one that is not susceptible to recurrent disease. $^{85}$

The risk of recurrence is higher in patients with metabolic defects involving extrahepatic sites, and the effects on the liver are largely secondary in those that are at highest risk of recurrence (eg, Niemann-Pick disease, Gaucher's disease, cystinosis and erythropoietic protoporphyria). ${ }^{85}$

\section{LATER NEW-ONSET DISEASES/INJURIES IN THE IN LIVER ALLOGRAFT}

\section{Biliary complications}

At the time of transplantation, reconstruction of the biliary tract occurs in the form of a duct-to-duct anastomosis or choledochojejunal anastomosis. Mucosal and/mural damage may occur in the process and lead to biliary tract complications, such as bile leaks, and anastomotic or intrahepatic strictures. ${ }^{145} 146$ The process of biliary wound healing occurs and may or may not be ineffectual. The general concepts of wound healing as they apply to the biliary tract, interleukin 6/gp130 signalling pathways, and ineffective wound healing, are discussed in detail elsewhere. ${ }^{12}$ This can affect the small extrahepatic biliary tree and/or the large extrahepatic biliary tree. Briefly, in the extrahepatic large bile ducts, biliary healing may lead to scarring and stricture formation. In the small extrahepatic bile ducts, impaired proliferation of the bile duct epithelium or exuberant responses can contribute to liver injury. ${ }^{12}$ Radiological tests such as MRI and/or allograft biopsies may be performed in the course of investigation of biliary complication post-transplant. Biliary complications or their 
Figure 9 Recurrent primary sclerosing cholangitis in a failed liver allograft. (A) Portal tract with mild changes, including periductal oedema and biliary epithelial degenerative changes (H\&E $\times 100)$. (B) Characteristic periductal lamellar oedema (Masson trichrome stain $\times 100)$. (C) Fibro-obliterative duct lesions ("fibrous knots") (Masson trichrome stain $\times 100$ ). (D) Marked portal expansion ductular reaction and fibrosis (Masson trichrome stain $\times 100$ ). (E) Periportal hepatocyte copper accumulation (rhodamine stain $\times 200$ ). (F) Features of early chronic rejection are present in the same liver allograft: marked biliary epithelial senescent changes (H\&E $\times 100$ ). This patient also had multiple episodes of acute cellular rejection during the early and late post-transplant period.
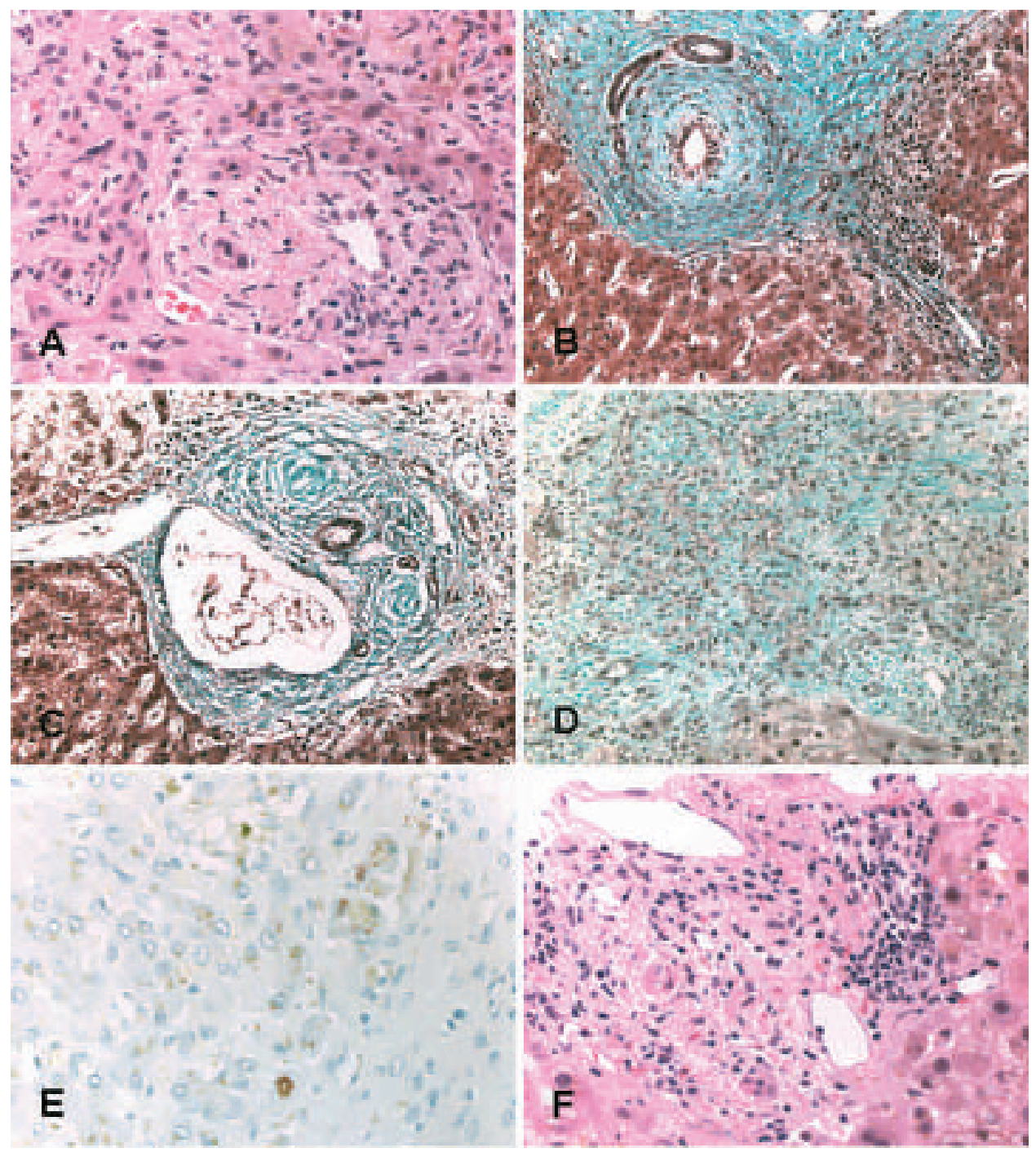

sequela may also be seen in biopsies performed for other reasons (eg, protocol surveillance biopsies for HCV in a patient with biliary stricture). Biliary complications occur early and late in the post-transplant course. All are discussed here for convenience.

\section{Biliary sludge syndrome}

Cold ischaemic-preservation injury depletes energy stores in microvascular endothelial cells and bile duct epithelium. As a result, metalloproteinases are activated. Biliary epithelium and endothelium are detached from underlying matrix. In the microvasculature, detachment of endothelium predisposes to thrombosis after reperfusion. ${ }^{8}{ }^{10}$ Reperfusion brings leucocytes that become activated by tissue damage, and they release effector molecules, causing more tissue damage and further ${\text { promote thrombogenesis. }{ }^{8} 10}^{10}$

Several factors, including increased sensitivity of bile duct cells to reperfusion injury, poor functional recovery after ATP depletion, invasion of polymorphonuclear leucocytes into bile ducts, and hydrophobic bile salts, appear to contribute to preservation-related injury of bile ducts. ${ }^{8} 10147148$ Damaged biliary epithelial cells are sloughed into the bile. Exposure of the underlying stroma to bile appears to serve as a nidus for crystallisation of biliary sludge. ${ }^{12}$ Injury of bile ducts is associated with hyperbilirubinaemia and underlies the longlasting phase of reperfusion graft injury. ${ }^{8} 10$

Morphological changes produced by bile sludge syndrome are present in the extrahepatic large bile ducts and intrahepatic large bile ducts, as well as in the small intrahepatic ducts. Since biopsies usually sample the peripheral liver, it is the latter that are encountered in biopsies. There is prominent ductular reaction consisting of biliary cells and periductal myofibroblasts. This occurs because of increased pressure in the biliary tree distal to the point of luminal obliteration. The proliferating ductules and myofibroblasts form a wedge of tissue that arises from the portal tract and distorts the liver architecture.

Morphological changes of the large bile ducts are usually seen at the time of re-transplantation in the excised failed graft. There is biliary sludge, mucosal ulcers and inflamed granulation tissue and myofibroblast proliferation in the wall of extrahepatic bile ducts and large intrahepatic bile ducts. ${ }^{11}$ Exposure of the underlying stroma serves as a stimulus for inflammation and activation of myofibroblasts. This leads to wound contraction and fibrosis, and eventually to strictures in large-calibre ducts. Complete fibrous obliteration of the bile duct lumens by concentric rings of fibrous tissue occurs. 


\section{Bile duct strictures}

To appreciate the pathophysiology of bile duct stricture formation, the blood supply to bile ducts is summarised as follows. Blood is supplied to intrahepatic bile ducts and extrahepatic bile ducts exclusively through hepatic arteries (HAs). ${ }^{149}$ Over $50 \%$ of the blood conveyed by HAs is primarily destined to the bile ducts. ${ }^{150}$ Intrahepatic arteries course in close proximity to the bile ducts. They drain into the peribiliary plexus, which is a rich microvascular network surrounding bile ducts. ${ }^{150}$ Blood supplying the bile ducts drains into the sinusoids via the portal system. Ischaemia-induced bile duct lesions have been collectively labelled as ischaemic cholangitis. ${ }^{151}$ The biliary epithelium is dependent on arterial blood flow, unlike the hepatic parenchyma with its dual arterial and portal venous blood supply. As such, the biliary epithelium is susceptible to injury when arterial blood flow is compromised. Ischaemic cholangitis manifests as segmental strictures with resultant mechanical impairment of bile flow and, occasionally, secondary infection of the biliary system. Biliary strictures in liver transplant recipients are related to a combination of large HA occlusion related to surgical reconstruction or sepsis, and/or damage to small-sized arteries and peribiliary plexus-due to preservation, reperfusion, rejection, $\mathrm{ABO}$ incompatibility or CMV infection. ${ }^{152}$ Biliary strictures may be anastomotic or nonanastomotic. Anastomotic biliary strictures are thought to result from technical surgical problems or local ischaemia; the incidence has been reported to be $<10 \%$ for deceased donor liver transplantation, and to be higher, up to $30 \%$, for living donor liver transplantation. ${ }^{153-159}$ Most anastomotic strictures appear within the first several months after transplantation, but they may also develop, less frequently, many years after transplantation. Intrahepatic biliary strictures are included in nonanastomotic strictures; they result primarily from hepatic artery thrombosis. ${ }^{152}$ Intrahepatic biliary strictures, without hepatic artery occlusion, are related to chronic ductopenic rejection, $\mathrm{ABO}$ incompatibility, ischaemia-reperfusion injury, or recurrence of primary disease, such as PSC or AIH. ${ }^{146}{ }^{147}{ }^{159-162}$ Nonanastomotic strictures tend to occur later after transplantation, are less amenable to treatment, are generally progressive, and adversely impact graft and patient survival. The biopsy features of duct obstruction in allografts are the same as those encountered in native livers. Most complications show predominantly neutrophilic portal inflammation, periductal oedema, and intraepithelial and intraluminal neutrophils within true portal bile ducts. Mild ductular proliferation, centrilobular hepatocanalicular cholestasis and small clusters of neutrophils throughout the lobules are also commonly seen. ${ }^{163}$ Chronic biliary tract strictures may be associated with chronic portal inflammation and biliary epithelial cell senescence. The differential diagnosis of early duct obstruction (within 6 months post OLT) is preservation injury with biliary sludge syndrome and ACR; the differentiating histological features are compared in table 1.

After 6 months post transplantation, biliary obstruction/ stricture mimics a broader spectrum of processes that include acute and chronic rejection, viral hepatitis and recurrent autoimmune disorders. Chronic intermittent biliary obstruction or cholangitis, as in patients with the biliary sludge syndrome, can be associated with a mixed, or a predominantly mononuclear, portal infiltrate and biliary epithelial cell senescence changes. Portal fibrosis with mild duct proliferation, mild portal neutrophilic or eosinophilic inflammation, and mild centrilobular cholestasis are features that suggest obstructive cholangiopathy ${ }^{1}$

\section{INFECTIOUS COMPLICATIONS}

Apart from recurrence original viral infections, usually viral hepatitis B and C (described above), other viral infections can affect liver graft, including EBV and CMV. Also newly acquired hepatitis $B$ or hepatitis $C$ infection should be borne in mind in patients transplanted for other reasons other than viral hepatitis. The scope of infections in liver allograft patients is broad, and also includes several non-viral agents that either constitute new or re-activated (mostly opportunistic) infections. The histological features in most cases are not different from those seen in the other organ systems, and therefore they are not discussed further in this review. However, the syndromes associated with EBV and CMV warrant further discussion in that they are not only well studied in liver patients, but they also represent important differential diagnoses to other more commonly encountered histopathological problems, and are therefore discussed in the following sections.

\section{Post-transplant EBV infection}

Post-transplant liver biopsy in the setting of EBV disease may be encountered in the context of clinical hepatitis, or in the setting of suspected or known PTLDs, for example: (a) post-transplant EBV infection including hepatitis, (b) PTLD in the liver, (c) spectrum of allograft conditions associated with extrahepatic PTLD.

The incidence of EBV infection post-transplant varies depending on whether the patient was exposed to EBV prior to transplantation. EBV infection post-transplant occurs in 63$80 \%$ of patients who are seronegative at the time of transplantation. Reactivation infections occur in $20-22 \%$ of patients exposed to the virus before transplantation. ${ }^{164} 165$ It appears that many patients are asymptomatic. In a paediatric series, only $15 \%$ of patients with primary post-transplant EBV hepatitis were symptomatic. ${ }^{165}$

A range of histological patterns can be seen in the allograft biopsies in EBV hepatitis. ${ }^{166-168}$ These range from the characteristic picture described in the immunocompetent host in infectious mononucleosis to a distinctive constellation of features. ${ }^{166}$ At one end of the spectrum is the typical EBV hepatitis pattern that usually shows mild portal and sinusoidal mononuclear infiltrates (fig 10). These infiltrates are composed of small and mildly atypical lymphocytes. The lymphocytes arrange themselves in a single file pattern within the sinusoids, and this pattern should suggest an EBV-related disorder. In situ hybridisation for EBV-encoded RNA (EBER) is confirmatory. Other lobular changes include focal hepatocellular swelling, acidophilic necrosis of hepatocytes and mild lobular disarray. Granulomas may occur. ${ }^{169}$ Another pattern is that of nonspecific reactive hepatitis. The liver sinusoids show mild lymphocytosis. Portal mononuclear inflammatory infiltrates may be of variable severity. Portal tracts with sparse infiltrates coexist with dense portal lymphocytic infiltrates elsewhere in the same biopsy. At the other end of the spectrum is a characteristic constellation of features described by Randhawa et al that consists of mixed mononuclear portal and sinusoidal infiltrates containing atypical large non-cleaved mononuclear cells and immunoblasts, associated hepatitic lobular activity, and relatively mild duct damage disproportionate to the severity of the infiltrate. ${ }^{166}$ Any of these patterns should arouse suspicion for EBV infection, and this should be relayed to the treating physician so that serological confirmation can be obtained. The patterns at the ends of the histological spectrum described above are sufficiently characteristic to raise suspicion for EBV. The pattern of non-specific reactive hepatitis carries a wider 


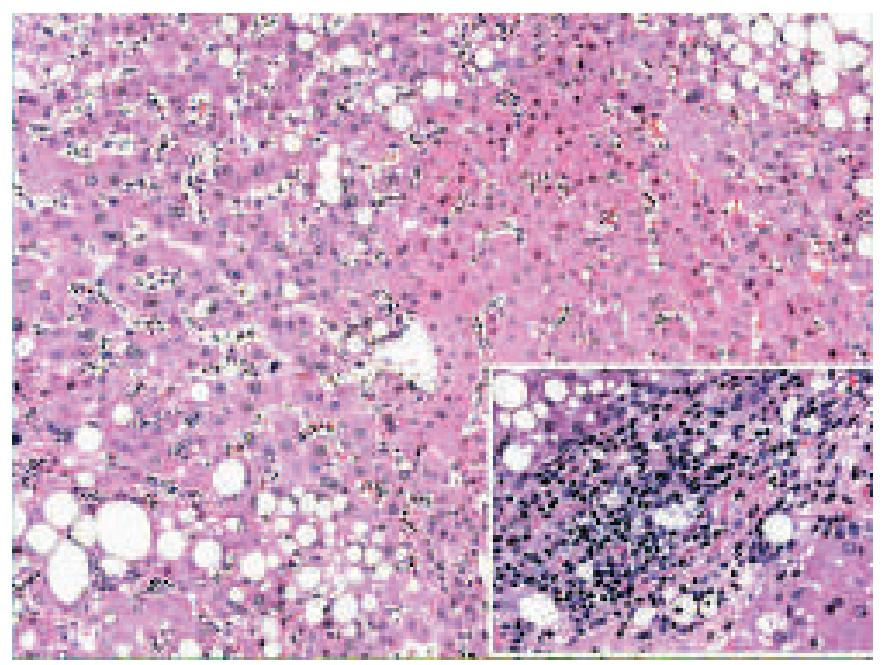

Figure 10 Epstein-Barr virus hepatitis. Low-power view of parenchyma showing sinusoidal lymphoid infiltrate in a single file pattern (H\&E $\times 100)$. Insert: high-power view of portal tract showing moderately dense portal infiltrate including small and mildly atypical lymphocytes (H\&E ×400).

differential diagnosis that should include EBV, especially if serology for usual hepatotropic viruses (HBV, HCV) is negative.

The differential diagnosis of a mononuclear infiltrate in the post-transplant setting is cellular rejection. In favour of EBV is the monomorphous composition of the portal infiltrate in EBV hepatitis, the lack of eosinophils and neutrophils and presence of atypical large cleaved lymphoid cells, and associated hepatitic changes. While EBV-related bile duct damage and phlebitis may occur, ${ }^{170}$ the tempo of these is more brisk when the portal infiltrate is mixed in the setting of cellular rejection. It should be remembered that cellular rejection and EBV hepatitis may coexist. This is especially more prone to occur in biopsies taken as follow-up after treatment for EBV hepatitis that includes reduction of immunosuppression

When there is a pre-existing diagnosis of PTLD and there is clinical cause to perform a liver biopsy, the most important consideration is whether acute rejection is present. Possible findings in such biopsies include acute rejection, EBV hepatitis and recurrent disease. In one series, acute rejection was found in $54 \%$ of biopsies, and features indeterminate for rejection in $29 \%$. EBV hepatitis was the primary diagnosis in $8 \%$ of biopsies, and secondary in an additional $25 \%$. Non-specific reactive hepatitis was seen in approximately $16 \%$ of biopsies, and $20 \%$ showed recurrence of primary liver disease. ${ }^{171}$ Immunoperoxidase staining showed primarily $\mathrm{T}$ cells. EBER was detected in $58.3 \%$ of biopsies, with and without acute rejection. ${ }^{171}$ In the rejection cases, the presence of occasional EBV-infected cells was thought to reflect an increased circulating viral burden in these patients. ${ }^{171}$ Positive in situ hybridisation for EBER in liver biopsies is only seen in the context of a high viral load in patients with PTLD or those at high risk for developing this complication. ${ }^{168}$

\section{Post-transplant CMV infection}

In liver transplant recipients, the overall incidence of CMV disease has been described as being up to $29 \% .{ }^{172}$ In transplant patients, the greatest risk of CMV hepatitis is transplantation of an organ from a CMV-serology-positive donor to a serologynegative patient $(\mathrm{D}+/ \mathrm{R}-)$. In liver transplant recipients, in the risk group of $\mathrm{D}+/ \mathrm{R}$ - the risk may be as high as $44-65 \%$ if no prophylaxis is given. ${ }^{173} 174 \mathrm{CMV}$ hepatitis is a significant complication of CMV infection after liver transplantation, with an incidence of $2-17 \% .{ }^{172} 175176$

CMV infection of the liver transplant is characterised by graft dysfunction. Thus the biopsy indication may be one of elevated serum transaminases. The diagnosis, however, should be based
Figure 11 (a) Low-power view of needle biopsy showing no obvious parenchymal inflammation (H\&E $\times 50$ ). (b) Higher magnification of the box in (a) showing a typical cytomegalovirus (CMV) intranuclear inclusion in an enlarged hepatocyte liver surrounded by few neutrophils. This was the only inclusion in the core biopsy and was seen on one level of one slide, emphasising the need for meticulous scrutiny of the biopsy in such cases (H\&E $\times 630$ ). (c) CMV immunostain showing immunoreactivity (brown colour) in the intranuclear CMV inclusions from another case, confirming their nature $(\times 400)$.
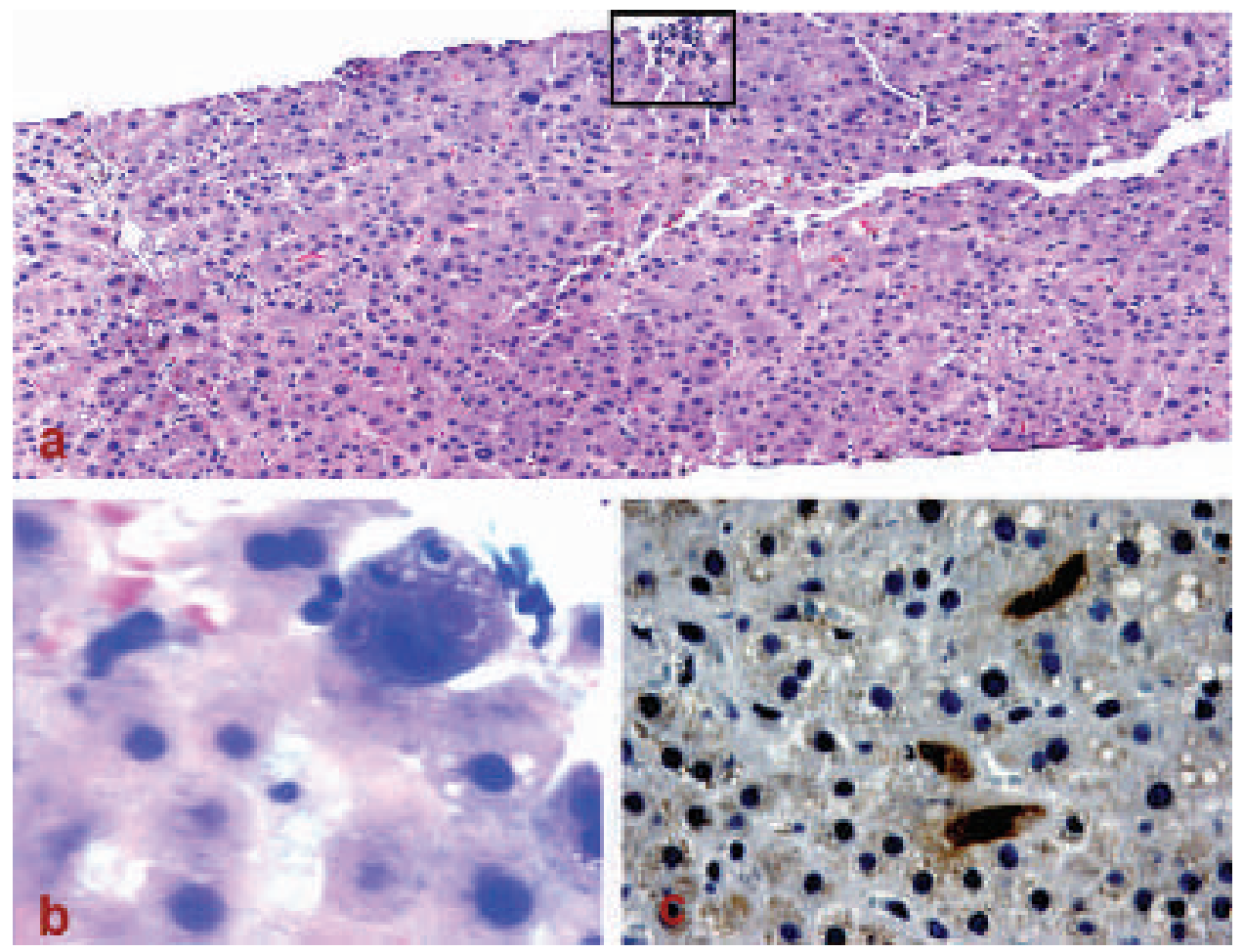
on liver biopsy. ${ }^{177} 178$ The histological features of CMV hepatitis are variable. In high-risk patients (ie, heavily immunosuppressed or naive recipients), CMV cytopathic effects may occur in any cell type of the liver. The characteristic CMV inclusions are large eosinophilic and intranuclear, surrounded by a clear halo (fig 11). Occasional small basophilic or amphophilic cytoplasmic inclusions may be present. ${ }^{179} \mathrm{CMV}$ hepatitis is characterised by spotty lobular necrosis, and mild lobular disarray. There is mononuclear, or mixed, portal inflammation, focal bile duct damage and aggregates of macrophages (microgranulomas) scattered throughout the parenchyma. Hepatocytes containing CMV inclusions may be associated with small clusters of neutrophils (microabscesses).

Dilemmas arise when, as is commonly the case, none of the characteristic features are apparent, or when features of CMV overlap or coexist with those of cellular rejection.

\section{Absence of characteristic positive signs}

The histological alterations associated with intrahepatic CMV infection may cause differential diagnostic problems, as the characteristic CMV inclusions are rarely seen. Neutrophilic abscesses are not specific or sensitive, and again are not always present in the biopsy. Lamps et al found microabscesses in only $17 \%$ of post OLT biopsies done for graft dysfunction; of the $17 \%$ who had microabscesses, only 19\% were proven to have CMV. ${ }^{180}$ Microabscesses were seen in other conditions, including infectious conditions (bacterial, viral and fungal), graft ischaemia and biliary obstruction, and they were of undetermined aetiology in $29 \%$ of cases.

Also, although CMV hepatitis tends to exhibit milder lobular disarray and hepatocyte swelling as compared with HCV or HBV hepatitis, CMV hepatitis can sometimes be difficult to distinguish from early recurrent HCV or HBV. CMV hepatitis may also posses overlapping features with EBV hepatitis: mild lymphoplasmacytic portal and lobular inflammation. If present, microabscesses and microgranulomas are helpful, as they are not generally associated with HBV or HCV infection, but immunoperoxidase staining for viral antigens (CMV, HSV and HBV) or in situ hybridisation for EBV should be performed, as either is usually diagnostic in these difficult cases.

\section{Overlapping features with, or associated rejection}

Other features of CMV hepatitis (eg, portal lymphocytic infiltration, some degree of endotheliitis and cholestasis) may lead to the misinterpretation of mild acute rejection. Follow-up biopsies after CMV treatment may be difficult to interpret as to the presence of residual CMV versus evolving acute or chronic rejection possibly related to lowering of immunosuppression in the face of the initial diagnosis of CMV hepatitis. In practice, the demonstration of CMV inclusions or its antigens by immunostaining takes precedence, resulting in reduction in immunosuppression and initiation of ganciclovir therapy. Correlation of time lines of enzyme improvement or worsening with immunosuppression lowering and/or initiation of ganciclovir treatment can be helpful in resolving the differential diagnosis.

There is reported association between CMV and chronic rejection. ${ }^{181} 182$ It appears that persistence of CMV DNA, and not acute CMV hepatitis, is associated with chronic rejection. Successful antiviral treatment of CMV infection does not exclude the persistence of the virus and the risk of chronic rejection.

\section{DE NOVO HEPATITIS}

\section{Idiopathic chronic hepatitis}

Unexplained chronic hepatitis (idiopathic chronic hepatitis $(\mathrm{ICH})$ ) in the adult liver allograft recipient is not uncommon, although its reported incidence is quite variable between different centres. ${ }^{183}$ The incidence ranges from $<10 \%$ and up to approximately $50 \%$ in different series. ${ }^{43} 144184-189$ ICH is characterised by a predominantly portal mononuclear inflammatory infiltrate associated with interface hepatitis. Lobular inflammation is of variable degrees, and hepatocyte necrosis or apoptosis is frequently present. By definition, the immunemediated pattern of inflammation designated as ICH also requires that bile duct injury or vascular lesions characteristic of acute or chronic rejection are minimal or absent. ${ }^{190}$ Thus, the features are largely similar to those seen in chronic hepatitis in the non-transplant setting. ${ }^{191}$

There are several potential reasons for the variable incidence of ICH among transplant centres. These include factors that could affect long-term outcome or late biopsy findings. ${ }^{183}$ To name some of these factors: the use of extended-criteria organs with influence from donor factors and the early postoperative course, severity of early acute rejection, low-grade rejection going unrecognised in centres where protocol biopsies are not routinely performed, and variation in terminology and histological threshold for diagnosis of ICH ("portal and lobular mononuclear inflammation" at one centre may be diagnosed as ICH, whereas a similar infiltrate may be termed as "nonspecific inflammation" in another centre).

The differential diagnosis includes a number of immunemediated entities that include cellular rejection, infections and de novo post OLT AIH. A chronic hepatitic form of rejection is probably the leading consideration. ${ }^{190}$ Centrilobular-based acute rejection is another possibility in those cases of $\mathrm{ICH}$ where central perivenulitis involving a majority of hepatic veins is present. ${ }^{42}$

Recurrent or newly acquired HCV or HBV should always be considered. These are discussed in detail in the section on recurrent disease. Other potential viral hepatitides include EBV (see section on post-transplant infections) and hepatitis $\mathrm{E}$ virus (HEV). Chronic HEV infection can develop in immunosuppressed patients, who may then serve as long-term carriers of the virus. It has been hypothesised that HEV may be a cause of chronic hepatitis in liver transplant recipients. Haagsma et al diagnosed chronic HEV infection in two liver transplant recipients. ${ }^{192}$ Fourteen cases of acute HEV infection developed in patients receiving solid organ transplants: three liver transplants, nine kidney transplants, and two kidney and pancreas transplants. All patients were positive for serum HEV RNA. Histological features of chronic hepatitis were present. ${ }^{193}$ Unidentified hepatotropic viruses have been suggested as a possible cause of chronic hepatitis, ${ }^{183}{ }^{194}$ but HEV may be one of these.

New-onset AIH diagnosis is based on a combination of the histopathological pattern of injury, autoimmune serology, and increased serum gammaglobulins. ${ }^{190} 194195$ This was mentioned above as a consideration in the diagnosis of late-occurring cellular rejection, and is further discussed below as a clinical entity.

The histological features of ICH on routine stains are nonspecific and thus, often, the aetiology cannot be determined on histological grounds alone. Correlation of histological findings with clinical events and time lines of enzyme elevation, if any, is required (eg, recent reduction in immunosuppression, recent illness interfering with absorption of medications, introduction 
of new drugs that may cause drug-induced liver injury or affect levels of immunosuppressants). Autoimmune and viral (including hepatotropic and non-hepatotropic viruses, eg, EBV) serology and immunoglobulin levels, particularly IgG, are an integral part of evaluation to complement histology. A careful search for ground glass hepatocytes to suggest infection with $\mathrm{HBV}$ is needed, and immunoperoxidase stains for HBsAg can further confirm the nature of such cells. This can be helpful in situations where a risk factor for HBV infection is not readily known. Immunostains for other viruses, such as herpes simplex and CMV, may be performed. In situ hybridisation for EBV performed on the liver biopsy should also be considered.

In most series of long-term biopsy follow-up studies it appears that ICH has a benign rather than a significantly adverse clinical outcome, ${ }^{43} 144$ 184-189 although there are a few studies that show evidence to the contrary. Among the latter, in their retrospective study, the Birmingham group reported mild inflammatory activity and mild to moderate fibrosis in the initial biopsies of 12 of 30 recipients with ICH. Approximately $41 \%$ of these 12 recipients subsequently developed marked graft dysfunction, new or progressive fibrosis was noted in approximately $50 \%$, and three patients developed cirrhosis. ${ }^{194}$

Seyam et al found histologically proven graft cirrhosis in 48 (representing $3.7 \%$ ) of patients in this series. ${ }^{196}$ Ten patients at a median of 7 years after transplantation had no apparent aetiology for cirrhosis; in all 10 patients, previous biopsies had shown features of chronic hepatitis of uncertain aetiology. The authors concluded that chronic hepatitis was the most frequent underlying pathological process in cases where the cause of cirrhosis remains uncertain, as they found in $20 \%$ of patients with graft cirrhosis. The prevalence of "cryptogenic" posttransplant cirrhosis was significantly higher in patients initially transplanted for fulminant seronegative hepatitis $(6 \%)$ than in those transplanted for other diseases (0.3\%). ${ }^{196}$ Therefore, until there is a better understanding of the true impact of $\mathrm{ICH}$, the histological pattern of chronic hepatitis should be reported and should trigger pathological and histological investigation as much as possible to exclude an underlying cause.

\section{De novo AlH}

In native liver, AIH does not have a pathognomonic feature, and its laboratory, serological and histological manifestations are found in acute and chronic liver disease of diverse causes. Thus, the diagnosis of autoimmune hepatitis requires confident exclusion of other causative factors.

In 1993, the International Autoimmune Hepatitis Group proposed diagnostic criteria, which were revised in 1999. ${ }^{128}$ 197-199 Due to the complexity of these criteria and their insufficient validation, the International Autoimmune Hepatitis Group devised a simplified scoring system for wider applicability in routine clinical practice. ${ }^{198}$ Histologically, mononuclear infiltrates that are plasma-cell predominant and interface activity are reasonably good markers of AIH in native livers. ${ }^{199} 200$ Thus, de novo AIH in the liver allograft is diagnosed by a plasma-cellrich infiltrate showing significant necroinflammatory interface and perivenular activity (fig 12). However, in the posttransplant setting, a new diagnosis of AIH is complicated by the need to distinguish this entity from recurrent HCV and rejection.

HCV infection appears to induce a genetic susceptibility to autoimmune processes, including in the liver. ${ }^{201-203}$ When differentiating HCV from de novo AIH post-transplant, the difficulty stems from the fact that HCV infection by itself in the non-transplant setting can be associated with multiple immunemediated extrahepatic manifestations, and chronic HCV liver disease can be associated with AIH-like features in native liver. ${ }^{199} 204$

Czaja et al reported higher serum levels of gammaglobulin and immunoglobulin G, higher frequency of cirrhosis, a higher mean Knodell score, a higher frequency of HLA-DR3, and a high titre of smooth muscle antibodies associated with the AIH-like pattern of $\mathrm{HCV}$-induced liver injury in the general population. ${ }^{199}$
Figure 12 (a) De novo post-transplant autoimmune hepatitis: low-power view of needle biopsy showing central perivenulitis with zone 3 hepatocyte drop out and portal inflammation. There is milder inflammation of the parenchyma outside zone 3 . The edge of the zone 3 areas with dropped-out hepatocytes is marked by arrows (H\&E $\times 50)$. HV, hepatic vein; PT, portal tract. (b) De novo post-transplant autoimmune hepatitis: higher magnification of zone 3 showing concentric inflammation and parenchymal necrosis around the hepatic vein (ie, central perivenulitis) (H\&E $\times 400)$. (c) De novo post-transplant autoimmune hepatitis: higher magnification of the portal tract, showing plasma-cell-rich infiltrate $(\mathrm{H \& E} \times 400)$.

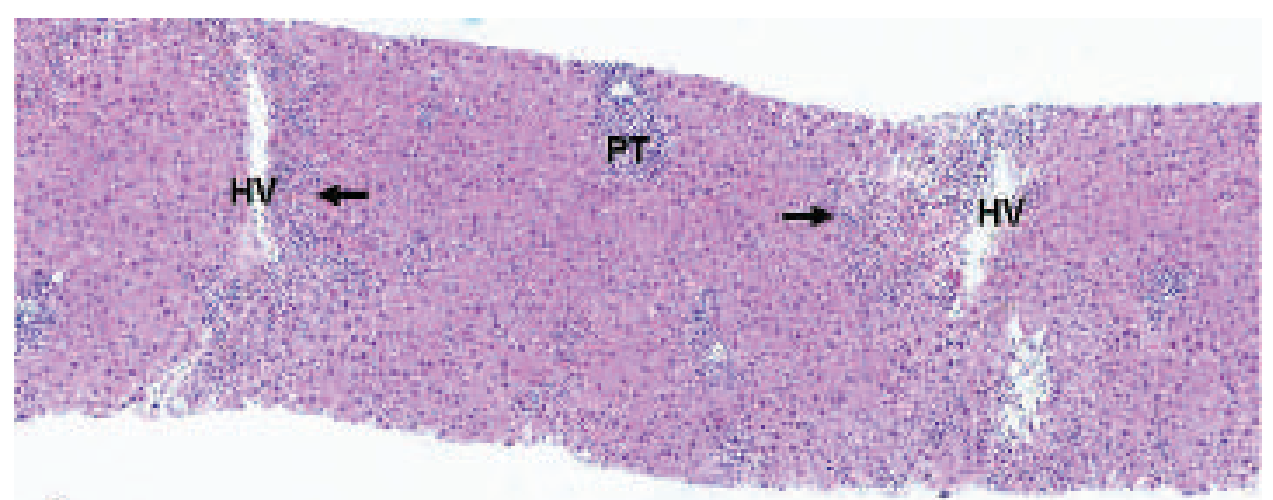

a

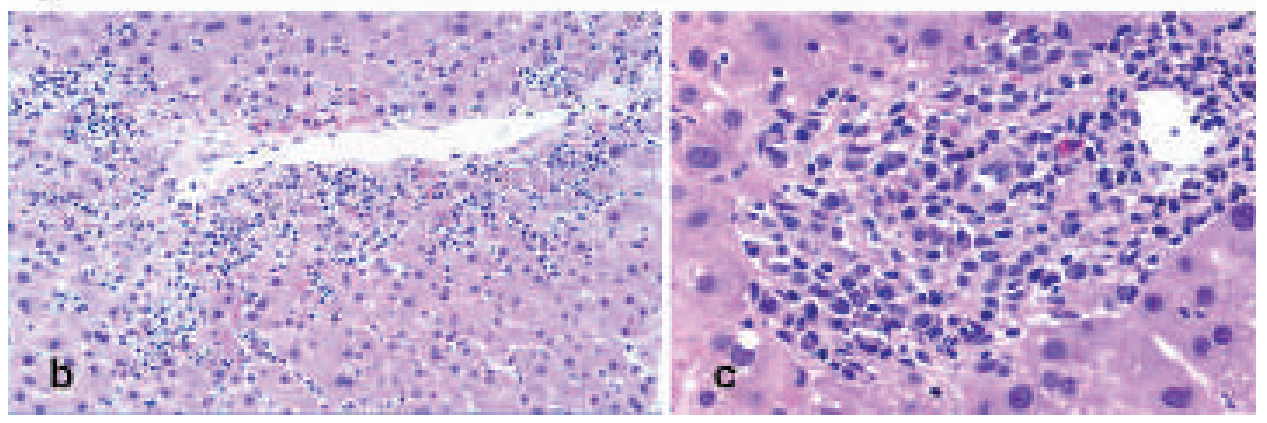




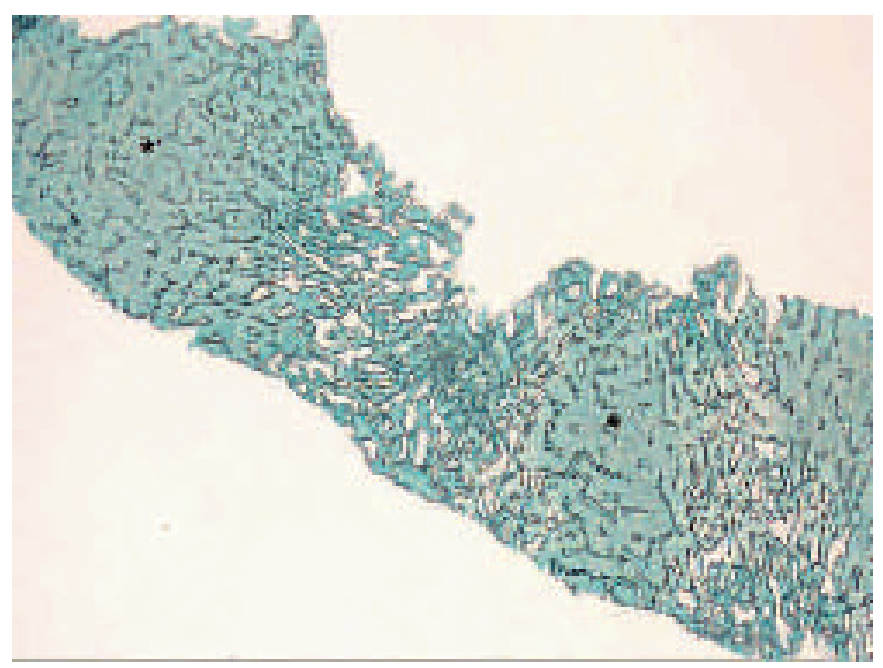

Figure 13 Nodular regenerative hyperplasia: reticulin stain showing the nodular parenchymal architecture. There are nodular hyperplastic areas of parenchyma $\left({ }^{*}\right)$ centred on portal tracts and not bound by fibrosis alternating with atrophic areas $(\times 50)$.

There is evidence in the literature to suggest that patients transplanted for HCV liver disease, like non-transplant patients with HCV, can develop AIH-like features in the graft associated with recurrent $\mathrm{HCV}$ or, after successful HCV therapy, with HCV RNA clearance.

Khettry et al reported "AIH-like" HCV based on histological hepatitis with moderate to severe portal, periportal and lobular necroinflammation with prominent plasma cells in 10\% (nine patients) of HCV recipients in their programme. There was a significantly higher incidence of CPV. ${ }^{97}$ Serological evidence of autoimmunity was present in six of nine $(66 \%)$ of the AIH-like $\mathrm{HCV}$ patients, supporting the hypothesis that prominent plasma cells are a marker of autoimmunity in liver allograft biopsies with chronic hepatitis. ${ }^{97}$

Berardi et al reported a series of 9 of $44 \mathrm{HCV}$ liver allograft recipients who developed what they termed "de novo autoimmune hepatitis" after at least 6 months of anti-HCV therapy for HCV recurrence. ${ }^{205}$ Although HCV RNA clearance was achieved in all but one case, these patients developed significant graft dysfunction and hepatitis. Extensive investigations excluded other causes including infectious ones, and led to a diagnosis of de novo AIH according to clinicopathological criteria defined by the International Autoimmune Hepatitis scoring system. ${ }^{128}$ Prednisone treatment and cessation of antiviral therapy resulted in varying outcomes: five remissions, and four graft failures with two deaths. That the liver allograft damage in this series was related to autoimmunity was reasonably convincing given HCV clearance.

In a study of highly selected patients, Fiel et al use the phrase "plasma cell hepatitis (de novo autoimmune hepatitis)" to describe what they eventually conclude to be a variant of acute rejection. ${ }^{206}$ The authors concluded that plasma cell hepatitis $(\mathrm{PCH})$ represents a form of acute rejection because $\mathrm{PCH}$ in these patients frequently developed in association with suboptimal immunosuppression; their cohort had a high incidence of acute rejection prior to developing $\mathrm{PCH}$ (which was felt to indicate a tendency toward rejection), and had a better outcome when treated with increased immunosuppression.

\section{The conundrum: CPV in recurrent HCV and de novo AIH- rejection or what is it?}

CPV (zone 3 inflammation surrounding the hepatic vein) with or without associated zone 3 necrosis is usually immunologically mediated, and mostly represents rejection in the context of liver transplantation. ${ }^{207-211}$ Besides $\mathrm{AIH}$, other causes of perivenular necrosis and inflammation are much less likely. ${ }^{212}$

In a series of 100 patients in a study published by the University of Pittsburgh Medical Center, ${ }^{46} 40$ patients had CPV,
Figure 14 (a) First biopsy from patient treated with previous episodes of cellular rejection and azathioprine therapy: hepatic vein with lumen obstructed by fibrous tissue $\left(^{*}\right)$ from markedly thickened intima (Masson trichrome stain $\times 400$ ). (b) Higher magnification of the biopsy in (a) showing severe sinusoidal congestion in zone 3 around the hepatic vein (Masson trichrome stain $\times 400$ ). (c) Second biopsy from the same patient 4 years later: low-power view showing organisation of collapsed parenchyma by fibrosis that is severe (Masson trichrome stain $\times 25$ ). (d) Second biopsy, as in (c), showing healed hepatic veins. There are subtle remnants of structural collagen from the distorted wall of a small hepatic vein (arrows) (Masson trichrome stain $\times 400$ ).
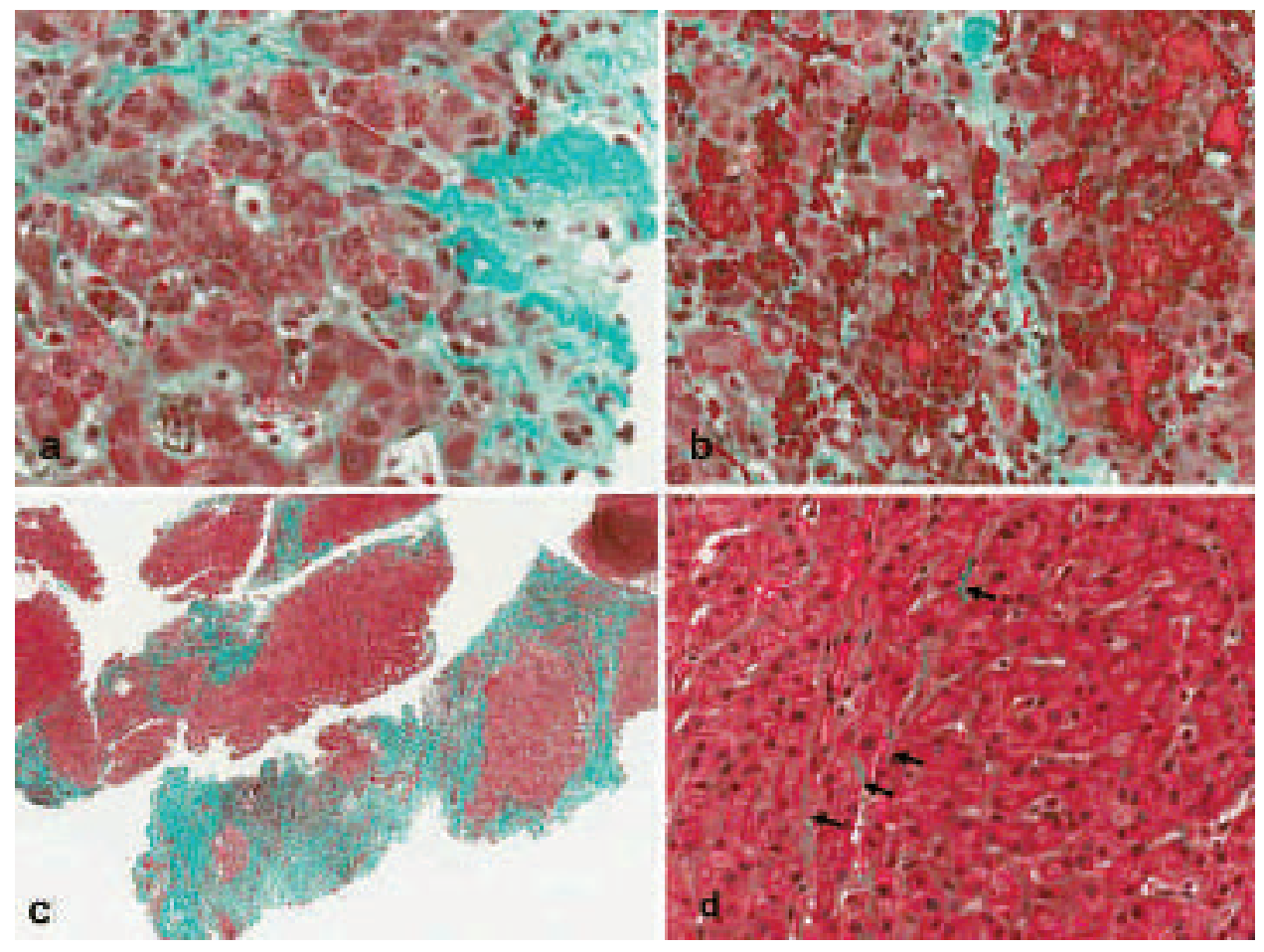
Figure 15 (a) Low-power view from a post-transplant liver biopsy of a patient with recurrent hepatitis $C$ virus and recent elevated transaminases $(\mathrm{H} \& \mathrm{EE} \times 25)$. Note mild portal inflammation accentuating towards one end of the core (arrowhead). Insert: high-power view of the portal tract with accentuated inflammation. Note that the inflammation here is mixed and there is bile duct injury by lymphocytes (arrow); these are features that mimic cellular rejection (H\&E $\times 400)$. (b) Repeat biopsy after the abscess was searched for by imaging: low-power view of organising abscess with portal tract at the edge (PT) (H\&E $\times 50)$. (c) Higher-power view of portal tract at periphery of abscess showing bile duct injury as a bystander next to an inflammatory lesion biopsy from the same patient 4 years later: low-power view showing organisation of collapsed parenchyma by fibrosis that is severe (H\&E $\times 200)$. (d) Higher-power view of abscess showing inflammatory cells including neutrophils (H\&E $\times 200$ ).
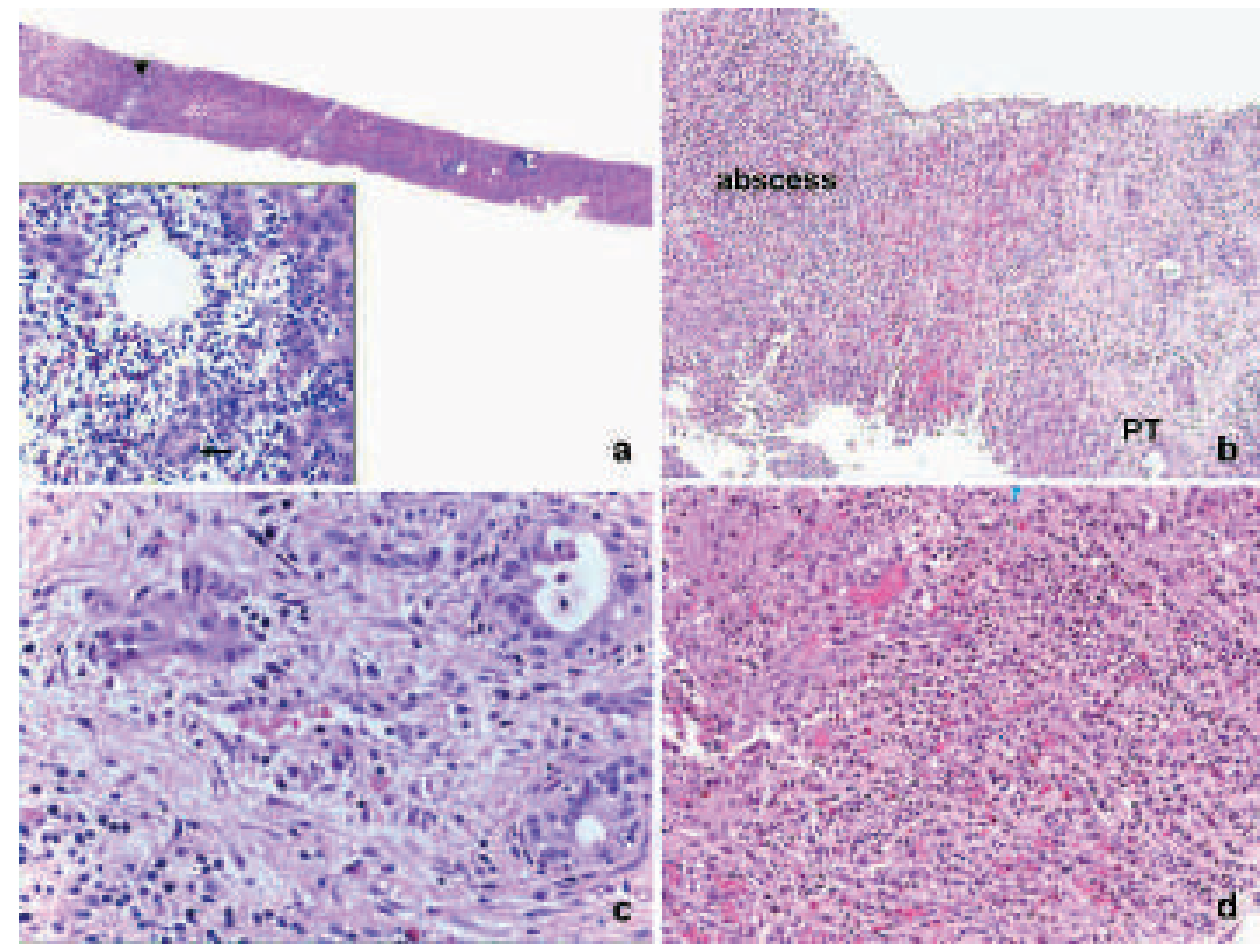

of which 12 were classified as ACR because of associated portalbased findings. Follow-up revealed that five of the remaining 28 patients subsequently developed portal-based ACR on separate biopsies, two patients developed de novo $\mathrm{AIH}$, and two developed chronic ductopenic rejection. In general, and until new insight emerges, CPV accompanied by portal-based features of ACR with or without "lobular hepatitis" is best regarded and treated as late ACR. When CPV is isolated, serological evidence for autoimmunity should be sought and, if present, (for now) is best regarded as AIH in an allograft, and classified as de novo or recurrent as the case may be. The remaining cases probably represent a variety of conditions not easily lumped together, and as these patients are followed-up a better understanding of the contributing disease process(es) should become clear, but should nevertheless be reported as "idiopathic" hepatitis, discussed with the treating clinicians and, if possible, followed up closely with early re-biopsy, the goal being to detect fibrosis progression and/or development of ductopenia.

It remains uncertain whether plasma-cell-rich centrilobular lesions (fig 12b) in HCV liver allograft recipients represent rejection, as concluded by Fiel at al, ${ }^{206}$ or an altered immune variant of $\mathrm{HCV}$, or de novo AIH. The arguments for and against have been recently discussed extensively by Demetris et al, ${ }^{203}$ but their conclusion was that perivenular inflammation and necrosis involving a majority of central veins, plasma-cell-rich or not, are immune-mediated injuries (cellular rejection and $\mathrm{AIH}$ ), and responsive to increased immunosuppression, regardless of the HCV status of the patient, and irrespective of whether or not the patient was post-transplant.

In recurrent $\mathrm{HCV}$, prominent lobular inflammation with zone 3 necrosis in HCV transplant patients should prompt the consideration as to whether these changes represent a severe or aggressive form of $\mathrm{HCV}$ recurrence, or $\mathrm{HCV}$ with superimposed cellular rejection with CPV, or de novo AIH. It would appear that lobular changes in de novo post-transplant $\mathrm{AIH}$ are more prominent than in the native liver $\mathrm{AIH} .{ }^{213}{ }^{214}$ The features that favour post-transplant $\mathrm{AIH}$ are nevertheless similar to those considered in the native liver and include: portal inflammation with numerous plasma cells, prominent interface hepatitis, and lobular inflammation (plasma cell rich) with zone 3 necrosis. Perivenular inflammation, and necrosis involving a majority of central veins, are not typical features of recurrent HCV in allografts; when they are found, an alternative explanation that includes an accompanying immune-mediated injury/cellular rejection should always be considered and further investigated clinically.

The decision to treat rejection or autoimmune phenomena in HCV-positive patients requires close clinicopathological correlation and an informed discussion with the clinician. In our experience at a large transplant centre, and similar to the opinion of Demetris et al, ${ }^{203}$ this decision depends on the severity of the perivenular damage and whether the short-term gain of less liver damage offsets a diminished ability to eventually clear the HCV infection. If left untreated, significant (moderate or severe) perivenular damage, whether plasma-cell-rich or not, promotes the occurrence of bridging fibrosis (portal-to-central and central-to-central). ${ }^{42} 97205206$

\section{DRUG-INDUCED LIVER INJURY}

Drug-induced liver injury can mimic many patterns of transplant-related and non-transplant-related liver pathology. A detailed description of drug-induced liver injury is beyond the scope of this review and is given elsewhere. ${ }^{215}$ Brief comments will however be made on some of the drugs commonly used in the post-transplant setting: immunosuppressants and sulfamethoxazole-trimethoprim (Septra).

Ciclosporin (CyA) and tacrolimus (KF506) hepatotoxicity were reported in liver allograft recipients in the early 1990s. However, newer insights indicate that many of the features thought to represent CyA and/or FK506 toxicities, such as perivenular necrosis/fibrosis, bile duct epithelial changes and sinusoidal foam cells, are in fact due to chronic rejection. ${ }^{48} 216-218$ In practical terms, these calcineurin inhibitors are more likely to 
present with renal toxicity leading to dose adjustments before hepatic injury becomes clinically apparent, and may explain why they are almost never reported in clinical practice. Sirolimus and azathioprine probably cause hepatotoxicity; the prevalence of these injuries is unknown partly because the drugs are infrequently used compared with the calcineurin inhibitors. However, in cases of liver allografts biopsied for elevated liver enzymes, including acute hepatic injury in patients on sirolimus (alkaline phosphatase and transaminases) or preferentially alkaline phosphatase elevation in the case of azathioprine, in the absence of other contending explanations and with nonspecific histopathological findings (such as centrilobular cholestasis, focal feathery degeneration of hepatocytes, peliosis and sinusoidal dilatation), drug toxicity should be considered and discussed with the clinicians. ${ }^{219-222}$ Importantly the tendency by azathioprine to cause endothelial injury, sometimes resulting in veno-occlusive disease (VOD) should be borne in mind, ${ }^{223} 224$ as is discussed more in the section on VOD below.

Sulfamethoxazole-trimethoprim (Bactrim, Septra) is a frequently post-transplant primarily for infection prophylaxis, and is unfortunately a known cause of cholestatic liver injury, which may be prolonged to 1-2 years after discontinuation, and sometimes presenting with pruritus. ${ }^{225}$ Liver biopsy in Septra toxicity is primarily cholestatic, sometimes causing "vanishing ducts" but minimal hepatocellular necrosis or inflammation. ${ }^{5426}$ Most times the cholestatic nature of injury is apparent, but sometimes cytokeratin 7 or other bile duct epithelial markers should be obtained once this possibility becomes relevant in the individual case.

\section{VASCULAR ABNORMALITIES}

\section{Nodular regenerative hyperplasia}

The original description of nodular regenerative hyperplasia $(\mathrm{NRH})$ is one of innumerable small parenchymal liver nodules usually $1 \mathrm{~mm}$ in diameter, with minimal or no parenchymal fibrosis. ${ }^{227} 228$ The hepatocyte cell plates are often two cells wide surrounding a central portal tract. NRH is associated with obliteration of small portal veins and occasionally small hepatic veins. The pathogenesis is felt to be ischaemic atrophy of the parenchyma, with secondary nodular hyperplasia in areas with favourable blood flow. ${ }^{228} 229$

$\mathrm{NRH}$ has been reported to develop up to 20 years after stem cell $^{230}$ and other solid organ transplantation. However, it is increasingly recognised in liver allografts and, as discussed earlier, especially in the context of $\mathrm{SFSS}^{24}$ As in the nontransplant setting, NRH is presumed to be due to chronic lowgrade vascular injury, which in the post-transplant setting may be partly due to abnormal activation of the immune system. A localised imbalance of portal vein and hepatic arterial inflow leads to periportal hepatocyte proliferation and $\mathrm{NRH}$ changes that may be regional or focal rather than diffuse. Regional hypoperfusion of small portal vein branches late after transplantation because of thrombosis and luminal obliteration can locally increase hepatic arterial flow. ${ }^{231}$ The diagnosis of NRH can be difficult in small biopsy; therefore a reticulin stain is a recommended tool when $\mathrm{NRH}$ is suspected; this stain helps to outline the typically subtle nodularity of liver parenchyma, with compressed reticulin fibres forming the boundaries of each nodule (fig 13).

\section{Veno-occlusive disease (sinusoidal obstruction syndrome)}

VOD is a recognised complication of bone marrow transplantation $^{232}$ and kidney transplantation in the context of azathioprine immunosuppression. ${ }^{233} 234$ The term VOD of the liver refers to a form of liver injury characterised clinically by the development of hepatomegaly, ascites and jaundice. The histological features are marked sinusoidal fibrosis, necrosis of zone 3 hepatocytes, and narrowing and eventual fibrosis of small hepatic venules. Recent studies suggest that the primary site of the toxic injury is sinusoidal endothelial cells, and this is followed by a series of biological processes that lead to circulatory compromise of centrilobular hepatocytes, fibrosis and obstruction of liver blood flow, primarily at the sinusoidal level, making "sinusoidal obstruction syndrome" a more appropriate term. ${ }^{235} 236$

VOD has been mostly reported anecdotally after liver transplantation, especially in patients with azathioprine-based immunosuppression. ${ }^{237} 238$ In the first large series of about 1000 consecutive liver transplant patient patients followed over a 9year period, the incidence of VOD was only $2 \%$, but with generally poor outcome. ${ }^{239}$ VOD occurred between 1 and 20 weeks post-transplant and showed an association with ACR. The venous endothelial inflammation was significantly enhanced compared with the bile duct inflammation in the study group, suggesting endothelialiitis-induced damage to the hepatic vein wall as a key pathogenetic pathway. In addition to azathioprine and prior cellular-rejection-related endothelialitis, patients who have had chemotherapy for PTLD are also at risk for developing VOD. ${ }^{239}$

The histological diagnosis of VOD can be difficult. It is characterised by small hepatic vein obliteration and centrilobular congestion with or without haemorrhagic necrosis, which may occur together or in separate foci. Obliterative venous lesion, although considered the main feature of VOD, can be difficult to recognise, especially if the biopsy is performed after the acute phase when the lesions have organised. Since the injury starts in the sinusoids and because terminal hepatic vein involvement is typically patchy rather than uniformly involved, patent small hepatic veins do not preclude this diagnosis. Therefore false negativity due to sampling or inadequately developed features is a potential problem in interpreting liver allograft biopsies. Also, haemorrhagic necrosis in zone 3, when present, could mask the injury of the corresponding hepatic vein. In suspicious cases, additional sections treated with elastic trichrome and reticulin stains are recommended as they are more often than not helpful (fig 14). Other causes of centrilobular/zone 3 necrosis include preservation injury, hepatic artery thrombosis and AMR. ${ }^{210}$ These other considerations are discussed in earlier sections of this review.

\section{THE SCENARIO OF THE FOCAL CHANGE}

In this section, we would like to offer personal observations and viewpoints, and propose an approach to some of the biopsy findings when vascular and biliary abnormalities are present focally in the liver graft. These are opinions based on local experience from our large-volume transplant centre.

Biliary strictures, non-specific inflammation, advanced fibrosis and intrahepatic obstruction of a branch of hepatic vein or portal vein with or without liver infarct can occur, and lead to one of the following scenarios:

(a) There are no enzyme abnormalities and the features are discovered incidentally in a biopsy done for other reasons (eg, features of biliary obstruction and advanced biliary fibrosis in a protocol biopsy for HCV surveillance with normal ALP). The explanation may be an intrahepatic stricture of a bile duct branch, without diffuse biliary disease, but the biopsy originated from the area drained by the affected duct. In this case the biliary features in the 


\section{Take-home messages}

- Successful interpretation of liver allograft is dependent on adequacy of sampling, familiarity with clinical context, working knowledge of differential diagnoses, clinical aspects of transplant hepatology, understanding of the clinical implication of every diagnosis, and close interaction with the clinical team.

- The scope of liver allograft pathology is broad but it can be divided into recurrence of original disease and de novo diseases; because pathogenesis in both categories is via immunological injury in many instances, there is overlap between and within these categories histologically. The predominant injury should be identified and communicated appropriately.

- Acute cellular rejection occurs usually in the first 3-6 months post-transplant and is characterised by mixed portal inflammation, phlebitis and duct injury, each graded on a scale of $0-3$ for a total index of $0-9$.

- Rejection sometimes shows atypical features that should be differentiated from other causes of inflammation other than rejection. Distinction of acute cell-mediated rejection from recurrent hepatitis C virus (HCV) infection is critical, as the treatment for one has deleterious effects on the other. Importantly, if the biopsy features are indeterminate or the biopsy shows features of both, this should be conveyed very clearly in the biopsy report.

- Of the recurrent diseases, viral hepatitis can be difficult to differentiate from rejection; active lobular inflammation, lessmixed portal inflammation, and none or occasional duct inflammation typify viral hepatitis but they overlap with features of atypical late-onset cellular rejection and may be especially difficult to distinguish from recurrent HCV. If testing is negative for the presence of HCV RNA, it is helpful in obtaining a correct diagnosis.

- Fibrosing cholestatic hepatitis is an aggressive form of recurrent HCV or hepatitis B virus, and is characterised by minimal inflammation, but marked hepatocellular injury, rapidly progressing fibrosis, and cholestasis resulting from heavy viral burden.

- The jury is still out as to whether plasma-rich central perivenulitis represents de novo autoimmune hepatitis or rejection; however, the consensus is that the injury needs to be treated by immunosuppression, as outcome is not favourable in many series.

- Bland cholestasis in the early post-transplant period has a broad differential diagnosis that includes sepsis, small-for-size graft syndrome, drug reaction and early duct obstruction. The biopsy is often obtained to confirm or exclude cellular rejection. For the remainder of differential diagnoses, clinical, microbiological and imaging correlation is required.

biopsy are discrepant with the non-cholestatic, hepatitic biochemistry.

(b) Hepatitic liver biochemistry with biopsy showing minimal or no changes and thus does not explain the abnormal enzymes. Focal necrotic hepatocellular lesions such as liver infarct may be the cause. Because these are focal and thus not sampled in a non-targeted biopsy, they may cause global elevation of transaminases. As discussed in the section on VOD, hepatic vein involvement in VOD is patchy and the characteristic lesions may not be sampled. (c) Biopsies originating at the edge of an asymptomatic, and as yet unrecognised infarct, may show portal and parenchymal inflammation including neutrophils, and suggest a diagnosis of cellular rejection. In these situations the inflammatory changes are uneven in the biopsy, and may be focally accentuated at some point along the length of the core or clearly accentuated towards one end of the core with a decreasing gradient in severity away from that end (fig 15). Correlation with clinical setting and additional radiological investigation are necessary to resolve the situation.

(d) Significant but patchy biliary disease (eg, multiple intrahepatic strictures from ischaemic cholangitis, recurrent PSC) causes cholestatic enzyme pattern leading to a biopsy if imaging is non-conclusive. If the biopsy originates from an area not drained by an affected duct, the biopsy may show non-specific changes or normal architecture. In our experience, if such a biopsy follows a negative magnetic resonance cholangiography, and histology shows no infiltrative process or chronic rejection, an endoscopic retrograde cholangiopancreatography should be considered, as this usually shows the subtle stricture(s) missed by magnetic resonance cholangiography.

(e) Changes adjacent to a mass lesion: a biopsy originating next to an intrahepatic mass lesion of any kind frequently produces inflammation local to the immediate lesion vicinity. A diagnosis of hepatitis in these instances should be made with caution, and only with appropriate clinical correlations. Also, fibrosis could be accentuated adjacent to a mass lesion, and not generalised to the whole liver. It should be noted that cirrhosis in the allograft rarely develops without prior documentation of progressive fibrosis, and rarely in association with CR. In making a diagnosis of cirrhosis in a needle biopsy out of context with prior (especially more recent) biopsies or clinical history, the pathologist should understand the scenario around the biopsy, especially potential origin next to a mass lesion.

Competing interests: None.

Provenance and peer review: Commissioned; not externally peer reviewed.

\section{REFERENCES}

1. Demetris $\mathbf{r}$ AJ, CJ, Minervini MI, et al. Transplantation pathology of the liver. In: Odze RD, Goldblum JR, eds. Surgical pathology of the GI tract, liver, biliary tract, and pancreas. 2nd edn. Philadelphia: Saunders/Elsevier, 2009:1169-229.

2. D'Antiga L, Dhawan A, Portmann B, et al. Late cellular rejection in paediatric liver transplantation: aetiology and outcome. Transplantation 2002;73:80-4.

3. Junge G, Tullius SG, Klitzing V, et al. The influence of late acute rejection episodes on long-term graft outcome after liver transplantation. Transplant Proc 2005; 37:1716-7.

4. Takada $\mathbf{Y}$, Taniguchi $H$, Fukunaga $K$, et al. Prolonged hepatic warm ischemia in nonheart-beating donors: protective effects of FK506 and a platelet activating factor antagonist in porcine liver transplantation. Surgery 1998;123:692-8.

5. Kootstra G, Kievit J, Nederstigt A. Organ donors: heartbeating and nonheartbeating. World J Surg 2002;26:181-4

6. Bilzer M, Gerbes AL. Preservation injury of the liver: mechanisms and novel therapeutic strategies. J Hepatol 2000;32:508-15.

7. Kakizoe S, Yanaga K, Starzl TE, et al. Evaluation of protocol before transplantation and after reperfusion biopsies from human orthotopic liver allografts: considerations of preservation and early immunological injury. Hepatology 1990;11:932-41.

8. Kukan M, Haddad PS. Role of hepatocytes and bile duct cells in preservationreperfusion injury of liver grafts. Liver Transp/ 2001;7:381-400.

9. Selzner N, Rudiger $H$, Graf $R$, et al. Protective strategies against ischemic injury of the liver. Gastroenterology 2003;125:917-36.

10. Teoh NC, Farrell GC. Hepatic ischemia reperfusion injury: pathogenic mechanisms and basis for hepatoprotection. J Gastroenterol Hepatol 2003;18:891-902.

11. Demetris AJ, Fontes P, Lunz JG 3rd, et al. Wound healing in the biliary tree of liver allografts. Cell Transplant 2006;15(Suppl 1):S57-65.

12. Demetris AJ, Lunz JG 3rd, Specht S, et al. Biliary wound healing, ductular reactions, and IL-6/gp130 signaling in the development of liver disease. World J Gastroenterol 2006;12:3512-22. 
13. Demetris AJ, Jaffe R, Starzl TE. A review of adult and pediatric post-transplant liver pathology. Pathol Annu 1987;22:347-86.

14. Ferrell L, Bass N, Roberts J, et al. Lipopeliosis: fat induced sinusoidal dilatation in transplanted liver mimicking peliosis hepatis. J Clin Pathol 1992;45:1109-10.

15. Cha I, Bass N, Ferrell LD. Lipopeliosis. An immunohistochemical and clinicopathologic study of five cases. Am J Surg Pathol 1994;18:789-95.

16. Bioulac-Sage $\mathbf{P}$, Balabaud C, Ferrell L. Lipopeliosis revisited: should we keep the term? Am J Surg Pathol 2002;26:134-5.

17. Kiuchi T, Kasahara M, Uryuhara K, et al. Impact of graft size mismatching on graft prognosis in liver transplantation from living donors. Transplantation 1999;67:321-7.

18. Lo CM, Fan ST, Chan JK, et al. Minimum graft volume for successful adult-to-adult living donor liver transplantation for fulminant hepatic failure. Transplantation 1996;62:696-8

19. Ludwig J, Batts KP, MacCarty RL. Ischemic cholangitis in hepatic allografts. Mayo Clin Proc 1992:67:519-26.

20. Nishizaki T, Ikegami T, Hiroshige $S$, et al. Small graft for living donor liver transplantation. Ann Surg 2001;233:575-80.

21. Marcos A, Olzinski AT, Ham JM, et al. The interrelationship between portal and arterial blood flow after adult to adult living donor liver transplantation. Transplantation 2000;70:1697-703.

22. Lautt WW. Mechanism and role of intrinsic regulation of hepatic arterial blood flow: hepatic arterial buffer response. Am J Physiol 1985;249:G549-56.

23. Smyrniotis V, Kostopanagiotou G, Kondi A, et al. Hemodynamic interaction between portal vein and hepatic artery flow in small-for-size split liver transplantation. Transp/ Int 2002;15:355-60.

24. Demetris AJ, Kelly DM, Eghtesad B, et al. Pathophysiologic observations and histopathologic recognition of the portal hyperperfusion or small-for-size syndrome. Am J Surg Pathol 2006;30:986-93.

25. Starzl TE, Demetris AJ. Liver transplantation: a 31-year perspective. Part I. Curr Probl Surg 1990;27:49-116.

26. Starzl TE, Demetris AJ. Liver transplantation: a 31-year perspective. Part II. Curr Probl Surg 1990;27:117-78.

27. Starzl TE, Demetris AJ. Liver transplantation: a 31-year perspective. Part III. Curr Probl Surg 1990:27:181-240.

28. Steinhoff G. Major histocompatibility complex antigens in human liver transplants. $J$ Hepatol 1990;11:9-15.

29. Desai M, Neuberger J. Chronic liver allograft dysfunction. Transplant Proc 2009:41:773-6.

30. Fisher LR, Henley KS, Lucey MR. Acute cellular rejection after liver transplantation: variability, morbidity, and mortality. Liver Transp/ Surg 1995;1:10-5.

31. Florman S, Schiano T, Kim L, et al. The incidence and significance of late acute cellular rejection (>1000 days) after liver transplantation. Clin Transplant 2004:18:152-5

32. Shaked A, Ghobrial RM, Merion RM, et al. Incidence and severity of acute cellular rejection in recipients undergoing adult living donor or deceased donor liver transplantation. Am J Transplant 2009;9:301-8.

33. Tippner C, Nashan B, Hoshino K, et al. Clinical and subclinical acute rejection early after liver transplantation: contributing factors and relevance for the long-term course. Transplantation 2001;72:1122-8.

34. Yilmaz F, Aydin U, Nart D, et al. The incidence and management of acute and chronic rejection after living donor liver transplantation. Transplant Proc 2006;38:1435-7.

35. Anand AC, Hubscher SG, Gunson BK, et al. Timing, significance, and prognosis of late acute liver allograft rejection. Transplantation 1995;60:1098-103.

36. Dousset B, Conti F, Cherruau B, et al. Is acute rejection deleterious to long-term liver allograft function? J Hepatol 1998:29:660-8.

37. Mor E, Gonwa TA, Husberg BS, et al. Late-onset acute rejection in orthotopic liver transplantation-associated risk factors and outcome. Transplantation 1992:54:821-4

38. No authors listed. Banff schema for grading liver allograft rejection: an international consensus document. Hepatology 1997:25:658-63.

39. Adams DH, Wang L, Hubscher SG, et al. Hepatic endothelial cells. Targets in liver allograft rejection? Transplantation 1989;47:479-82.

40. Ludwig J, Batts KP. Ploch M, et al. Endotheliitis in hepatic allografts. Mayo Clin Proc 1989;64:545-54

41. Scholz M, Auth MK, Markus BH. The immunological role of biliary epithelial cells in human liver transplant rejection. Transpl Immunol 1997;5:142-51.

42. Demetris AJ, Adeyi 0, Bellamy CO, et al. Liver biopsy interpretation for causes of late liver allograft dysfunction. Hepatology 2006:44:489-501.

43. Pappo 0, Ramos H, Starzl TE, et al. Structural integrity and identification of causes of liver allograft dysfunction occurring more than 5 years after transplantation. Am J Surg Pathol 1995; 19:192-206.

44. Cakaloglu Y, Devlin J, O'Grady J, et al. Importance of concomitant viral infection during late acute liver allograft rejection. Transplantation 1995;59:40-5.

45. Hassoun Z, Shah V, Lohse CM, et al. Centrilobular necrosis after orthotopic liver transplantation: association with acute cellular rejection and impact on outcome. Liver Transp/ 2004:10:480-7.

46. Krasinskas AM, Demetris AJ, Poterucha JJ, et al. The prevalence and natural history of untreated isolated central perivenulitis in adult allograft livers. Liver Transp/ 2008; 14:625-32.

47. Sundaram SS, Melin-Aldana H, Neighbors K, et al. Histologic characteristics of late cellular rejection, significance of centrilobular injury, and long-term outcome in pediatric liver transplant recipients. Liver Transp/ 2006:12:58-64.
48. Demetris A, Adams D, Bellamy C, et al. Update of the International Banff Schema for Liver Allograft Rejection: working recommendations for the histopathologic staging and reporting of chronic rejection. An International Panel. Hepatology 2000:31:792-9.

49. Demetris AJ. Distinguishing between recurrent primary sclerosing cholangitis and chronic rejection. Liver Transp/ 2006;12(11 Suppl 2):S68-72.

50. Quiroga J, Colina I, Demetris AJ, et al. Cause and timing of first allograft failure in orthotopic liver transplantation: a study of 177 consecutive patients. Hepatology 1991:14:1054-62

51. Blakolmer K, Jain A, Ruppert $\mathrm{K}$, et al. Chronic liver allograft rejection in a population treated primarily with tacrolimus as baseline immunosuppression: longterm follow-up and evaluation of features for histopathological staging. Transplantation 2000;69:2330-6.

52. Wiesner RH, Batts KP, Krom RA. Evolving concepts in the diagnosis, pathogenesis, and treatment of chronic hepatic allograft rejection. Liver Transp/ Surg 1999:5:388-400.

53. Kashyap R, Jain A, Reyes J, et al. Causes of retransplantation after primary liver transplantation in 4000 consecutive patients: 2 to 19 years follow-up. Transplant Proc 2001:33:1486-7.

54. Yao F, Behling CA, Saab S, et al. Trimethoprim-sulfamethoxazole-induced vanishing bile duct syndrome. Am J Gastroenterol 1997:92:167-9.

55. Terminology for hepatic allograft rejection. International Working Party. Hepatology 1995;22:648-54.

56. Della-Guardia B, Almeida MD, Meira-Filho SP, et al. Antibody-mediated rejection: hyperacute rejection reality in liver transplantation? A case report. Transplant Proc 2008:40:870-1.

57. Demetris AJ, Jaffe R, Tzakis A, et al. Antibody-mediated rejection of human orthotopic liver allografts. A study of liver transplantation across ABO blood group barriers. Am J Pathol 1988;132:489-502.

58. Haga $\mathbf{H}$, Egawa $\mathrm{H}$, Shirase $\mathrm{T}$, et al. Periportal edema and necrosis as diagnostic histological features of early humoral rejection in ABO-incompatible liver transplantation. Liver Transpl 2004;10:16-27.

59. Furuya T, Murase N, Nakamura K, et al. Preformed lymphocytotoxic antibodies: the effects of class, titer and specificity on liver vs. heart allografts. Hepatology 1992:16:1415-22.

60. Demetris AJ, Murase N, Nakamura K, et al. Immunopathology of antibodies as effectors of orthotopic liver allograft rejection. Semin Liver Dis 1992;12:51-9.

61. Nakamura K, Murase N, Becich MJ, et al. Liver allograft rejection in sensitized recipients. Observations in a clinically relevant small animal model. Am J Pathol 1993;142:1383-91.

62. Abouljoud MS, Escobar F, Douzdjian V, et al. Recurrent disease after liver transplantation. Transplant Proc 2001;33:2716-9.

63. Kotlyar DS, Campbell MS, Reddy KR. Recurrence of diseases following orthotopic liver transplantation. Am J Gastroenterol 2006;101:1370-8.

64. Yusoff IF, House AK, De Boer WB, et al. Disease recurrence after liver transplantation in Western Australia. J Gastroenterol Hepatol 2002:17:203-7.

65. Beckebaum S, Sotiropoulos GC, Gerken G, et al. Hepatitis B and liver transplantation: 2008 update. Rev Med Virol 2009;19:7-29.

66. Marzano A. The prevention of viral recurrence in the long term. Dig Liver Dis 2009;41 (Suppl 2):S195-7.

67. Mas A. Liver transplantation for hepatitis B virus. Pre-emptive and peri-operative prophylaxis. Dig Liver Dis 2009;41(Suppl 2):S191-4.

68. Yilmaz N, Shiffman ML, Todd Stravitz R, et al. Prophylaxsis against recurrance of hepatitis B virus after liver transplantation: a retrospective analysis spanning 20 years. Liver Int 2008;28:72-8.

69. Phillips MJ, Cameron R, Flowers MA, et al. Post-transplant recurrent hepatitis B viral liver disease. Viral-burden, steatoviral, and fibroviral hepatitis B. Am J Pathol 1992; 140:1295-308

70. Schreibman IR, Schiff ER. Prevention and treatment of recurrent Hepatitis B after liver transplantation: the current role of nucleoside and nucleotide analogues. Ann Clin Microbiol Antimicrob 2006;5:8

71. Faust TW. Recurrent primary biliary cirrhosis, primary sclerosing cholangitis, and autoimmune hepatitis after transplantation. Liver Transp/ 2001;7(11 Suppl 1):S99-108.

72. Gautam M, Cheruvattath R, Balan V. Recurrence of autoimmune liver disease after liver transplantation: a systematic review. Liver Transp/ 2006:12:1813-24.

73. Mottershead M, Neuberger J. Transplantation in autoimmune liver diseases. World J Gastroenterol 2008;14:3388-95.

74. Schreuder TC, Hubscher SG, Neuberger J. Autoimmune liver diseases and recurrence after orthotopic liver transplantation: what have we learned so far? Transpl Int 2009;22:144-52.

75. Tamura S, Sugawara Y, Kaneko J, et al. Recurrence of cholestatic liver disease after living donor liver transplantation. World J Gastroenterol 2008;14:5105-9.

76. Lim JK, Keeffe EB. Liver transplantation for alcoholic liver disease: current concepts and length of sobriety. Liver Transp/ 2004;10(10 Suppl 2):S31-8.

77. Lucey MR, Carr K, Beresford TP, et al. Alcohol use after liver transplantation in alcoholics: a clinical cohort follow-up study. Hepatology 1997:25:1223-7.

78. Tang H, Boulton R, Gunson B, et al. Patterns of alcohol consumption after liver transplantation. Gut 1998:43:140-5.

79. Heimbach JK. Successful liver transplantation for hilar cholangiocarcinoma. Curr Opin Gastroenterol 2008;24:384-8.

80. Heimbach JK. Liver transplantation for hepatocellular carcinoma. Cancer J 2008;14:95-9.

81. Rosen CB, Heimbach JK, Gores GJ. Surgery for cholangiocarcinoma: the role of liver transplantation. HPB (Oxford) 2008:10:186-9. 
82. Said A, Lucey MR. Liver transplantation: an update 2008. Curr Opin Gastroenterol 2008;243):339-45.

83. Tamura S, Kato T, Berho M, et al. Impact of histological grade of hepatocellular carcinoma on the outcome of liver transplantation. Arch Surg 2001;136:25-30; discussion 31

84. Zimmerman MA, Ghobrial RM, Tong MJ, et al. Recurrence of hepatocellular carcinoma following liver transplantation: a review of preoperative and postoperative prognostic indicators. Arch Surg 2008;143:182-8; discussion 188.

85. Jaffe R. Liver transplant pathology in pediatric metabolic disorders. Pediatr Dev Pathol 1998;1:102-17.

86. Eisenbach C, Sauer P, Mehrabi A, et al. Prevention of hepatitis B virus recurrence after liver transplantation. Clin Transplant 2006;20(Suppl 17):111-6.

87. Marzano A, Angelucci E, Andreone P, et al. Prophylaxis and treatment of hepatitis B in immunocompromised patients. Dig Liver Dis 2007;39:397-408.

88. Olivera-Martinez MA, Gallegos-Orozco JF. Recurrent viral liver disease (hepatitis B and C) after liver transplantation. Arch Med Res 2007;38:691-701.

89. Riediger C, Berberat PO, Sauer P, et al. Prophylaxis and treatment of recurrent viral hepatitis after liver transplantation. Nephrol Dial Transplant 2007;22(Suppl 8):viii37-viii46.

90. Demetris AJ, Lunz JG 3rd. Early HCV-associated stellate cell activation in aggressive recurrent HCV: what can liver allografts teach about HCV pathogenesis? Liver Transp/ 2005:11:1172-6.

91. Longerich T, Schirmacher P. General aspects and pitfalls in liver transplant pathology. Clin Transplant 2006;20(Suppl 17):60-8.

92. Thung SN. Histologic findings in recurrent HBV. Liver Transp/ 2006;12(11 Suppl 2): $S 50-3$.

93. Marinos G, Rossol S, Carucci P, et al. Immunopathogenesis of hepatitis B virus recurrence after liver transplantation. Transplantation 2000;69:559-68.

94. Demetris AJ, Jaffe R, Sheahan DG, et al. Recurrent hepatitis B in liver allograft recipients. Differentiation between viral hepatitis $\mathrm{B}$ and rejection. Am J Pathol 1986;125:161-72

95. Brown RS. Hepatitis C and liver transplantation. Nature 2005;436(7053):973-8.

96. Dixon LR, Crawford JM. Early histologic changes in fibrosing cholestatic hepatitis C. Liver Transpl 2007;13:219-26.

97. Khettry U, Huang WY, Simpson MA, et al. Patterns of recurrent hepatitis $C$ after liver transplantation in a recent cohort of patients. Hum Pathol 2007;38:443-52.

98. Petrovic LM. Early recurrence of hepatitis C virus infection after liver transplantation. Liver Transp/ 2006;12(11 Suppl 2):S32-7.

99. Watt KD, Burak K, Deschenes M, et al. Recurrent hepatitis $C$ post-transplantation: where are we now and where do we go from here? A report from the Canadian transplant hepatology workshop. Can J Gastroenterol 2006;20:725-34.

100. Asanza CG, Garcia-Monzon C, Clemente G, et al. Immunohistochemical evidence of immunopathogenetic mechanisms in chronic hepatitis $\mathrm{C}$ recurrence after liver transplantation. Hepatology 1997;26:755-63.

101. Berenguer M. Host and donor risk factors before and after liver transplantation that impact HCV recurrence. Liver Transp/ 2003;9:S44-7.

102. Berenguer $\mathbf{M}$. What determines the natural history of recurrent hepatitis $C$ after liver transplantation? J Hepatol 2005:42:448-56.

103. McCaughan GW, Zekry A. Mechanisms of HCV reinfection and allograft damage after liver transplantation. J Hepatol 2004;40:368-74.

104. Belli LS, Silini E, Alberti A, et al. Hepatitis C virus genotypes, hepatitis, and hepatitis C virus recurrence after liver transplantation. Liver Transp/ Surg 1996;2:200-5

105. Charlton M. Hepatitis C infection in liver transplantation. Am J Transplant 2001;1:197-203.

106. Gane $\mathbf{E}$. The natural history and outcome of liver transplantation in hepatitis $\mathbf{C}$ virusinfected recipients. Liver Transp/ 2003;9:S28-34.

107. Gane EJ. The natural history of recurrent hepatitis $C$ and what influences this. Liver Transp/ 2008;14(Suppl 2):S36-44.

108. Gawrieh S, Papouchado BG, Burgart LJ, et al. Early hepatic stellate cell activation predicts severe hepatitis C recurrence after liver transplantation. Liver Transp/ 2005;11:1207-13.

109. Lake JR. The role of immunosuppression in recurrence of hepatitis C. Liver Transp/ 2003;9:S63-6.

110. McCaughan GW, Zekry A. Impact of immunosuppression on immunopathogenesis of liver damage in hepatitis $\mathrm{C}$ virus-infected recipients following liver transplantation. Liver Transp/ 2003;9:S21-7.

111. Ramirez S, Perez-Del-Pulgar S, Forns X. Virology and pathogenesis of hepatitis C virus recurrence. Liver Transpl 2008;14(Suppl 2):S27-35.

112. Rodriguez-Luna H, Douglas DD. Natural history of hepatitis C following liver transplantation. Curr Opin Infect Dis 2004;17:363-71.

113. Rosen HR. Hepatitis $C$ in the liver transplant recipient: current understanding and treatment. Microbes Infect 2002;4:1253-8.

114. Russo MW, Firpi RJ, Nelson DR, et al. Early hepatic stellate cell activation is associated with advanced fibrosis after liver transplantation in recipients with hepatitis C. Liver Transp/ 2005;11:1235-41.

115. Zekry A, Bishop GA, Bowen DG, et al. Intrahepatic cytokine profiles associated with posttransplantation hepatitis C virus-related liver injury. Liver Transpl 2002;8:292-301.

116. Ziarkiewicz-Wroblewska B, Wroblewski T, Wasiutynski A. Morphological features and differential diagnosis of hepatitis $C$ recurrence after liver transplantation - literature review and results of single transplantation center. Ann Transplant 2008:13:12-20.
117. Berenguer $\mathbf{M}$, Aguilera V, Prieto $\mathbf{M}$, et al. Significant improvement in the outcome of HCV-infected transplant recipients by avoiding rapid steroid tapering and potent induction immunosuppression. J Hepatol 2006;44:717-22.

118. Tisone G, Orlando G, Cardillo A, et al. Complete weaning off immunosuppression in HCV liver transplant recipients is feasible and favourably impacts on the progression of disease recurrence. J Hepatol 2006;44:702-9.

119. Spengler U, Nattermann J. Immunopathogenesis in hepatitis $C$ virus cirrhosis. Clin Sci (Lond) 2007;112:141-55.

120. Burton JR Jr, Rosen HR. Acute rejection in HCV-infected liver transplant recipients: The great conundrum. Liver Transp/ 2006;12(11 Suppl 2):S38-47.

121. Hubscher SG PB. Transplantation Pathology. In: Burt AD, PB, Ferrell LD, eds. MacSween's pathology of the liver. 5th edn. London: Churchill Livingstone, 2007:815-79.

122. Ayata G, Gordon FD, Lewis WD, et al. Liver transplantation for autoimmune hepatitis: a long-term pathologic study. Hepatology 2000;32:185-92.

123. Gonzalez-Koch A, Czaja AJ, Carpenter HA, et al. Recurrent autoimmune hepatitis after orthotopic liver transplantation. Liver Transp/ 2001;7:302-10.

124. Hubscher SG. Recurrent autoimmune hepatitis after liver transplantation: diagnostic criteria, risk factors, and outcome. Liver Transp/ 2001;7:285-91.

125. Ratziu V, Samuel D, Sebagh M, et al. Long-term follow-up after liver transplantation for autoimmune hepatitis: evidence of recurrence of primary disease. J Hepatol 1999;30:131-41.

126. Reich DJ, Fiel I, Guarrera JV, et al. Liver transplantation for autoimmune hepatitis. Hepatology 2000;32:693-700.

127. Vergani D, Mieli-Vergani G. Mechanisms of autoimmune hepatitis. Pediatr Transplant 2004:8:589-93.

128. Alvarez F, Berg PA, Bianchi FB, et al. International Autoimmune Hepatitis Group Report: review of criteria for diagnosis of autoimmune hepatitis. $J$ Hepatol 1999:31:929-38

129. Dmitrewski J, Hubscher SG, Mayer AD, et al. Recurrence of primary biliary cirrhosis in the liver allograft: the effect of immunosuppression. J Hepatol 1996;24:253-7.

130. Hashimoto E, Shimada M, Noguchi S, et al. Disease recurrence after living liver transplantation for primary biliary cirrhosis: a clinical and histological follow-up study. Liver Transp/ 2001;7:588-95.

131. Liermann Garcia RF, Evangelista Garcia C, McMaster P, et al. Transplantation for primary biliary cirrhosis: retrospective analysis of 400 patients in a single center. Hepatology 2001;33:22-7.

132. Neuberger J. Recurrent primary biliary cirrhosis. Liver Transp/ 2003;9:539-46.

133. Goss JA, Shackleton CR, Farmer DG, et al. Orthotopic liver transplantation for primary sclerosing cholangitis. A 12 -year single center experience. Ann Surg 1997:225:472-81; discussion 481-3

134. Graziadei IW, Wiesner RH, Batts KP, et al. Recurrence of primary sclerosing cholangitis following liver transplantation. Hepatology 1999:29:1050-6.

135. Graziadei IW, Wiesner RH, Marotta PJ, et al. Long-term results of patients undergoing liver transplantation for primary sclerosing cholangitis. Hepatology 1999;30:1121-7.

136. Gordon F. Recurrent primary sclerosing cholangitis: clinical diagnosis and long-term management issues. Liver Transp/ 2006;12(11 Suppl 2):S73-5.

137. Gow PJ, Chapman RW. Liver transplantation for primary sclerosing cholangitis. Liver 2000;20:97-103.

138. Graziadei IW. Recurrence of primary sclerosing cholangitis after liver transplantation. Liver Transp/ 2002;8:575-81.

139. Oldakowska-Jedynak U, Nowak M, Mucha K, et al. Recurrence of primary sclerosing cholangitis in patients after liver transplantation. Transplant Proc 2006; $38: 240-3$

140. Vera A, Moledina S, Gunson B, et al. Risk factors for recurrence of primary sclerosing cholangitis of liver allograft. Lancet 2002;360(9349):1943-4.

141. Mackie J, Groves K, Hoyle A, et al. Orthotopic liver transplantation for alcoholic liver disease: a retrospective analysis of survival, recidivism, and risk factors predisposing to recidivism. Liver Transpl 2001;7:418-27.

142. Burra P, Lucey MR. Liver transplantation in alcoholic patients. Transp/ Int 2005; 18:491-8.

143. Burke A, Lucey MR. Non-alcoholic fatty liver disease, non-alcoholic steatohepatitis and orthotopic liver transplantation. Am J Transplant 2004;4:686-93.

144. Contos MJ, Cales W, Sterling RK, et al. Development of nonalcoholic fatty liver disease after orthotopic liver transplantation for cryptogenic cirrhosis. Liver Transpl 2001; 7:363-73.

145. Sanchez-Urdazpal L, Gores GJ, Ward EM, et al. Diagnostic features and clinical outcome of ischemic-type biliary complications after liver transplantation. Hepatology 1993;17:605-9.

146. Sanchez-Urdazpal L, Gores GJ, Ward EM, et al. Ischemic-type biliary complications after orthotopic liver transplantation. Hepatology 1992;16:49-53.

147. Noack K, Bronk SF, Kato A, et al. The greater vulnerability of bile duct cells to reoxygenation injury than to anoxia. Implications for the pathogenesis of biliary strictures after liver transplantation. Transplantation 1993;56:495-500.

148. Carrasco L, Sanchez-Bueno F, Sola J, et al. Effects of cold ischemia time on the graft after orthotopic liver transplantation. A bile cytological study. Transplantation 1996;61:393-6.

149. Takasaki S, Hano H. Three-dimensional observations of the human hepatic artery (arterial system in the liver). J Hepatol 2001;34:455-66.

150. Ekataksin W, ZZ, Wake K, et al. The hepatic microcirculatory subunits: an over three-century-long search for the missing link between an exocrine unit and an 
endocrine unit in mammalian liver nodules. In: Motta PM, ed. Recent advances in microscopy of cells, tissues and organs. Rome: University of Rome La Sapienza Press, 1997:375-80.

151. Batts KP. Ischemic cholangitis. Mayo Clin Proc 1998:73:380-5.

152. Deltenre P, Valla DC. Ischemic cholangiopathy. J Hepatol 2006;44:806-17.

153. Verdonk RC, Buis $\mathrm{Cl}$, Porte RJ, et al. Anastomotic biliary strictures after liver transplantation: causes and consequences. Liver Transp/ 2006;12:726-35.

154. Greif F, Bronsther OL, Van Thiel DH, et al. The incidence, timing, and management of biliary tract complications after orthotopic liver transplantation. Ann Surg 1994;219:40-5

155. Mosca S, Militerno G, Guardascione MA, et al. Late biliary tract complications after orthotopic liver transplantation: diagnostic and therapeutic role of endoscopic retrograde cholangiopancreatography. J Gastroenterol Hepatol 2000;15:654-60.

156. Chahin NJ, De Carlis L, Slim AO, et al. Long-term efficacy of endoscopic stenting in patients with stricture of the biliary anastomosis after orthotopic liver transplantation. Transplant Proc 2001;33:2738-40.

157. Thethy $\mathbf{S}$, Thomson B, Pleass $\mathrm{H}$, et al. Management of biliary tract complications after orthotopic liver transplantation. Clin Transplant 2004;18:647-53.

158. Yazumi S, Chiba T. Biliary complications after a right-lobe living donor liver transplantation. J Gastroenterol 2005; 40:861-5.

159. Pascher A, Neuhaus P. Bile duct complications after liver transplantation. Transp/ Int 2005;18:627-42.

160. Colonna J0 2nd, Shaked A, Gomes AS, et al. Biliary strictures complicating liver transplantation. Incidence, pathogenesis, management, and outcome. Ann Surg 1992;216:344-50; discussion 350-2.

161. Li S, Stratta RJ, Langnas AN, et al. Diffuse biliary tract injury after orthotopic liver transplantation. Am J Surg 1992;164:536-40.

162. Guichelaar MM, Benson JT, Malinchoc M, et al. Risk factors for and clinical course of non-anastomotic biliary strictures after liver transplantation. Am J Transplant 2003;3:885-90.

163. Demetris A, CJ, Minervini M, et al Transplantation pathology of the liver. In: In: Odze RD, Goldblum JR, eds. Surgical pathology of the GI tract, liver, biliary tract and pancreas. Philadelphia: Saunders Elsevier, 2009:1177-80.

164. Lamy ME, Favart AM, Cornu C, et al. Epstein-Barr virus infection in 59 orthotopic liver transplant patients. Med Microbiol Immunol 1990;179:137-44.

165. Smets F, Bodeus M, Goubau P, et al. Characteristics of Epstein-Barr virus primary infection in pediatric liver transplant recipients. J Hepatol 2000;32:100-4.

166. Randhawa PS, Markin RS, Starzl TE, et al. Epstein-Barr virus-associated syndromes in immunosuppressed liver transplant recipients. Clinical profile and recognition on routine allograft biopsy. Am J Surg Pathol 1990;14:538-47.

167. Randhawa PS, Jaffe R, Demetris AJ, et al. The systemic distribution of EpsteinBarr virus genomes in fatal post-transplantation lymphoproliferative disorders. An in situ hybridization study. Am J Pathol 1991;138:1027-33.

168. Randhawa PS, Jaffe R, Demetris AJ, et al. Expression of Epstein-Barr virusencoded small RNA (by the EBER-1 gene) in liver specimens from transplant recipients with post-transplantation lymphoproliferative disease. N Engl J Med 1992;327:1710-4.

169. Ishak K. Granulomas of liver. In: Ioachim HL, ed. Pathology of granulomas. New York: Raven, 1983:308-9

170. Chang MY, Campbell WG Jr. Fatal infectious mononucleosis. Association with liver necrosis and herpes-like virus particles. Arch Pathol 1975;99:185-91.

171. Randhawa P, Blakolmer K, Kashyap R, et al. Allograft liver biopsy in patients with Epstein-Barr virus-associated posttransplant lymphoproliferative disease. Am J Surg Pathol 2001;25:324-30.

172. Paya CV, RR. Cytomegalovirus infection after soli organ transplantation. In: Bowden RA, Ljungman P, Paya CV, eds. Transplant infections. Philadelphia: Lippincott, Williams and Wilkins, 2003:298-325.

173. Gane E, Saliba F, Valdecasas GJ, et al. Randomised trial of efficacy and safety of oral ganciclovir in the prevention of cytomegalovirus disease in liver-transplant recipients. The Oral Ganciclovir International Transplantation Study Group [corrected]. Lancet 1997;350(9093):1729-33.

174. Paya CV, Hermans PE, Wiesner RH, et al. Cytomegalovirus hepatitis in liver transplantation: prospective analysis of 93 consecutive orthotopic liver transplantations. J Infect Dis 1989;160:752-8.

175. Lautenschlager I, Halme L, Hockerstedt K, et al. Cytomegalovirus infection of the liver transplant: virological, histological, immunological, and clinical observations. Transpl Infect Dis 2006;8:21-30.

176. Seehofer D, Rayes N, Neumann UP, et al. Changing impact of cytomegalovirus in liver transplantation - a single centre experience of more than 1000 transplantations without ganciclovir prophylaxis. Transpl Int 2005;18:941-8.

177. Colina F, Juca NT, Moreno E, et al. Histological diagnosis of cytomegalovirus hepatitis in liver allografts. J Clin Pathol 1995;48:351-7.

178. Washington K. Update on post-liver transplantation infections, malignancies, and surgical complications. Adv Anat Pathol 2005;12:221-6.

179. Demetris A, TA, Delaney CP, et al. Pathology of liver transplantation In: Busuttil R, KG, eds. Transplantation of the liver. Philadelphia: WB Saunders, 1996:681-723.

180. Lamps LW, Pinson CW, Raiford DS, et al. The significance of microabscesses in liver transplant biopsies: a clinicopathological study. Hepatology 1998;28:1532-7.

181. O'Grady JG, Alexander GJ, Sutherland S, et al. Cytomegalovirus infection and donor/recipient HLA antigens: interdependent co-factors in pathogenesis of vanishing bile-duct syndrome after liver transplantation. Lancet 1988;2(8606):302-5.
182. Lautenschlager I, Hockerstedt $\mathrm{K}$, Jalanko $\mathrm{H}$, et al. Persistent cytomegalovirus in liver allografts with chronic rejection. Hepatology 1997;25:190-4.

183. Shaikh OS, Demetris AJ. Idiopathic posttransplantation hepatitis? Liver Transp/ 2007:13:943-6.

184. Sebagh M, Rifai K, Feray C, et al. All liver recipients benefit from the protocol 10 year liver biopsies. Hepatology 2003;37:1293-301.

185. Berenguer $\mathbf{M}$, Rayon JM, Prieto $\mathbf{M}$, et al. Are posttransplantation protocol liver biopsies useful in the long term? Liver Transp/ 2001;7:790-6.

186. Rosenthal P, Emond JC, Heyman MB, et al. Pathological changes in yearly protocol liver biopsy specimens from healthy pediatric liver recipients. Liver Transp/ Surg 1997;3:559-62.

187. Slapak GI, Saxena R, Portmann B, et al. Graft and systemic disease in long-term survivors of liver transplantation. Hepatology 1997;25:195-202.

188. Heneghan MA, Zolfino T, Muiesan P, et al. An evaluation of long-term outcomes after liver transplantation for cryptogenic cirrhosis. Liver Transp/ 2003:9:921-8.

189. Burra P, Mioni D, Cecchetto A, et al. Histological features after liver transplantation in alcoholic cirrhotics. J Hepatol 2001;34:716-22

190. Evans HM, Kelly DA, McKiernan PJ, et al. Progressive histological damage in live allografts following pediatric liver transplantation. Hepatology 2006;43:1109-17.

191. Scheuer PJ. Classification of chronic viral hepatitis: a need for reassessment. J Hepatol 1991;13:372-4.

192. Haagsma EB, van den Berg AP, Porte RJ, et al. Chronic hepatitis E virus infection in liver transplant recipients. Liver Transp/ 2008;14:547-53.

193. Kamar N, Selves J, Mansuy JM, et al. Hepatitis E virus and chronic hepatitis in organ-transplant recipients. N Engl J Med 2008;358:811-7.

194. Syn WK, Nightingale P, Gunson B, et al. Natural history of unexplained chronic hepatitis after liver transplantation. Liver Transp/ 2007;13:984-9.

195. Riva S, Sonzogni A, Bravi M, et al. Late graft dysfunction and autoantibodies afte liver transplantation in children: preliminary results of an Italian experience. Liver Transp/ 2006;12:573-7.

196. Seyam M, Neuberger JM, Gunson BK, et al. Cirrhosis after orthotopic liver transplantation in the absence of primary disease recurrence. Liver Transpl 2007;13:966-74

197. Johnson PJ, McFarlane IG. Meeting report: International Autoimmune Hepatitis Group. Hepatology 1993;18:998-1005.

198. Hennes EM, Zeniya M, Czaja AJ, et al. Simplified criteria for the diagnosis of autoimmune hepatitis. Hepatology 2008:48:169-76.

199. Czaja AJ, Carpenter HA. Histological findings in chronic hepatitis $\mathrm{C}$ with autoimmune features. Hepatology 1997:26:459-66.

200. Czaja AJ, Carpenter HA. Sensitivity, specificity, and predictability of biopsy interpretations in chronic hepatitis. Gastroenterology 1993;105:1824-32.

201. Dai YD, Carayanniotis G, Sercarz E. Antigen processing by autoreactive B cells promotes determinant spreading. Cell Mol Immunol 2005;2:169-75.

202. Vanderlugt CL, Miller SD. Epitope spreading in immune-mediated diseases: implications for immunotherapy. Nat Rev Immunol 2002;2:85-95.

203. Demetris AJ, Sebagh M. Plasma cell hepatitis in liver allografts: Variant of rejection or autoimmune hepatitis? Liver Transp/ 2008;14:750-5.

204. Kessel A, Toubi E. Chronic HCV-related autoimmunity: a consequence of viral persistence and lymphotropism. Curr Med Chem 2007;14:547-54.

205. Berardi S, Lodato F, Gramenzi A, et al. High incidence of allograft dysfunction in liver transplanted patients treated with pegylated-interferon $\alpha-2 b$ and ribavirin for hepatitis C recurrence: possible de novo autoimmune hepatitis? Gut 2007:56:237-42.

206. Fiel MI, Agarwal K, Stanca C, et al. Posttransplant plasma cell hepatitis (de novo autoimmune hepatitis) is a variant of rejection and may lead to a negative outcome in patients with hepatitis C virus. Liver Transp/ 2008;14:861-71.

207. Porter KA. Pathology of liver transplantation. Transplant Rev 1969;2:129-70.

208. Demetris AJ, Lasky S, Van Thiel DH, et al. Pathology of hepatic transplantation: A review of 62 adult allograft recipients immunosuppressed with a cyclosporine/ steroid regimen. Am J Pathol 1985;118:151-61.

209. Demetris AJ, Fung JJ, Todo S, et al. Conversion of liver allograft recipients from cyclosporine to FK506 immunosuppressive therapy - a clinicopathologic study of 96 patients. Transplantation 1992;53:1056-62.

210. Ludwig J, Gross JB Jr, Perkins JD, et al. Persistent centrilobular necroses in hepatic allografts. Hum Pathol 1990;21:656-61.

211. Demetris AJ, Eghtesad B, Marcos A, et al. Recurrent hepatitis $C$ in liver allografts: prospective assessment of diagnostic accuracy, identification of pitfalls, and observations about pathogenesis. Am J Surg Pathol 2004;28:658-69.

212. Demetris AJ. Central venulitis in liver allografts: considerations of differential diagnosis. Hepatology 2001;33:1329-30.

213. Salcedo M, Vaquero J, Banares R, et al. Response to steroids in de novo autoimmune hepatitis after liver transplantation. Hepatology 2002;35:349-56.

214. Aguilera I, Sousa JM, Gavilan F, et al. Glutathione S-transferase T1 mismatch constitutes a risk factor for de novo immune hepatitis after liver transplantation. Liver Transp/ 2004;10:1166-72.

215. Lewis JH, KD. Hepatic injury due to drugs, chemicals and toxins. In: Burt AD, Portmann BC, Ferrell LD, eds. MacSween's pathology of the liver. Philadelphia: Churchill Livingstone, 2007:649-59.

216. Wisecarver JL, Earl RA, Haven MC, et al. Histologic changes in liver allograft biopsies associated with elevated whole blood and tissue cyclosporine concentrations. Mod Pathol 1992;5:611-6.

217. Kassianides C, Nussenblatt R, Palestine AG, et al. Liver injury from cyclosporine $A$ Dig Dis Sci 1990;35:693-7. 
218. Fisher A, Mor E, Hytiroglou P, et al. FK506 hepatotoxicity in liver allograft recipients. Transplantation 1995:59:1631-2.

219. Hebert MF, TS, Carithers RL. Immunomodulating agents and the transplant situation. In: Kaplowitz N, Deleve L, eds. Drug-induced liver disease. New York: Marcel Dekker, 2003:633-51.

220. Neff GW, Ruiz P, Madariaga JR, et al. Sirolimus-associated hepatotoxicity in liver transplantation. Ann Pharmacother 2004:38:1593-6.

221. Niemczyk M, Wyzgal J, Perkowska A, et al. Sirolimus-associated hepatotoxicity in the kidney graft recipient. Transpl Int 2005:18:1302-3.

222. Degott C, Rueff B, Kreis $\mathrm{H}$, et al. Peliosis hepatis in recipients of renal transplants. Gut 1978; 19:748-53

223. Holtmann M, Schreiner 0, Kohler H, et al. Veno-occlusive disease (VOD) in Crohn's disease (CD) treated with azathioprine. Dig Dis Sci 2003:48:1503-5.

224. Haboubi NY, Ali HH, Whitwell HL, et al. Role of endothelial cell injury in the spectrum of azathioprine-induced liver disease after renal transplant: light microscopy and ultrastructural observations. Am J Gastroenterol 1988;83:256-61.

225. Mohi-ud-din R, Lewis JH. Drug- and chemical-induced cholestasis. Clin Liver Dis 2004;8:95-132, vii.

226. Kowdley KV, Keeffe EB, Fawaz KA. Prolonged cholestasis due to trimethoprim sulfamethoxazole. Gastroenterology 1992:102:2148-50.

227. Stromeyer FW, Ishak KG. Nodular transformation (nodular "regenerative" hyperplasia) of the liver. A clinicopathologic study of 30 cases. Hum Pathol 1981:12:60-71

228. Wanless IR. Micronodular transformation (nodular regenerative hyperplasia) of the liver: a report of 64 cases among 2,500 autopsies and a new classification of benign hepatocellular nodules. Hepatology 1990;11:787-97.
229. Wanless IR, Liu JJ, Butany J. Role of thrombosis in the pathogenesis of congestive hepatic fibrosis (cardiac cirrhosis). Hepatology 1995;21:1232-7.

230. Snover DC, Weisdorf S, Bloomer J, et al. Nodular regenerative hyperplasia of the liver following bone marrow transplantation. Hepatology 1989:9:443-8.

231. Kondo F. Benign nodular hepatocellular lesions caused by abnormal hepatic circulation: etiological analysis and introduction of a new concept. J Gastroenterol Hepatol 2001;16:1319-28.

232. Bearman SI. The syndrome of hepatic veno-occlusive disease after marrow transplantation. Blood 1995;85:3005-20.

233. Eisenhauer T, Hartmann H, Rumpf KW, et al. Favourable outcome of hepatic venoocclusive disease in a renal transplant patient receiving azathioprine, treated by portacaval shunt. Report of a case and review of the literature. Digestion 1984;30:185-90.

234. Katzka DA, Saul SH, Jorkasky D, et al. Azathioprine and hepatic venocclusive disease in renal transplant patients. Gastroenterology 1986;90:446-54.

235. Wang X, Kanel GC, DeLeve LD. Support of sinusoidal endothelial cell glutathione prevents hepatic veno-occlusive disease in the rat. Hepatology 2000;31:428-34.

236. DeLeve LD, Shulman HM, McDonald GB. Toxic injury to hepatic sinusoids: sinusoidal obstruction syndrome (veno-occlusive disease). Semin Liver Dis 2002:22:27-42.

237. Sterneck M, Wiesner R, Ascher N, et al. Azathioprine hepatotoxicity after liver transplantation. Hepatology 1991;14:806-10.

238. Dhillon AP, Burroughs AK, Hudson M, et al. Hepatic venular stenosis after orthotopic liver transplantation. Hepatology 1994;19:106-11.

239. Sebagh M, Debette M, Samuel D, et al. "Silent" presentation of veno-occlusive disease after liver transplantation as part of the process of cellular rejection with endothelial predilection. Hepatology 1999;30:1144-50.

\section{Access the latest content chosen by our Editors}

BMJ Journals editors select an article from each issue to be made free online immediately on publication. Other material is free after 12 months to non-subscribers. Access the Editor's Choice from the home page-or expand your horizons and see what the other BMJ Journals editors have chosen by following the links on any BMJ Journal home page. 